LOCAL CALIBRATION OF MEPDG FOR SUPERPAVE PAVEMENTS IN ONTARIO: ENHANCE RUTTING CALIBRATION AND PRELIMINARY STUDY ON IRI MODEL

\author{
by \\ Maryam Amir \\ BEng, Tehran University, Iran ,2003
}

\author{
A thesis \\ presented to Ryerson University \\ in partial fulfillment of the \\ requirements for the degree of \\ Master of Applied Science \\ in the Program of \\ Civil Engineering
}

Toronto, Ontario, Canada, 2017

(C) Maryam Amir 2017 


\section{AUTHOR'S DECLARATION}

I hereby declare that I am the sole author of this thesis. This is a true copy of the thesis, including any required final revisions, as accepted by my examiners.

I authorize Ryerson University to lend this thesis to other institutions or individuals for the purpose of scholarly research.

I further authorize Ryerson University to reproduce this thesis by photocopying or by other means, in total or in part, at the request of other institutions or individuals for the purpose of scholarly research.

I understand that my thesis may be electronically available to the public. 


\title{
PAVEMENTS LOCAL CALIBRATION OF MEPDG FOR SUPERPAVE PAVEMENTS IN ONTARIO: ENHANCE RUTTING CALIBRATION AND PRELIMINARY STUDY ON IRI MODEL
}

\author{
by \\ Maryam Amir \\ Master of Applied Science, 2017 \\ Civil Engineering, Ryerson University \\ Toronto, Canada
}

\begin{abstract}
The AASHTO Mechanistic-Empirical Pavement Design Guide requires local calibration to account for local conditions, materials, and engineering practices. Previous local calibration studies in Ontario focused mainly on permanent deformation models for pavement rutting. The objectives of this study are twofold. First, to provide an enhanced calibration for the rutting models by using more vigilantly cross-verified input data and updated observed rutting data. Second, to perform a trial calibration for the international roughness index (IRI) model by considering three different calibration methods. Cracking models calibration, being performed by another colleague, has not yet been finalized; therefore, the IRI model calibration cannot be finalized in this study. Based upon 63 Superpave sections, the local calibration coefficients were found to be $\beta_{A C}=1.7692, \beta_{T}=1.0, \beta_{N}=0.6262, \beta_{G B}=0.0968$ and $\beta_{S G}=0.2787$, which reduced the standard deviation of residuals to a value of $1 \mathrm{~mm}$. The IRI calibration study found that the initial IRI value plays an important role in the calibration.
\end{abstract}

Keywords: International Roughness Index (IRI) model; local calibration; Mechanistic-Empirical Pavement Design Guide (MEPDG); rutting model; Superpave. 


\section{ACKNOWLEDGEMENTS}

First, I would like to profess my deepest gratitude to my supervisor, Dr. Arnold Yuan. His remarkable support, suggestions, astute criticism and continuous guidance during all phases of this dissertation made this thesis possible.

I gratefully acknowledged that this research is part of a project funded by the Ministry of Transportation of Ontario (MTO) Highway Infrastructure Innovation Funding Program. My sincere thanks also goes to Mr. Warren Lee, Mr. Stephen Lee and Mr. Li Ningyuan from the MTO, Pavement and Foundation Section, for their generous and valuable help.

Also, I would like to thank all the participants of the Ryerson Research Group led by Dr. Yuan on the MEPDG Local Calibration; in particular, I would like to acknowledge and express my sincere thanks for the great help from Mr. Gyan Gautam and Ms. Chowdhury Ahmed in the early stage of my study.

Furthermore, I would like to extend my gratitude to Dr. Medhat Shehata and Dr. Bhagwant Persaud, members of the oral examination committee, for their valuable comments and suggestions along with their support and continuous guidance during my MASc study period at Ryerson.

I would also like to extend my deepest thanks to Mr. Desmond Rogan, the network administrator of the Department of Civil Engineering, for his support in network connections.

My greatest gratitude and appreciation would be towards my beloved family, whose support and love helped me throughout the entire process. I will be grateful forever for your love. Especially my mother, father and dearest sisters; there are not enough words to describe how grateful I am to all of you. 


\section{TABLE OF CONTENTS}

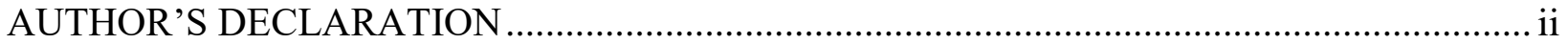

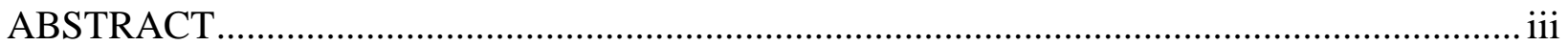

ACKNOWLEDGEMENTS ............................................................................................ iv

TABLE OF CONTENTS ...............................................................................................

LIST OF FIGURES …............................................................................................ vii

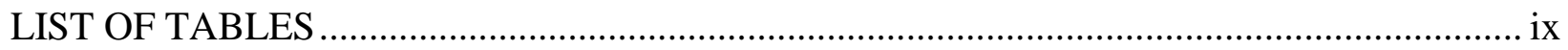

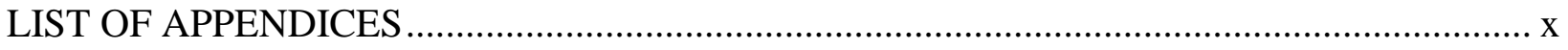

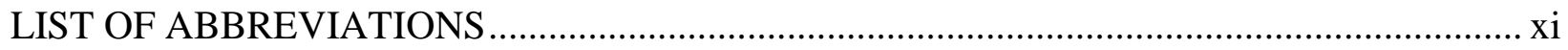

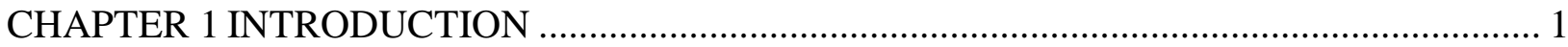

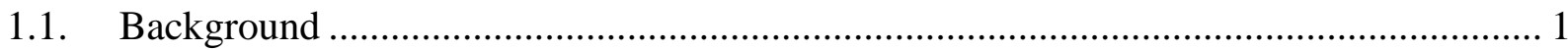

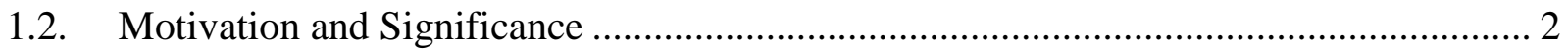

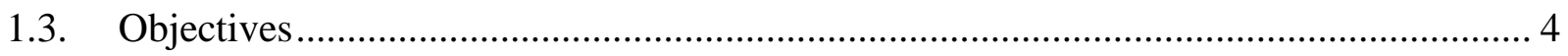

1.4. Research Methodology .......................................................................................... 4

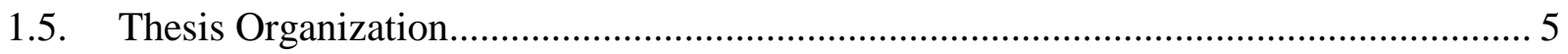

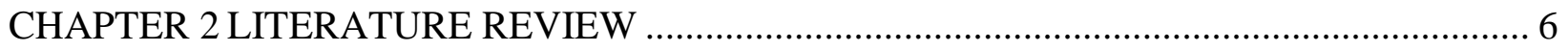

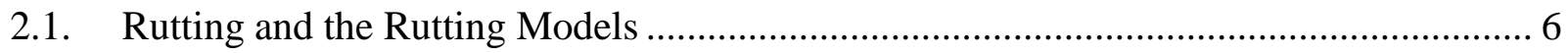

2.1.1. MEPDG AC Rutting Transfer Function ........................................................ 7

2.1.2. Base/ Subgrade Rutting Transfer Function ...................................................... 8

2.2. Pavement Smoothness and the IRI Model ........................................................... 11

2.2.1. MEPDG International Roughness Index Transfer Function............................. 13

2.3. Calibration Factors - Previous Local Calibration Studies ........................................ 15

CHAPTER 3 RUTTING MODEL CALIBRATION .......................................................... 17

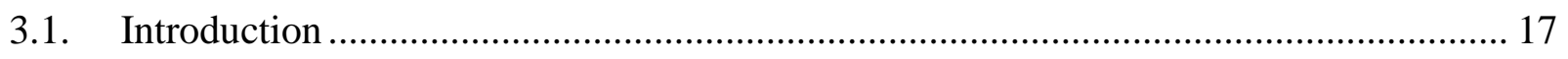




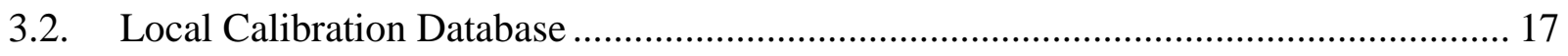

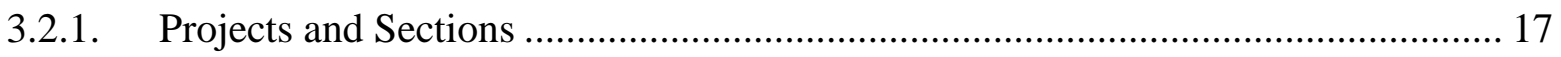

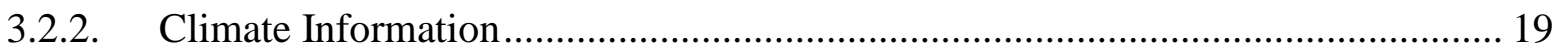

3.2.3. Pavement Structures and Materials.................................................................... 19

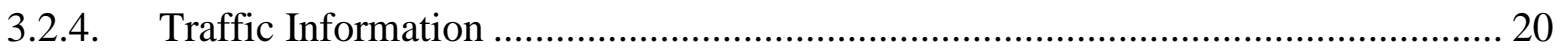

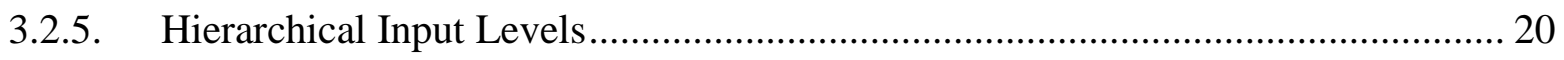

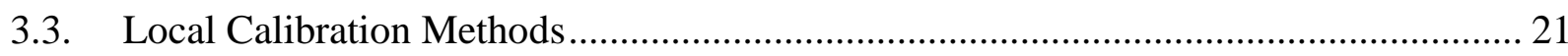

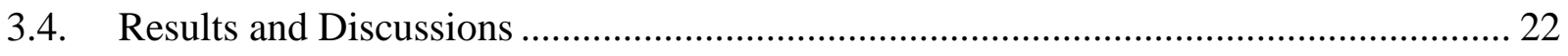

3.4.1. Bias and Error of Global Calibration ................................................................. 22

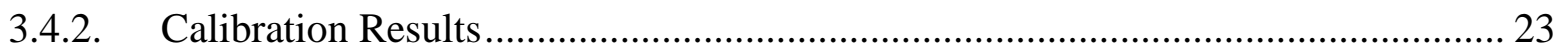

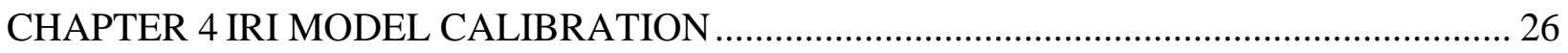

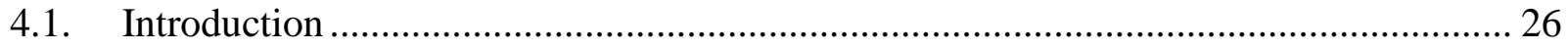

4.2. Local Calibration Database ………………………........................................... 26

4.3. Local Calibration Methods ....................................................................................... 26

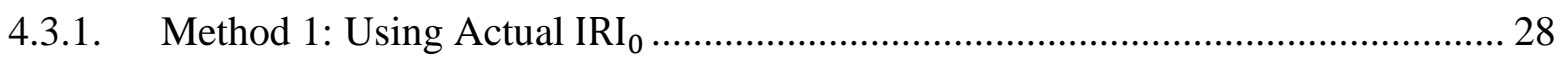

4.3.2. Method 2: Calculating IRI I $_{0}$ from linear regression ............................................. 30

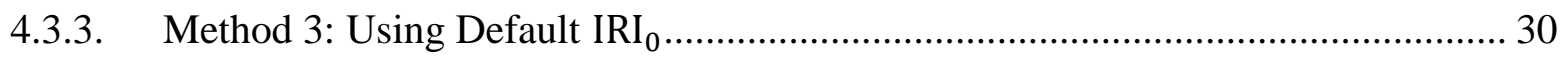

4.4. Results and Discussions ........................................................................................ 31

4.4.1. Bias and Error of Global Calibration ...................................................................... 31

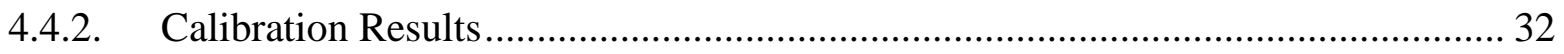

CHAPTER 5 SUMMARY, CONCLUSIONS AND RECOMMENDATIONS............................. 40

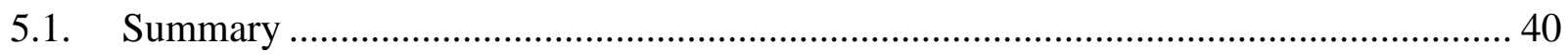

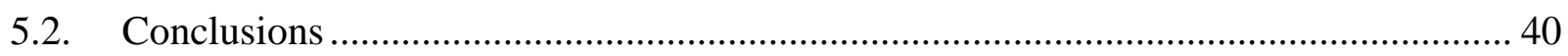

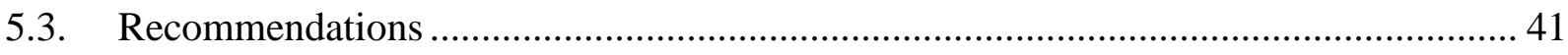

APPENDIX A: PAVEMENT SECTIONS, STRUCTURES, AND MATERIALS …………....... 42 
APPENDIX B: CLIMATE, TRAFFIC AND OTHER INPUTS USED IN AASHTOWARE

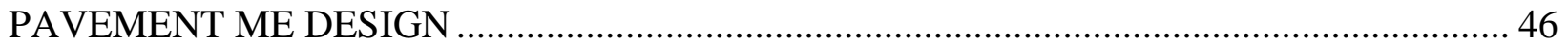

APPENDIX C: MTO DEFAULT PARAMETERS FOR AASHTOWARE PAVEMENT ME

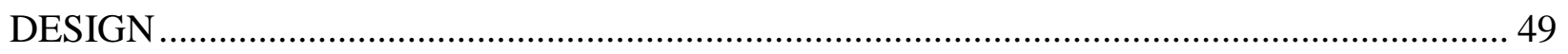

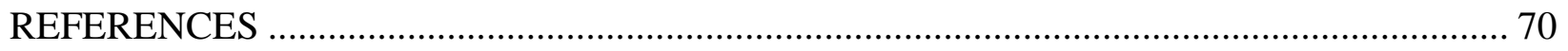




\section{LIST OF FIGURES}

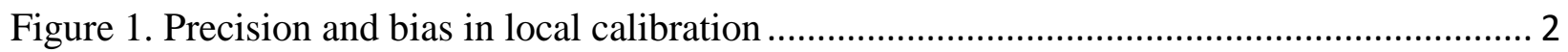

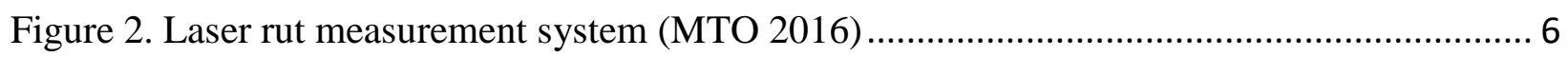

Figure 3. MTO ARAN 9000 longitudinal profile data (MTO 2016) ........................................... 12

Figure 4. Location of the 34 Ontario climate stations (MTO 2016) ............................................ 19

Figure 5. Performance of the default rutting models applied in Ontario's Superpave roads........ 23

Figure 6. Measured vs. predicted total rut depth (calibration set) ................................................. 24

Figure 7. Measured versus predicted total rut depth (validation set)........................................... 24

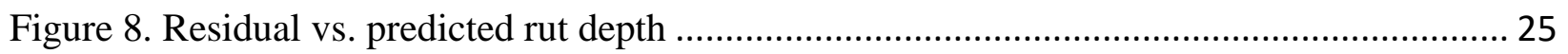

Figure 9. IRI0 fluctuation - actual vs. default values................................................................ 28

Figure 10. Performance of the default IRI model applied in Ontario's Superpave roads ............ 32

Figure 11. Measured vs. MEPDG-predicted IRI - calibration method 1 ..................................... 32

Figure 12. Measured vs. MEPDG-predicted IRI - validation method 1 ....................................... 33

Figure 13. Residual vs. predicted IRI - method 1 ……........................................................... 34

Figure 14. Measured vs. MEPDG-predicted IRI - calibration method 2 …................................. 35

Figure 15. Measured vs. MEPDG-predicted IRI - validation method 2 ...................................... 36

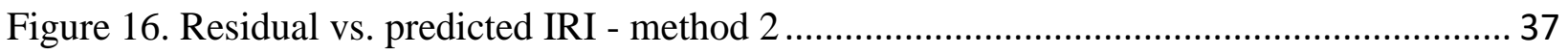

Figure 17. Measured versus MEPDG predicted $\triangle \mathrm{IRI}$ - calibration method 3 …......................... 38 


\section{LIST OF TABLES}

Table 1. Calibration factors from previous studies - IRI model ........................................... 16

Table 2. Summary of rut-depth and IRI thresholds (MTO 2016) ......................................... 18

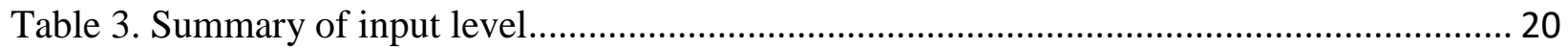

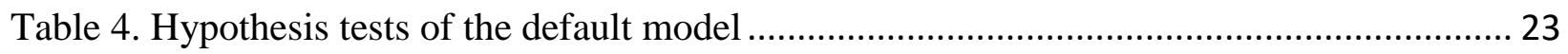

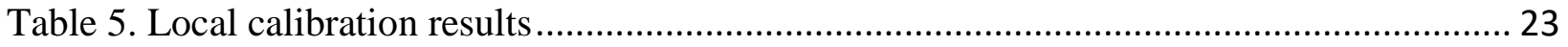

Table 6. Summary statistics of the rutting model calibration ............................................... 25

Table 7. Comparison of layer contributions between the globally and locally calibrated models 25 Table 8. Ontario's recommended default IRI $(\mathrm{m} / \mathrm{km})$ parameters for treatments and facility type

Table 9. Comparing Se values for different $\mathrm{IRI}_{0}$ using global coefficients ............................ 28

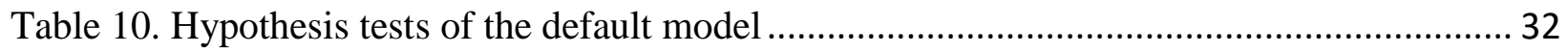

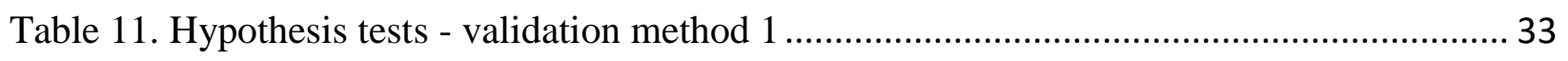

Table 12.Summary of local calibration effort for Ontario's Superpave pavement IRI model method 1

Table 13. Summary of statistical parameters: local calibration efforts for Ontario's Superpave

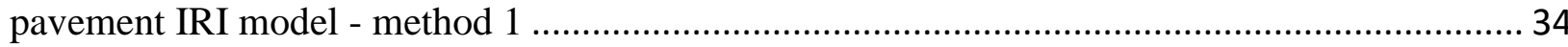

Table 14. Hypothesis tests - validation method 2 ........................................................... 35

Table 15. Summary of local calibration efforts for Ontario's Superpave pavement IRI model... 36

Table 16. Summary of statistical parameters- local calibration efforts for Ontario's Superpave

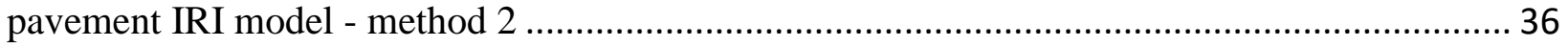

Table 17. Summary of local calibration efforts for Ontario's Superpave pavement IRI model -

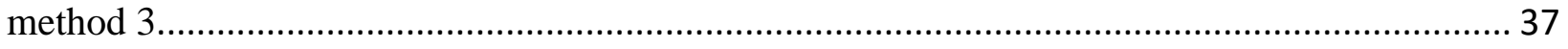

Table 18. Summary of local calibration efforts for Ontario's Superpave pavement IRI model... 38

Table 19. Simulated future design conditions - value of Se ................................................... 39 


\section{LIST OF APPENDICES}

Table A-1 Selected Superpave sections used in the study 42

Table A-2- Material and structural information for the selected Superpave sections 44

Table B-1 Climate input information used for this study 46

$\begin{array}{ll}\text { Table B-2 Traffic input values used for this study } & 47\end{array}$

Table B-3 Material input values for ac and unbound materials 48

Table C-1 Typical Superpave and SMA materials and their properties (MTO 2016) 49

Table C-2 Ontario typical granular material properties (MTO 2016) 50

Table C-3 Ontario typical subgrade properties (MTO 2016) 51

Table C-4 Ontario typical Marshal Mix properties (MTO 2016) 52

Table C-5 Ontario climate stations detailed information (MTO 2016) 53

Table C-6. Percentage of trucks within design lane - recommended values for Ontario (MTO 2016) 55

Table C-7. Southern Ontario - typical axle per truck values (MTO 2016) 56

Table C-8 Northern Ontario - typical axle-per-truck values (MTO 2016) 57

Table C-9 Southern Ontario - single-axle load distribution (MTO 2016) 58

Table C-10 Southern Ontario - tandem-axle load distribution (MTO 2016) 60

Table C-11 Southern Ontario - tridem-axle load distribution (MTO 2016) 62

Table C-12 Southern Ontario - quad-axle load distribution (MTO 2016) 63

Table C-13 Northern Ontario - single-axle load distribution (MTO 2016) 64

Table C-14 Northern Ontario - tandem-axle load distribution (MTO 2016) 66

Table C-15 Northern Ontario - tridem-axle load distribution (MTO 2016) 68

Table C-16 Northern Ontario - quad-axle load distribution (MTO 2016) 69 


\section{LIST OF ABBREVIATIONS}

AADTT Annual Average Daily Truck Traffic

AASHO American Association of State Highway Officials, the predecessor of AASHTO

AASHTO American Association of State Highway and Transportation Officials

AC Asphalt Concrete

ADOT Arizona Department of Transportation

GB Granular Base

SG Sub Grade

ARAN Automatic Road Analyzer

CBR California Bearing Ratio

ESAL Equivalent Single-Axle Load

FHWA Federal Highway Administration

GB Granular base

GWT Ground Water Table

HMA Hot Mix Asphalt

IRI International Roughness Index

LTPP Long Term Pavement Performance

MEPDG Mechanistic-Empirical Pavement Design Guide

MTO Ministry of Transportation of Ontario

MoDOT Missouri Department of Transportation

NCHRP National Cooperative Highway Research Program

PMS Pavement Management Systems

PR Public Roads

RSS Residual Sum of Square

SMA Stone Matrix Asphalt 


\section{CHAPTER 1 INTRODUCTION}

\subsection{Background}

Many studies have been performed to develop an enhanced method for highway pavement structural design. Between 1940 and 1960, under the leadership of Highway Research Board, a number of large-scale road tests were performed; the Maryland Road Test, the WASHO Road Test, and the AASHO Road Test (Yoder and Witczak, 1975). Among these, the AASHO Road Test is the most important. It was the first road test to quantify an empirical connection between pavement performances and influencing factors such as structural design and varying axle loads. The empirical equations were adopted in the first Interim Guide for Design of Rigid and Flexible Pavements, published in 1961. With modifications based upon subsequent studies, these equations continued to be used until the 1993 AASHTO design guide.

The major disadvantage of the empirical method is the limited range of parameters in terms of structural design, materials, traffic loading, environmental and climatic conditions, and maintenance practices that the original AASHO Road Test could support. As axle loads increase, new materials are developed, and climate changes, the empirical equations have been found to be inappropriate and their performance predictions unjustified. At the dawn of the twenty-first century, progressive pavement engineers decided to overthrow the empirical design method and develop a new method that had more mechanistic underpinnings. This ambition resulted in the Mechanistic-Empirical Pavement Design Guide (MEPDG), the product of a joint effort by AASHTO and FHWA under the NCHRP project 1-37A.

The MEPDG was developed to find the cause and effect of stresses in pavement performance indices. Within MEPDG, we initially assumed a trial design, along with inputs for traffic and climate conditions. Using this information, mechanistic models calculate pavement responses (stress strain, deflection), Pavement responses are converted to distress predictions (Rutting, Cracking and IRI) by empirical models in the software.

In project 1-37A, the empirical models were calibrated using the Long-Term Pavement Performance (LTPP) database. Since the database used in the calibration covers pavement design from a large portion of the USA and some provinces in Canada, including Ontario, the calibration is called global calibration. However, from the outset of MEPDG development it has 
been expected that globally calibrated models may inaccurately predict pavement performance in response to some local conditions. Hence, for those user agencies, software output cannot be a precise representation of current or future pavement performance.

The MTO decided to allocate budget from Highway Infrastructure Innovation Funding for further research on this topic. For Ontario's flexible pavements, Ryerson research group concluded that the MEPDG should be locally calibrated for its rutting, cracking and IRI models.

\subsection{Motivation and Significance}

The goal of calibration, either global or local calibration, is to produce the most accurate (nonbias) and precise (reliable) prediction of pavement performances (figure 1).

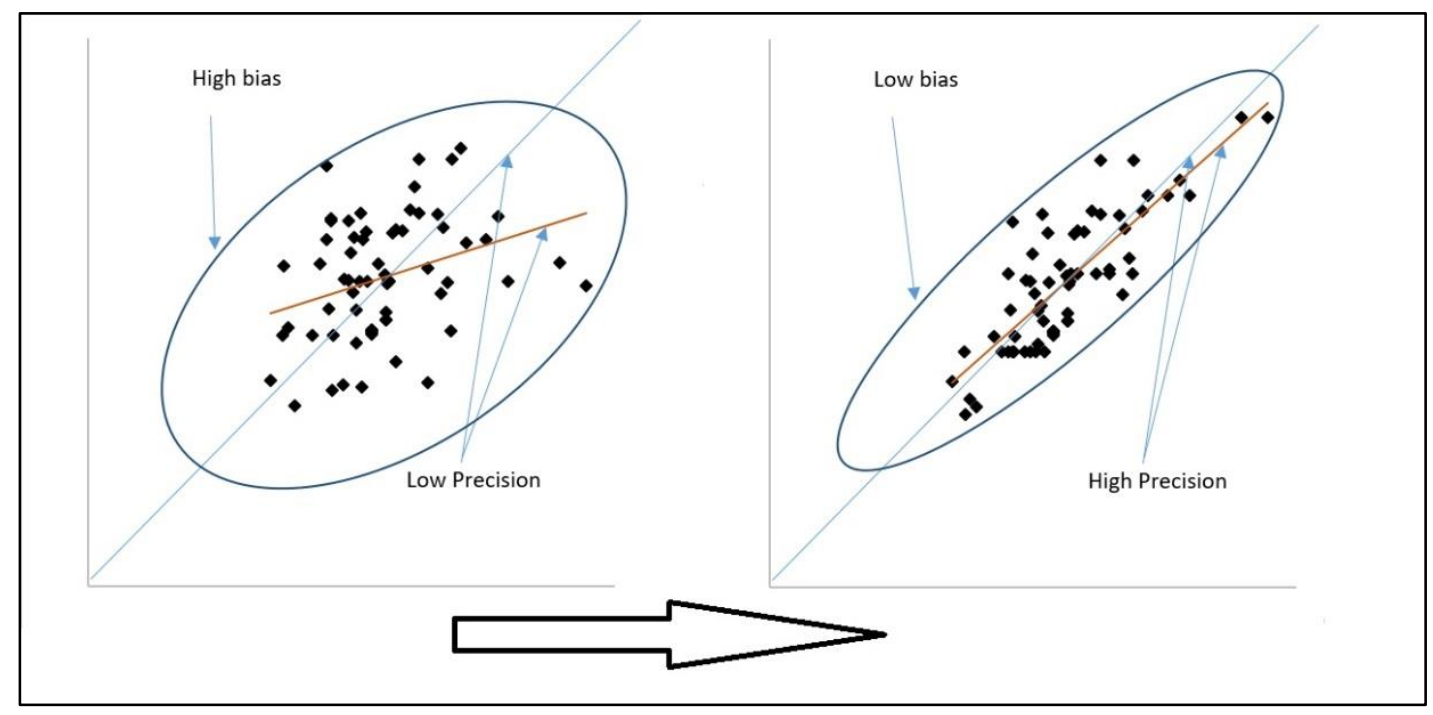

Figure 1. Precision and bias in local calibration

The MTO, as a leading transportation agency, is mandated to adopt the AASHTO MEPDG. For future design, preliminary studies within the MTO showed that transfer models needed to be calibrated. Since 2010, a Ryerson research group led by Dr. Yuan has been tasked to conduct the local calibration. The study started with the development of a local calibration database. In this project, Jannat (2012) developed a database that later turned out to predominantly cover the Marshall type of mixes, which are no longer used by the MTO. Nevertheless, using this database, Jannat (2012) confirmed the dire need for local calibration of the rutting models and identified the major challenges that would be faced if the cracking models were to be calibrated. She further confirmed the need for calibration of the IRI model, although the extent of bias and residuals in this model was less than that found in the other distress 
models. Based upon her study, the research group, upon discussion with the MTO, established local calibration priority in the following order: rutting models first, followed by cracking models (fatigue, thermal), and concluding with IRI.

Using the same calibration database, Waseem (2013) performed a sophisticated rutting model calibration, in which he identified the major challenge of rutting model calibration to be the unknown layer contributions among asphalt concrete (AC), granular base and subbase, and subgrade soil. Using the observed rutting series from PMS database, Waseem also experimented with a section-by-section longitudinal calibration method, which was the first attempt at a local calibration study in North America. He also developed a semi-automated calibration procedure, which could drastically improve the efficiency of the calibration exercise.

Later on, the study group realized the defect in the local calibration database. Therefore, for subsequent studies, the group developed a new calibration database for Superpave, which has been used in Ontario since 2001. Based upon the new database, Gautam (2015) recalibrated the rutting model and compared the results of Marshall mixes and Superpave materials. In addition, he made a great effort to enhance the local calibration method by identifying the local calibration coefficients that should be set using prior information and the coefficients that could be identified through the regression analysis.

Gautam (2015) suggested that the traffic and temperature exponents in the AC rutting model could be set at a specific value based on the most recent rutting study, NCHRP project 930A. In doing so, the indeterminacy issue due to lack of layer contribution was largely reduced, if not completely resolved. However, the data in his study resulted in zero or close-to-zero coefficients in the subgrade or base/subbase models, which was a major drawback of the calibration result. This was the motivation the first part of this study; Amir (2017), to further enhance the local calibration of rutting models.

Regarding IRI model calibration, as mentioned before, this was intended to be the last transfer model to be calibrated. Within the research group, Ahmed (2017) conducted a parallel study, focusing on the cracking models. Unfortunately, cracking model calibration was not successfully completed before this study started. As a result, it was decided that IRI calibration in this study would focus on exploration of the best calibration method. Therefore, this work represents a preliminary study using uncalibrated cracking models. 


\subsection{Objectives}

The objectives of this study are: firstly, to perform an enhanced calibration for rutting models by revising the input database; and secondly, to perform a trial calibration of the IRI model using three different calibration methods. To accomplish these tasks, coefficient values of the models will be revised in such a way that the most accurate (non-biased) and precise (reliable) predictions of observed values can be obtained. The local calibration database will be developed based on typical Ontario's Superpave and SMA pavement sections under MTO's jurisdiction.

\subsection{Research Methodology}

Based on the literature review performed for this study, it was apparent there was an immediate need to enhance current calibrated rutting models and to perform a preliminary local calibration on the latest global IRI model for Ontario's flexible pavement. The calibration strategy used in this research was cross sectional or, as named by Waseem (2013), a pooled calibration method. By cross-sectional calibration, author means to perform calibration on a pool of rutting measurement values. An enhanced calibration database was built upon the one previously developed and used by Jannat (2012), Waseem (2013) and Gautam (2015). For the purpose of this study, a total of 63 sections were selected and their raw observed IRI and rut depth data were extracted from Ontario's PMS 2015 database. Since the methodology of measuring rut depth and IRI has changed over the past few years, this study only uses the 2015 database for analysis.

For this study, the latest version of the MEPDG software (V2.3) was used. Using output from the software, rutting and IRI calculation procedures were simulated within an Excel file. Finally, using least square linear regression technique, local calibration was performed to produce a non-bias and precise performance prediction model.

To maintain the integrity and validity of the result, for rutting, the effects of zero bias constraint on the produced standard error was evaluated using two methods. The IRI model is a function of pavement distress over time. Because cracking model calibration had not been completed prior to this study, the predicted IRI results from the default global model were not up to date. Meanwhile, the initial IRI (IRI $)$ value was found to have a governing effect on the final predicted value of IRI. Therefore, three methods based on different IRI $_{0}$ values were proposed to explore the best approach for performing local calibration of the IRI model. 


\subsection{Thesis Organization}

The thesis is divided into five chapters and three appendices. This first chapter presents the background, motivation, objectives and methodology of the study as well as thesis organization. Chapter 2 summarizes the result from a literature review on rutting and IRI models with a focus on global and local calibration studies. Chapter 3 is dedicated to the enhanced rutting calibration and highlights major differences between the current research results and previous studies. Chapter 4 is devoted to the preliminary IRI model calibration, with an emphasis on the discussion of the best methods to be used for a successful local calibration of the IRI model. Chapter 5 concludes the thesis with a summary, conclusions and recommendations for future study. The three appendices provide more detailed information, including material properties and structural information, in addition to summarized information on climate, traffic and other input data to be used in AASHTOWare Pavement ME design. 


\section{CHAPTER 2 LITERATURE REVIEW \\ 2.1. Rutting and the Rutting Models}

Rutting is one of the pavement distresses that may occur in flexible pavement due to repeated traffic load, plastic shear deformation and material densification. To measure rut depth, an automated road analyzer (ARAN) system has been used by the MTO since the late 1990s. The first-generation ARAN contained ultrasonic sensors spaced at 4-inch intervals along the bar in order to cover the full width of a lane and to produce a cross-sectional profile of the pavement surface. Figure 2 represents the second-generation system, or the ARAN-9000 vehicle, which uses a laser rut-measurement system (LRMS). This system provides a higher resolution of 1280 points per profile. The new system has an expected measurement precision of $\pm 1 \mathrm{~mm}$.

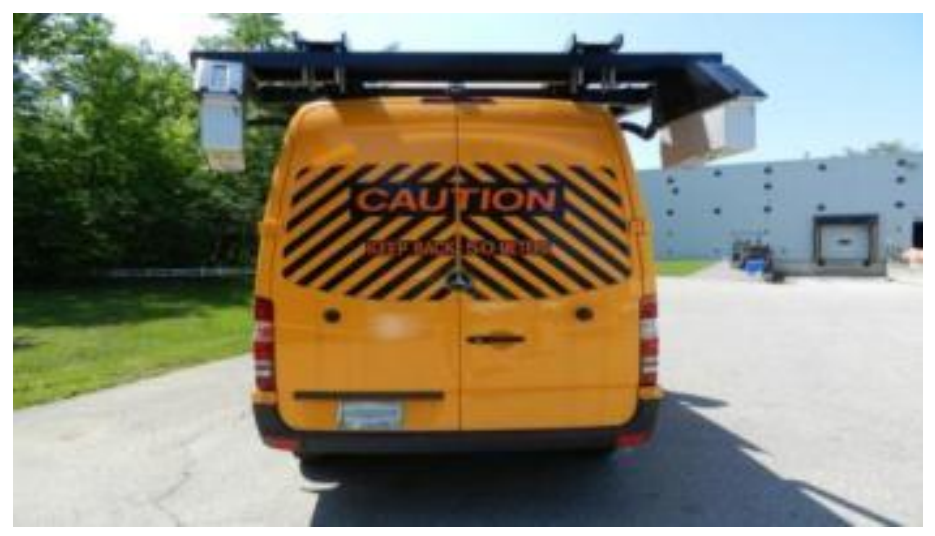

Figure 2. Laser rut measurement system (MTO 2016)

The most important part of project 1-37A was a calibration of distress transfer functions in order to adopt the design with the industry (NCHRP 719). The process of using calculated pavement responses data from MPEDG through the transfer function to predict what we actually measured in pavement surface (observed data) is calibration, which is not only model fitting but also confirms the data quality.

To provide an unbiased model for pavement distress and a reasonable standard error for pavement performance prediction, a validation of global calibration has been successfully performed for MEPDG under NCHRP project 1-37A. Data gathered for this project was from 136 sections using varied type of soil, climate, traffic and structural data. A total of 94 LTPP sections were used for calibration and validation of new construction pavements. Data from 42 
LTPP sections were used for calibration and validation of AC-over-AC overlay. Sections with the following materials were excluded:

- PMA (polymer-modified asphalt)

- RAP (recycled asphalt pavement)

- WMA (warm-mix asphalt)

Under project 9-30A, the original rut-depth model (Kaloush) was enhanced in addition to adding and calibrating following rut-depth transfer function models:

- Verstraeten deviator stress-based transfer function

- WesTrack shear strain, shear stress transfer function

- Improved versions of MEPDG software (Leahy, etc.)

Model evaluation in NCHRP project 9-30A was based on their accuracy, sensitivity to HMA mixture volumetric properties such as aggregate blend and its sensitivity to temperature and robustness (Von Quintus et al., 2012).

For the new version of MEPDG, AASHTO decided to include just the original rut depth transfer functions. The following presents a summary of the latest rutting models for the AC and unbounded materials:

\subsubsection{MEPDG AC Rutting Transfer Function}

$$
\varepsilon_{p(H M A)}=\varepsilon_{r} K_{z} \beta_{A C} 10^{k_{r 1}}(T)^{k_{r 2} \beta_{T}}(N)^{k_{r 2} \beta_{N}}
$$

where

$\varepsilon_{r}$

$\varepsilon_{p}$

$T$

$N$

$\beta_{A C}, \beta_{N}, \beta_{T}$

$K_{r 1}$

$K_{r 2}$

$K_{r 3}$

$K_{Z}$
$=$ Resilient strain (HMA layer), $\mathrm{mm} / \mathrm{mm}$

$=$ Accumulated plastic strain (HMA layers), $\mathrm{mm} / \mathrm{mm}$

$=$ Pavement or mix temperature, ${ }^{0} \mathrm{C}$

$=$ Number of load application of a particular axle type

=local calibration coefficients

$=$ Plastic deformation factor, for global calibration equals to -3.35412

$=$ Plastic deformation factor based on temperature effect, for global

calibration equals to 1.5606

$=$ Plastic deformation factor based on wheel loads effect, for global calibration equals to 0.4791

=Depth function, $K_{Z}=\left(C_{1}+C_{2} D\right)\left(0.328196^{D}\right)$ 


$$
\begin{array}{ll}
C_{1} & =-0.1039 H_{H M A}^{2}+2.4868 H_{H M A}-17.342 \\
C_{2} & =0.0172 H_{H M A}^{2}-1.7331 H_{H M A}+27.428 \\
D & =\text { Mid depth of related layer, } \mathrm{mm} \\
H_{H M A} & =\text { Thickness of HMA layers, } \mathrm{mm}
\end{array}
$$

2.1.2. Base/ Subgrade Rutting Transfer Function

$$
\left(\frac{\varepsilon_{P}}{\varepsilon_{v}}\right)=\beta_{G B-S G} k_{S 1}\left(\frac{\varepsilon_{0}}{\varepsilon_{r}}\right) e^{-\left(\frac{\rho}{n}\right)^{\beta}}
$$

$$
\begin{array}{ll}
\varepsilon_{p} & =\text { Accumulated plastic strain (Base/ Subgrade layers) }, \mathrm{mm} / \mathrm{mm} \\
N & =\text { Number of load application of a particular axle type } \\
\varepsilon_{0} & =\text { Material properties gained from repeated load permanent deformation }
\end{array}
$$
test in laboratory, $\mathrm{mm} / \mathrm{mm}$

$$
\begin{array}{ll}
\varepsilon_{r} & =\text { Resilient strain value from laboratory test which help to obtain } \\
\varepsilon_{v}, \rho \text { and } \beta, \mathrm{mm} / \mathrm{mm} & =\text { Average vertical elastic strain obtained from structural response model, } \\
& = \\
k_{S 1} & =\text { Global calibration coefficients; if fine grained material, value would be } \\
\beta_{G B-S G} & \quad 1.35 \text { and for granular material would be } 2.03 \\
& =
\end{array}
$$
fine grained and granular materials

$$
\begin{array}{ll}
\log \beta & =-0.61119-0.017638\left(W_{c}\right) \\
W_{c} & =\text { Water content, } \% \\
\rho & =10^{9}\left(\left(\frac{C_{0}}{1-\left(10^{9}\right)^{\beta}}\right)\right)^{1 / \beta} \\
C_{0} & =\ln \left(\frac{a_{1} M_{r}^{b_{1}}}{a_{9} M_{r}^{b_{9}}}\right)=-4.89285 \\
M_{r} & =\text { Resilient modulus of the unbound layer or sublayer, psi } \\
a_{1,9} & =\text { Regression constants; } a_{1}=0.15 \text { and } a_{9}=20.0 \\
b_{1,9} & \quad=\text { Regression constants equals to zero }
\end{array}
$$


As mentioned before, the global models overestimate the total rut depth for Ontario roads. In the following, the results of previous local calibration studies for Ontario's roads performed by the Ryerson research group team on rutting models are reviewed.

For the first attempt in Ontario to calibrate rutting models for flexible pavements, Jannat (2012) developed a database. Using ME version 2 with this Marshal Mix flexible pavements database, the Jannat, Yuan and Shehata (2014) analysis showed overestimated rutting values for Ontario's flexible pavement sections. To develop a more precise regression equation for local calibration of rutting, they recommended clustering the database based on highway classes. As mentioned before, the main goal of local calibration is to eliminate bias and to reduce the RSS. For RSS minimization, it is commonly expected that by using the appropriate optimization toolbox, unique optima would be generated. A study performed by Waseem and Yuan (2013) showed multiple local optima within the optimization process. Based on their study, unknown layer contribution to rutting was the main cause of the phenomenon of multiple local optima. To address the issue of layer contribution to the rutting model, Waseem (2013) attempted a sophisticated local calibration of the rutting model for Ontario's Marshal Mix flexible pavements. Waseem decided to use a $50 \%$ layer contribution for both AC and granular layer individually and to set a zero contribution for the subgrade layer in the case of rehabilitated pavements. For new or reconstructed studies, following the layer contribution measured by AAHTO in 1962, he decided to use 32\% for AC, 59\% for granular layers and $9 \%$ for subgrade layers. In the Waseem and Yuan (2013) study, the authors proposed a new approach of longitudinal (section-by-section) calibration for performing a local calibration study. That resulted in the following range of coefficient values: $\mathrm{AC}$ layer coefficient values: $\beta_{A C}=0.14$ to $0.47, \beta_{N}=0.975$ to 1.738 (effect of temperature on permanent deformation) and $\beta_{T}=0.229$ to 1.105 (effect of traffic on permanent deformation).

In addition, Waseem (2013) decided to perform a cross-sectional local calibration study, which resulted in the following local calibration coefficients: $\beta_{A C}=0.19, \beta_{N}=1.23, \beta_{T}=0.77$, $\beta_{G B}=0.985$ with prefix value of $\beta_{S G}=$ zero. His coefficient resulted in an improved $\mathrm{R}^{2}$ value of 0.464 and reduced standard error equal to $1.608 \mathrm{~mm}$ comparing to global values.

Waseem (2013) analysis was based on the Marshal Mix flexible pavements database. From 2001, the MTO began to use Superpave material rather than Marshal Mix, which demonstrated an immediate need for the inclusion of Superpave sections in calibration studies. 
Therefore, Gautam (2015) performed a local calibration study on rutting models for both Marshal Mix and Superpave pavement sections to investigate the need of different set of coefficients for the mentioned pavement types.

To simplify his analysis, Gautam (2015) decided to use prefixed values for both traffic and the temperature exponent. Based on equation 1, temperature $(n)$ and traffic coefficient $(m)$ refer to the exponent part of temperature and number of load application indices $\left(n=K_{r 2} \beta_{N}\right.$, $\left.m=k_{r 3} \beta_{T}\right)$. To find the best prefixed values, he performed an analysis on results derived from NCHRP project 9-30A and NCHRP report 719.

Within NCHRP project 9-30A, a total of 60 field section were used to perform trench investigation and 46 laboratory samples were used to perform shear and repeated load triaxle tests. Within NCHRP project 9-30A, using rutting results derived from the mentioned tests, longitudinal calibration was performed to determine the temperature and traffic coefficients of the rutting model. Based on result derived from NCHRP project 9-30A, Gautam performed statistical and sensitivity analyses to introduce an appropriate value for a local calibration study for Ontario's flexible pavements. His analysis resulted in a traffic exponent of $n=K_{r 2} \beta_{n}$ equal to 0.3 and temperature exponent $m=k_{r 3} \beta_{T}$ equal to 1.5606 . In equation 1 , the value of global filed calibration parameters $\left(k_{r 2}, k_{r 3}\right)$ is equal to 0.4791 and 1.5606 . This resulted in prefixed values of 0.6262 and 1 for $\beta_{\mathrm{N}}$ and $\beta_{T}$ respectively. This study used the same values for its $\mathrm{AC}$ rutting model local calibration.

Since the focus of the current study is on Superpave sections, Gautam (2015) calibration result for Marshal Mix sections will not be included. Similar to Waseem (2013), he used both longitudinal and cross-sectional approaches to perform local calibration of rutting models. his cross-sectional calibration resulted in the following coefficient values: $\beta_{A C}=2.692, \beta_{G B}=0.000$ and $\beta_{S G}=0.185$ with average layer contribution of $31.21 \%, 0.00 \%$ and $68.79 \%$.

Gautam (2015) results, was succeeded to reduce the standard error value to $1.2 \mathrm{~mm}$, yet having a zero contribution of the granular layer to rutting was far beyond reality. For further details of Ryerson work's in previous rutting model calibration, refer to Gautam et al. (2016).

Local calibration studies on both rutting and IRI models have been performed by many regional agencies through North America. A comprehensive literature review on rutting models has been performed by Gautam (2015). Section 2.3 of this study is mainly focused on a literature review for IRI models. 


\subsection{Pavement Smoothness and the IRI Model}

IRI, one of the pavement performance indicators, stands for international roughness index. It measures the surface roughness for any pavement type. The MTO uses ARAN to measure IRI and other pavement performance indicators for Ontario's highway. In January 2010, the existing ARAN vehicle was replaced by the latest version of ARAN. The new version contains almost all of the previous subsystems, such as GPS, Laser SDP, etc., as well as some further improvements. The new ARAN vehicle consists of the following instruments:

- Three sets of cameras, to collect images every 20 feet as ARAN travels along the highway.

- High-speed laser distance measurement system, utilizing 36 ultrasonic sensors to measure rutting and roughness along the road.

- High-speed laser distance measuring system, consist of two infrared lasers and accelerometers along the wheel path to measure roughness along the road.

- GPS to detect and store the location of each datum.

- DMI (distance measuring instrument).

- Three onboard computers.

To calculate IRI, longitudinal profile data for the road are captured continuously using both laser and accelerometer instruments (RoLine Laser inertial profiler). Sample of roughness profile generated by ARAN can be found in figure 3 . 


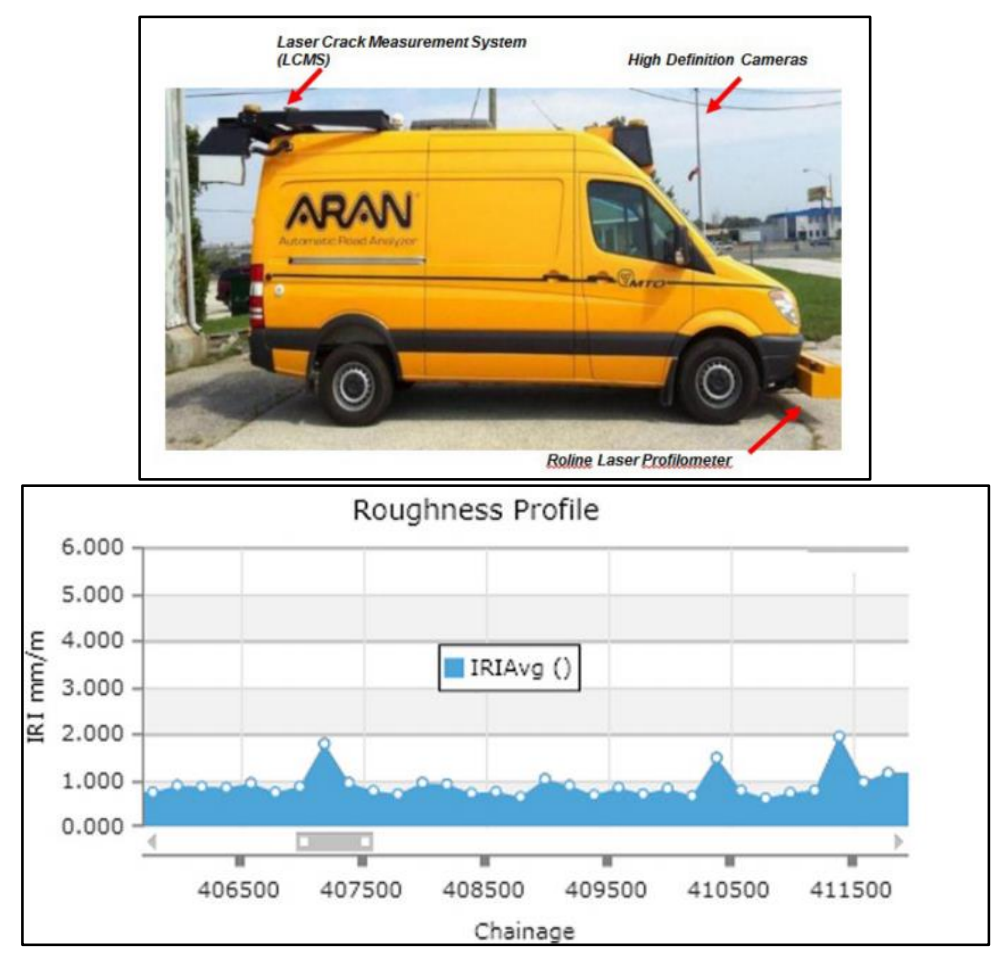

Figure 3. MTO ARAN 9000 longitudinal profile data (MTO 2016)

In the AASHO Road Test, roughness was presented as present serviceability rating (PSR) which was scaled from zero (very poor) to five (excellent). Value was determined based on traveller interpretation of their ride comfort. Later on, an effort was made by AASHTO to find an actual correlation between ride comfort and pavement distresses, which led to major findings on the correlation between smoothness of the road, its rut-depth variation and the severity of cracks.

Based on the study performed by the Transportation Research Board of Washington, DC, a relationship is observed between the smoothness of a road and its design structure, climate and site conditions.

The first empirical IRI model was developed by Darter and Al-Omari (1992), representing a significant relationship between IRI and variation of rutting along the road. Within same study, significant correlation was observed between number of transverse cracks, potholes, swells, depressions and the smoothness of the road.

In NCHRP project 1-37A, an enhanced IRI model was evolved to introduce the relationship between road smoothness and pavement distresses. To develop an IRI model for flexible pavements, distress data was gathered from an LTPP database for different types of flexible pavements. Based on new and overlaid flexible pavements, data was separated into two separate groups. In addition to the data cleaning process, one major task was to develop an 
appropriate estimation of initial IRI values for each section. Considering the direct relationship between IRI trend and pavement age, a back calculation method was used to fit a linear model for the trend of IRI versus their pavement age within the service life of each section. Stepwise regression was performed on 493 new and 61 flexible overlaid pavement data points, which led to two separate models for new and overlaid flexible pavement.

Another important variable influencing the rate of pavement smoothness deterioration,was found to be flexible pavement base type, such as granular, asphalt-treated and cement-treated base. Therefore, the IRI model was modified based on pavement base type cluster regression.

The following represents the current MEPDG IRI model for flexible pavement with granular base:

2.2.1. MEPDG International Roughness Index Transfer Function

$$
I R I=I R I_{0}+C_{1}(R D)+C_{2}\left(F C_{\text {Total }}\right)+C_{3}(T C)+C_{4}(S F)
$$

IRI $=$ Predicted IRI, in $/ \mathrm{mi}$

$I R I_{0}$ $=$ Initial IRI after construction, in/mi

$F C_{\text {Total }}$ $=$ Area of fatigue cracking (combined alligator, longitudinal, and reflection cracking in the wheel path), percent of total lane area

$T C$ $=$ Length of transverse cracking, feet/mile

SF $=$ Site factor

$R D$ $=$ Average rut depth, inches

$C_{1}, C_{2}, C_{3}, C_{4}$ $=$ IRI model calibration factor, equal to $40,0.4,0.008,0.015$ respectively

$$
S F=(\text { Frost })+\operatorname{Swell}(\text { Age })^{1.5}
$$
Frost $\quad=\left\{\ln \left[\left(\mathrm{P}_{\text {recip }}+1\right)(\mathrm{FI}+1) \mathrm{p}_{02}\right]\right\}$
Swell $\left.\quad=\ln \left[\left(\mathrm{P}_{\text {recip }}+1\right)(P I+1) \mathrm{p}_{200}\right]\right\}$
$\mathrm{P}_{\text {recip }}=$ Mean annual precipitation $(\mathrm{mm})$
FI $\quad=$ Mean annual freezing index $\left({ }^{\circ} \mathrm{C}-\right.$ days $)$
$\mathrm{P}_{0.02}, \mathrm{P}_{200}=$ Percent of subgrade material passing $0.02 \mathrm{~mm}$ and $0.075 \mu \mathrm{m}$ sieve respectively


Following is current IRI standard deviation model for flexible pavements based on Alex Gotlif ARA/TRANS, e-mail message to author, November 4, 2016. IRI standard deviation model is hardcoded in the software therefore users cannot change them.

$$
\begin{aligned}
S_{e(I R I)}^{2}= & \operatorname{Var}_{I R I_{0}}+C_{2}^{2} \operatorname{Var}_{\text {bot }}+C_{3}^{2} \operatorname{Var}_{\text {Thermal }}+C_{1}^{2} \operatorname{Var}_{\text {Rut }}-\operatorname{Var}_{\text {IRIMeas }}-C_{1}^{2} \operatorname{Cov}_{R u t}^{2} \text { Rut }_{\text {Tot }}- \\
& C_{2}^{2} \operatorname{Cov}_{\text {Bot }}^{2} \operatorname{Crack}_{\text {Tot }}-C_{3}^{2} \operatorname{Cov}_{\text {Tran }}^{2} \operatorname{Crack}_{\text {Trans }}+S_{e}^{2}
\end{aligned}
$$

where:

$S_{e(I R I)}^{2}$

$\operatorname{Var}_{I R I_{0}}$

$\operatorname{Var}_{b o t}$

$\operatorname{Var}_{\text {Thermal }}$

$\operatorname{Var}_{\text {Rut }}$

$\operatorname{Var}_{\text {IRIMeas }}$

$\operatorname{Cov}_{R u t}$

Rut $_{\text {Tot }}$

$\operatorname{Cov}_{\text {Bot }}$

Crack $_{\text {Tot }}$

$\operatorname{Cov}_{\text {Tran }}$

Crack $_{\text {Trans }}$

$S_{e}^{2}$

$S_{e}^{2}$
$=$ Standard deviation of IRI at the predicted level of mean IRI

$=$ Variance of initial IRI (obtained from LTPP $)=\left(\mathrm{IRI}_{\mathrm{ini}} / 10\right)^{2},(\mathrm{in} / \mathrm{mi})^{2}$

$=$ Variance of bottom-up cracking, $(\text { percent lane area })^{2}$

$=$ Variance of thermal cracking, $(\mathrm{ft} . / \text { mile })^{2}$

$=$ Variance of total rutting (all rutting sub-models), (in) ${ }^{2}$

$=$ Variance of initial IRI measurement $=0.4472,(\mathrm{in} / \mathrm{mi})^{2}$

$=$ Coefficient of variation of the rutting measurement $=0.2$

$=$ Total rutting, (in)

$=$ Coefficient of variation of the bottom cracking measurement $=0.38$

$=$ Total fatigue cracking, (percent of lane area)

$=$ Coefficient of variation of the bottom cracking measurement $=0.09$

$=$ Total transverse cracking length (ft. $/$ mile)

$=$ Variance of overall model error, $(\mathrm{in} / \mathrm{mi})^{2}$

$=25.1148 \mathrm{LN}(\mathrm{IRI})-87.95062$

Jannat (2012) developed a local calibration database featuring Marshall-type mixes. Using this database, she performed a study to validate the IRI global model for Ontario conditions. To produce an optimized predicted model for IRI, Jannat suggested to cluster IRI database based on Ontario's zones. Marshall-type mixes are no longer used by the MTO, so her database could not be used for this part of the study. As mentioned before, during sequence planning for MEPDG local calibration for Ontario, it was decided that calibration of IRI model 
would be the last step, therefore current study would introduce the first effort to perform a trial calibration for the IRI model.

\subsection{Calibration Factors - Previous Local Calibration Studies}

Local calibration studies on both rutting and IRI models have been performed by many regional agencies through North America. A comprehensive literature review on rutting models has been performed by Gautam (2015), so this section mainly focuses on a literature review for IRI models.

For Missouri, Donahue (2008) performed a local calibration of the IRI model after calibrating rutting and transverse cracking models using MoDOT and LTPP databases. The bias after calibration seemed to be acceptable, although not all the null hypothesis tests resulted in pvalues more that $5 \%$. Compared to global validation results, the local calibration effort generated better results with a reduced $S_{e}$ value equals to $12.8 \mathrm{inch} / \mathrm{mile}$.

For Iowa, Gopalakrishnan et al. (2013) performed a study on local calibration for Iowa flexible pavements. Longitudinal cracking and thermal cracking model calibrations were still evolving and the accuracy of the national calibrated IRI model seemed to be acceptable for Iowa conditions, having bias of $0.67 \mathrm{inch} / \mathrm{mile}$ with $S_{e}$ value equal to $12.35 \mathrm{inch} / \mathrm{mile}$. Therefore, it was decided to use global IRI model.

For Arizona, using the global calibration coefficient for predicting the IRI value resulted in imprecise prediction. Local calibration for the IRI model was performed by Darter et al. (2014) using 180 pavement sections from the LTPP and ADOT pavement management database, which led to reasonable prediction of IRI with reduced standard error equal to $8 \mathrm{inch} / \mathrm{mile}$.

For Colorado, Mallela et al. (2013) performed a validation study on the MEPDG IRI global model for Colorado's flexible pavement, which indicated imprecise prediction of IRI. Therefore, an effort was made to perform a local calibration of the model for Colorado's flexible pavement by using 343 sections. This led to significant improvement in elimination of bias with reduced standard error equal to $17.2 \mathrm{inch} / \mathrm{mile}$.

For Ohio, using the global calibration coefficient for predicting the IRI value resulted in biased prediction. In order to eliminate bias, Glover and Mallela (2009) performed a local calibration of the IRI model for Ohio's local conditions. After local calibration, a decent correlation between observed and predicted IRI was observed. Although bias was not eliminated 
entirely, local calibration results seemed to be more acceptable than global ones and resulted in a reduced standard error equal to $15.9 \mathrm{inch} / \mathrm{mile}$

Table 1. Calibration factors from previous studies - IRI model

\begin{tabular}{|c|c|c|c|}
\hline State & Factors & Local & References \\
\hline \multirow{4}{*}{ Missouri } & $C_{1}(R D)$ & 17.7 & \multirow{4}{*}{ Donahue (2008) } \\
\hline & $C_{2}\left(F C_{\text {Total }}\right)$ & 0.975 & \\
\hline & $C_{3}(T C)$ & 0.008 & \\
\hline & $C_{4}(S F)$ & 0.01 & \\
\hline \multirow{4}{*}{ Iowa } & $C_{1}(R D)$ & 40 & \multirow{4}{*}{ Gopalakrishnan et al. (2013) } \\
\hline & $C_{2}\left(F C_{\text {Total }}\right)$ & 0.4 & \\
\hline & $C_{3}(T C)$ & 0.008 & \\
\hline & $C_{4}(S F)$ & 0.015 & \\
\hline \multirow{4}{*}{ Arizona } & $C_{1}(R D)$ & 1.2281 & \multirow{4}{*}{ Darter et al. (2014) } \\
\hline & $C_{2}\left(F C_{\text {Total }}\right)$ & 0.1175 & \\
\hline & $C_{3}(T C)$ & 0.008 & \\
\hline & $C_{4}(S F)$ & 0.028 & \\
\hline \multirow{4}{*}{ Colorado } & $C_{1}(R D)$ & 35 & \multirow{4}{*}{ Mallela et al. (2013) } \\
\hline & $C_{2}\left(F C_{\text {Total }}\right)$ & 0.3 & \\
\hline & $C_{3}(T C)$ & 0.02 & \\
\hline & $C_{4}(S F)$ & 0.019 & \\
\hline \multirow{4}{*}{ Ohio } & $C_{1}(R D)$ & 17.6 & \multirow{4}{*}{ Glover and Mallela (2009) } \\
\hline & $C_{2}\left(F C_{\text {Total }}\right)$ & 1.37 & \\
\hline & $C_{3}(T C)$ & 0.01 & \\
\hline & $C_{4}(S F)$ & 0.066 & \\
\hline
\end{tabular}




\section{CHAPTER 3 RUTTING MODEL CALIBRATION}

\subsection{Introduction}

As mentioned before, the main focus of this study will be on recalibrating the rutting models for Ontario's Superpave pavements. General frame work would be performing calibration on the pool of rut depth measurement values which was named Cross sectional calibration by Ryerson research group team. Database includes only 2015 database; one-year selection was based on the fact that measurement methodology in ARAN continues to change in the last few years. To perform local calibration split sample method was used. For calibration purpose software procedure was simulated within an Excel file. At the end a non-bias and precise performance prediction model was introduced using least square linear regression technique.

\subsection{Local Calibration Database}

\subsubsection{Projects and Sections}

The local calibration database used in this study was built upon previous database that were originally developed and used by Waseem (2013), Gautam (2015) and Ahmed (2017). A total of 148 Superpave sections were originally identified and processed by the previous studies. However, only 63 of the sections were found to be appropriate for the purpose of this study. Effort has been made to produce a clean accurate database. The following are the criteria considered to select those sections:

- The selected sections should be a comprehensive representative of the set of materials, geotechnical conditions and structural designs in Ontario. Therefore, the selected sections include projects from both southern and northern Ontario.

- MTO (2011) reintroduced Stone Mastic Asphalt (SMA) to the list of approved premium surface mix for its relatively high rut resistance characteristic after its surface friction issue was resolved. Therefore, unlike previous studies this study database included SMA sections as well.

- The construction type should be either a new construction or an AC-over-AC rehabilitation pavement.

- Since the MTO's PMS database does not maintain accurate construction and maintenance 
records, each section was carefully assessed by using their time-series performance data to accurately determine the maintenance and rehabilitation history and thus the year of its latest major rehabilitation. Sections with service life of less than 3 years was eliminated.

- For all of the sections, raw observed data for rut depth was extracted from Ontario's PMS 2015 database. The one-year selection was based on the fact that measurement methodology in ARAN continues to change, and the data are not consistent from year to year. As mentioned in chapter 1, a previous study on rutting models was based on a PMS database up to 2012. The PMS 2015 database has been generated from the latest ARAN methodology with highest accuracy so far. Therefore, using the 2015 database will be result in a reduction of measurement variance.

- To improve the calibration result it would be better to include sections with performances outside the range of critical values stated in table 2. But unfortunately, the available observed IRI values within this study varied from $0.7-1.7 \mathrm{~m} / \mathrm{km}$ and observed rut depth data ranged from 2.4 to $6.7 \mathrm{~mm}$. This could result in less precise prediction for both models.

Table 2. Summary of rut-depth and IRI thresholds (MTO 2016)

\begin{tabular}{|c|c|c|c|}
\hline Performance Criteria & Limit & Pavement Type & Highway type \\
\hline \multirow{3}{*}{ IRI } & 1.9 & \multirow{2}{*}{ Superpave } & Freeway \\
\cline { 2 - 2 } & 2.3 & & Arterial \\
\cline { 2 - 2 } & 2.7 & & Collector \\
\cline { 2 - 2 } & 3.3 & & Local \\
\hline \multirow{3}{*}{ Rut Depth } & 10 & \multirow{2}{*}{ Superpave } & Freeway \\
\cline { 2 - 2 } & 13 & & Arterial \\
\cline { 2 - 2 } & 17 & & Collector \\
\cline { 2 - 2 } & 17 & & Local \\
\cline { 2 - 2 } & & & \\
\cline { 2 - 2 } & & & \\
\end{tabular}

- New section structural information has been partially re-created from available MTO report, to make sure of the accuracy and completeness of their pavement design structure database.

- Summary of the location, material and structural information for the selected Superpave sections can be found in table A-2 and table A-2. 


\subsubsection{Climate Information}

For each section the average of several nearest weather station was found and selected from the "Weather stations for MEPDG in Ontario", accessed January 16, 2017, https://www.google.com/maps/d/viewer?msa=0\&mid=13iBJ4hBSeGc_gTw_KJsEtwHXPXk.

Based on mentioned website a total of 34 weather stations is available within Ontario, database for those station would be updated by AASHTO occasionally (see figure 4).

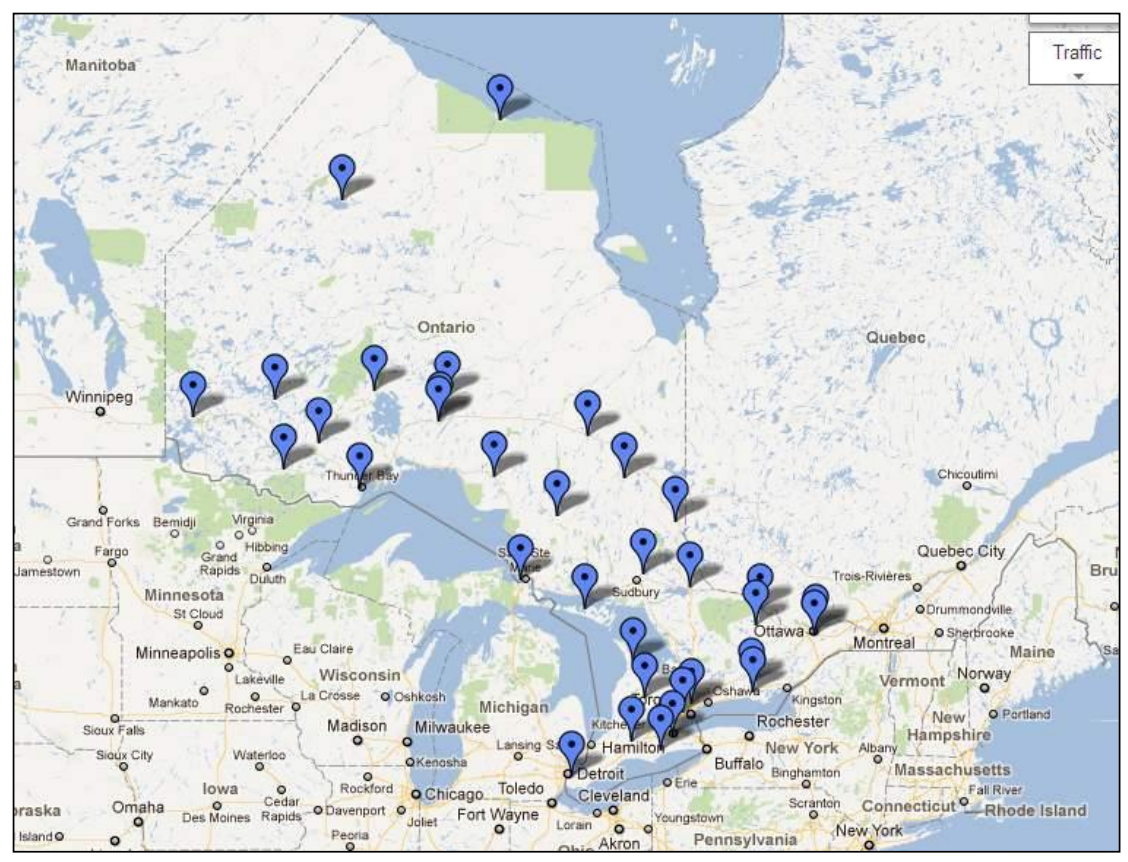

Figure 4. Location of the 34 Ontario climate stations (MTO 2016)

Climate input information used for this study can be found in table B-1 and table C-5.

\subsubsection{Pavement Structures and Materials}

The focus of this study is on flexible pavements with typical structure of AC layers and unbound layers. Section selection was expanded by including SMA sections as well, and their information was revised and modified completely.

AC layer for this study includes following Superpave materials:

- Stone matrix asphalt (SMA)

- Superpave $12.5 \mathrm{~mm}(\mathrm{SP} 12.5)$

- Superpave $12.5 \mathrm{~mm}$ friction course 1 (SP12.5 FC1)

- Superpave $12.5 \mathrm{~mm}$ friction course 2 (SP12.5 FC2)

- Superpave $19 \mathrm{~mm}$ (SP19) 
- Superpave $25 \mathrm{~mm}$ (SP25)

Detailed specification for asphalt material can be found in table C-1. Unbound material includes typical Ontario's granular and fine materials, which has been reported in table C-2 and C-3 of this study. Used input information for AC and unbound layers can be found in table B-3.

\subsubsection{Traffic Information}

Section selection was based on an effort to including diverse Ontario traffic conditions in this study. For each section based on their LHRS information, traffic data was obtained from iCorridor website. However, since some AADTT information was found to be not completely precise, AADTT information of each section was compared by their available information within the MTO traffic database. Summary of traffic inputs used for this research can be found in table B-2.

\subsubsection{Hierarchical Input Levels}

Summary of input level used for this research can be found in table 3. Based on available information, input level 3 was used for the purpose of this study. In this level, default regional or national inputs will be used.

Table 3. Summary of input level

\begin{tabular}{|c|c|}
\hline Input Group /Input Parameter & Input Level Used \\
\hline Truck Traffic & Level 2 \\
\hline Axle Load Distributions & Level 2 \\
\hline Lane \& Directional Truck Distribution & Level 2 \\
\hline Truck Volume Distribution & Level 3 \\
\hline Axle Configuration, Tire Spacing & Level 3 \\
\hline Truck Wander \\
\hline Tire Pressure \\
\hline \multicolumn{2}{|c|}{ Climate } \\
\hline Wind Speed, Temperature, Cloud Cover, Precipitation, Relative \\
Humidity \\
\hline HMA layers Material Properties \\
\hline Volumetric Properties \\
\hline HMel 2 \\
\hline HMA Dynamic Modulus \\
\hline HMA Coefficient of Thermal Expansion \\
\hline Unbound layers Material Properties \\
\hline Revel 3 \\
\hline Resilient Modulus -All Unbound Layers & Level 3 3 \\
\hline Moisture-Density Relationships & Level 3 \\
\hline Classification and volumetric properties & Level 3 \\
\hline Saturated Hydraulic Conductivity & Level 3 \\
\hline
\end{tabular}




\begin{tabular}{|c|c|}
\hline \multicolumn{2}{|c|}{ Soil-Water Characteristic Relationships } \\
\hline All Materials physical properties \\
\hline Unit weight & Level 3 \\
\hline Poisson's Ratio & Level 3 \\
\hline Other Thermal Properties & Level 3 \\
\hline
\end{tabular}

\subsection{Local Calibration Methods}

In this research, the general principles and steps suggested by the AASHTO, Guide for the Local Calibration of the Mechanical-Empirical Pavement Design Guide (2010) was followed in this study. To develop a non-biased and precise performance prediction model, the following criteria were considered:

- $\quad$ Minimizing Residual Sum of Square (RSS)

$$
R S S=\sum_{i=1}^{n}\left(D_{\text {Total-i }}-d_{\text {Total-i }}\right)^{2}
$$

- Eliminating Bias

$$
\text { Bias }=\sum_{i=1}^{n}\left(D_{\text {Total }-i}-d_{\text {Total-i }}\right)
$$

where

$$
\begin{array}{ll}
R S S & =\text { Residual Sum of Square } \\
D_{\text {Total }-i} & =\text { Calculated total rut depth as specified in equation 5 } \\
d_{\text {Total }-i} & =\text { Observed total rut depth } \\
n & =\text { Number of rut depth measurements }
\end{array}
$$

The total amount of the calculated rut depth would be calculated based on the cumulative ruts which occurs in all of the pavement layers.

$$
D_{\text {Total }}=D_{A C}+D_{G B}+D_{S G}
$$

To develop an optimization model, this study aimed to create a simulating procedure of equation (7) in an Excel file. Since the traffic and temperature exponents $\beta_{N}$ and $\beta_{T}$ in the AC models have been prefixed, the total rut depth model can be rewritten as the following linear regression model:

$$
D_{\text {Total }}=\beta_{A C} D_{(A C-\text { Global })}+\beta_{G B} D_{(G B-G l o b a l)}+\beta_{S G} D_{(S G-G l o b a l)}+\varepsilon
$$

Where:

$D_{(A C-\text { Global })}=$ Calculated rut depth in AC layer based on the global model 
$D_{(G B-G l o b a l)}=$ Calculated rut depth in granular base layer based on the global model

$D_{(S G-G l o b a l)}=$ Calculated rut depth in subgrade layer based on the global model

$\varepsilon \quad=$ Model error term, following normal distribution $\mathrm{N}\left(\sigma^{2}, 0\right)$

To maintain the integrity and validity of the results, effects of zero bias constraint on the produced standard deviation of residual error was evaluated using following methods:

- Method 1: Minimizing the RSS without forcing the bias to zero

- Method 2: Minimizing the RSS by forcing the bias to zero

For each method, optimization analysis was performed based on calculated predicted rut depth for each layer and their correspondent observed values. Using Microsoft Excel Solver, new optimized coefficient values were obtained considering the least residual sum of square, both with and without the constraint of zero bias, for method 1 and 2 respectively. For this study, for the purpose of recalibration and validation, it was decided to split the database into $70 \%$ and $30 \%$ respectively.

From the total of 63 legitimate sections, 46 sections were chosen randomly for calibration. The remaining 17 sections were used to validate the result of calibration.

\subsection{Results and Discussions}

\subsubsection{Bias and Error of Global Calibration}

Based on result of previous research studies it was concluded that rutting model needs to be calibrated for Ontario's conditions. Yet considering following enhancements which differs from previous studies, at the beginning stage of this research, preliminary evaluation on the selected Superpave sections was performed to assess the prediction performance of global rut depth model:

This study used the most recent MTO default parameters to execute the latest version of MEPDG software (V.2.3) on the expanded database included SMA sections.

MEPDG software was executed at 50\% reliability to predict rutting values for the lifetime of each section from its latest major rehabilitation up to 2015. To verify the feasibility of the rut-depth global model, statistical analysis was performed based on MEPDG results and respective observed data. That resulted in an average bias equal to $10.32 \mathrm{~mm}$ with a standard error of residual equal to $10.63 \mathrm{~mm}$. 
Based on the results derived from figure 5 and table 4, measured and predicted rut depth are not from the same population for both models, meaning that the global rut-depth models produce biased prediction for rutting and needs to be recalibrated for Ontario's conditions.

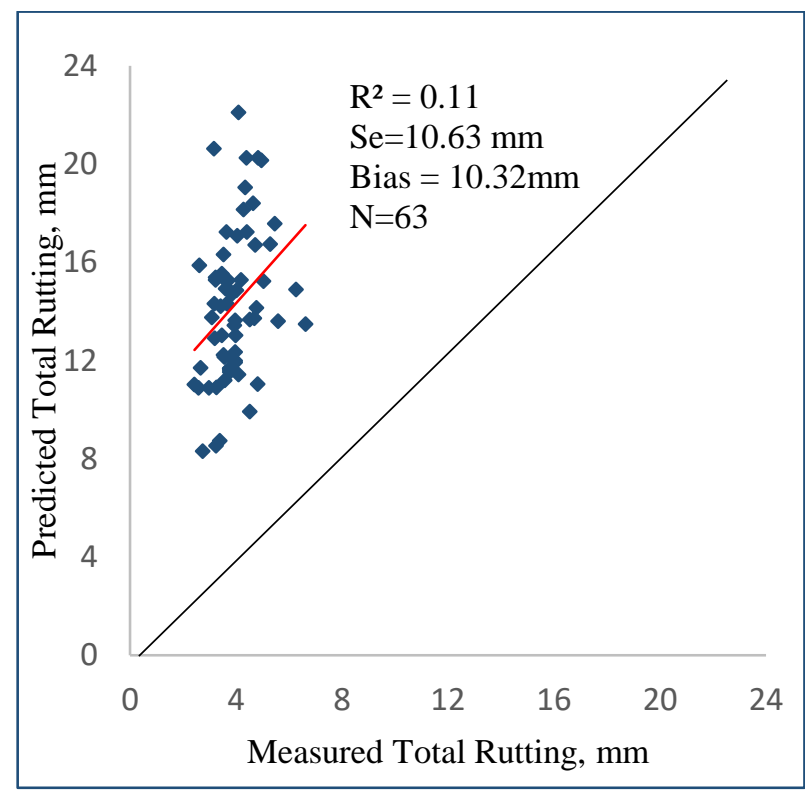

Figure 5. Performance of the default rutting models applied in Ontario's Superpave roads

Table 4. Hypothesis tests of the default model

\begin{tabular}{|c|c|c|c|c|l|c|}
\hline $\begin{array}{c}\text { Null hypothesis } \\
\text { Testing }\end{array}$ & DF & Parameter & Test & $\begin{array}{c}\text { Null hypothesis } \\
\text { Testing }\end{array}$ & DF & Parameter \\
\hline t-test & 63 & - & 27.59 & 1.99 & $<0.0001$ & Rejected \\
\hline F-test & 63 & - & 14.14 & 1.51 & $<0.0001$ & Rejected \\
\hline
\end{tabular}

3.4.2. Calibration Results

Table 5. Local calibration results

\begin{tabular}{|c|c|c|}
\hline Coefficient/Parameter & Method 1 & Method 2 \\
\hline$\beta_{A C}$ & 1.7009 & 1.7692 \\
\hline$\beta_{G B}$ & 0.0943 & 0.0968 \\
\hline$\beta_{S G}$ & 0.2737 & 0.2787 \\
\hline$S_{e}$ & $1.002 \mathrm{~mm}$ & $1.006 \mathrm{~mm}$ \\
\hline Bias & 4.07 & 0 \\
\hline
\end{tabular}

Based on result derived from table 5, it was concluded that using a constraint of zero bias will not result in significant variation for both calibration coefficients and their respective $S_{e}$ values. Therefore, using method 2, cross-sectional calibration methodology was performed on $70 \%$ of selected Ontario's Superpave pavement sections. 


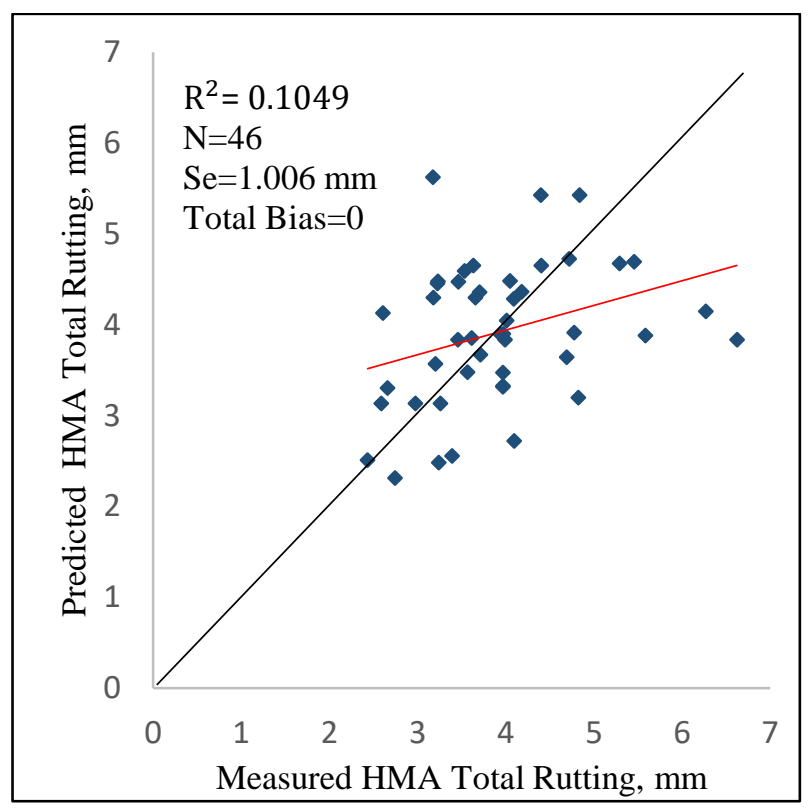

Figure 6. Measured vs. predicted total rut depth (calibration set)

The calibrated models obtained from method 2 were used on the remaining 17 validation databases. The resulting statistics were standard error $0.66 \mathrm{~mm}$ and average bias $0.019 \mathrm{~mm}$.

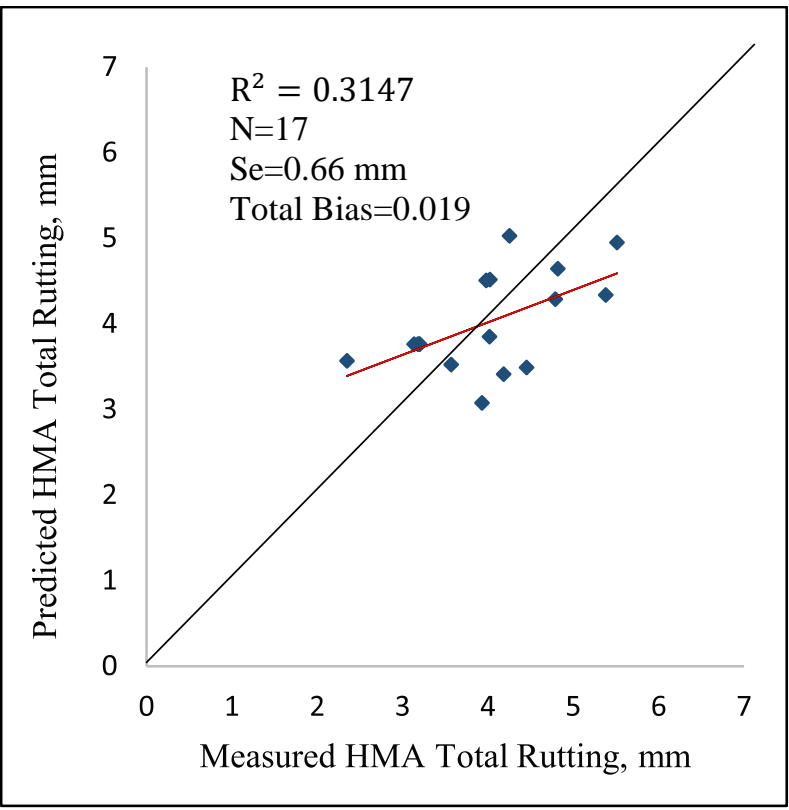

Figure 7. Measured versus predicted total rut depth (validation set)

As verified in figures 6 and 7, the bias and standard error of the residuals for the validation sets were found to be comparable to that from the calibration sets. A further F-test was performed and resulted in a p-value of $6 \%$, which indicated a good validation. 
Table 6. Summary statistics of the rutting model calibration

\begin{tabular}{|c|c|c|c|}
\hline $\begin{array}{c}\text { Statistical } \\
\text { Parameters }\end{array}$ & $\begin{array}{c}\text { Global Model } \\
\text { based on } \\
\text { AASHTO }\end{array}$ & $\begin{array}{c}\text { Local Calibration } \\
\text { Performed on 70\% of selected } \\
\text { Ontario's Superpave pavement } \\
\text { sections }\end{array}$ & Validation \\
\hline$R^{2}$ & 0.577 & 0.1049 & 0.3147 \\
\hline $\begin{array}{c}\text { Standard Error of the } \\
\text { Estimate, } \mathrm{S}_{\mathrm{e}}\end{array}$ & 2.717 & $1.0065(\mathrm{~mm})$ & $0.66(\mathrm{~mm})$ \\
\hline $\begin{array}{c}\text { Number of data } \\
\text { points, } \mathrm{N}\end{array}$ & 334 & 46 & 17 \\
\hline
\end{tabular}

Table 7. Comparison of layer contributions between the globally and locally calibrated models

\begin{tabular}{|c|c|c|c|c|}
\hline \multirow{2}{*}{ Layers } & \multicolumn{2}{|c|}{ Global model } & \multicolumn{2}{c|}{ Calibrated Model } \\
\cline { 2 - 5 } & Coefficients & Layer Contribution & Coefficients & Layer Contribution \\
\hline$A C$ & 1 & $23 \%$ & 1.7692 & $19 \%$ \\
\hline$G B$ & 1 & $11 \%$ & 0.0968 & $9 \%$ \\
\hline$S G$ & 1 & $66 \%$ & 0.2787 & $72 \%$ \\
\hline
\end{tabular}

The final detailed result can be found in tables 6 and 7. Commenting on the accuracy of the layer contribution would be hard since there was no available trench investigation at the time of this study. Figure 8 shows random distribution of residual errors around zero line without any constant decrease or increase trend. From vertical distribution of the scatter, it can be concluded that predicted rut depth falls within two standard error of the estimate of measured values, which indicates a very low bias.

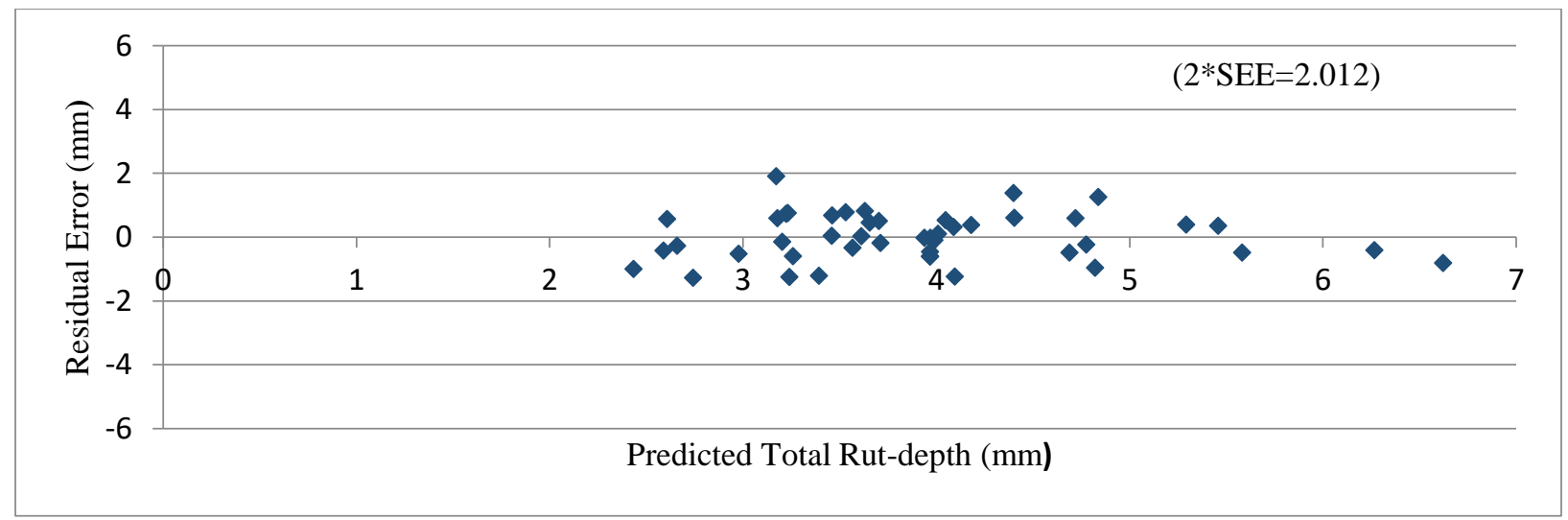

Figure 8. Residual vs. predicted rut depth 


\section{CHAPTER 4 IRI MODEL CALIBRATION}

\subsection{Introduction}

The focus of this part of the study was on performing a preliminary local calibration of the current global IRI model for Ontario's Superpave pavements. One important factor that needs to be discussed is that the cracking model calibration has not yet been finalized. For this reason, the IRI study focused on an exploration and presentation of the best calibration method.

\subsection{Local Calibration Database}

The calibration database has been already discussed in section 3.2. The following discussion focuses on the obtained observed IRI data used within this study. Within this part, sections have been checked for reasonableness and consistency of their distress measurement data, particularly for their $\mathrm{IRI}_{0}$ values. For each selected section, observed historical IRI measurement data was obtained from Ontario's ARAN database. From the same database used in chapter 3, a total of 52 sections was selected. It is important to understand that for each proposed calibration methods, data selection criteria varied as following:

Method 1 database selection was based on the availability of measured $\operatorname{IRI}_{0}$ values, therefore only 40 sections were found to be appropriate for its analysis. Method 2 data selection was based on the minimum number of available sections for both overlaid and new/reconstruction conditions, which resulted in the selection of 41 sections. Method 3 did not have any constraints therefore all of the 52 sections were included in its analysis.

\subsection{Local Calibration Methods}

As mentioned earlier, to perform cross sectional local calibration for IRI model, the general methodology recommended by AASHTO Guide for the Local Calibration of the MechanicalEmpirical Pavement Design Guide (2010) was followed.

To have an accurately predicted IRI, following criteria should be considered:

- Minimizing Residual Sum of Square (RSS)

$$
R S S=\sum_{i=1}^{n}\left(I R I_{\text {Predicted }-i}-I R I_{\text {Observed }-i}\right)^{2}
$$

- Eliminating Bias 


$$
\text { Bias }=\sum_{i=1}^{n}\left(I R I_{\text {Predicted }-i}-I R I_{\text {Observed }-i}\right)
$$

MEPDG software consists of the following empirical IRI model:

$$
I R I=I R I_{0}+C_{1}(R D)+C_{2}\left(F C_{\text {Total }}\right)+C_{3}(T C)+C_{4}(S F)
$$

The main challenge observed for calibrating IRI model for Ontario's Superpave pavement was selecting an appropriate IRI ${ }_{0}$. The initial IRI refers to the smoothness of pavement within six months after completed construction date. In current database, regardless of new or rehabilitated pavements, IRI observed values varies from 0.72 to $1.97 \mathrm{~m} / \mathrm{km}$; therefore, using table 8 default parameters for $\mathrm{IRI}_{0}$ may result in additional variation in the local calibration.

Table 8. Ontario's recommended default IRI $(\mathrm{m} / \mathrm{km})$ parameters for treatments and facility type

\begin{tabular}{|c|c|c|}
\hline Treatments & Freeway & Arterial \\
\hline Hot Mix Overlay 1 lift & 1 & 1 \\
\hline Hot Mix Overlay 2 lifts & 0.9 & 0.9 \\
\hline Mill + Hot Mix Overlay 1 ,2,3 lift & 1 & 1 \\
\hline New or Reconstruction to AC & 0.8 & Not available \\
\hline
\end{tabular}

For better understanding the effects of the chosen $\mathrm{IRI}_{0}$ on the final result, see figure 9 for a comparison between the fluctuation of actual $\mathrm{IRI}_{0}$ and the default values for both overlay and new pavement sections. Comparing the measured $\mathrm{IRI}_{0}$ values with their default ones, the standard deviation of the residual was found to be $0.22 \mathrm{~m} / \mathrm{km}$ and $0.16 \mathrm{~m} / \mathrm{km}$ for new and overlaid pavement respectively.

In addition, using global IRI model, software was executed for 52 sections using chosen $\mathrm{IRI}_{0}$ of each model. Subsequently models standard error of residual was calculated. Results can be found in table 9 . 


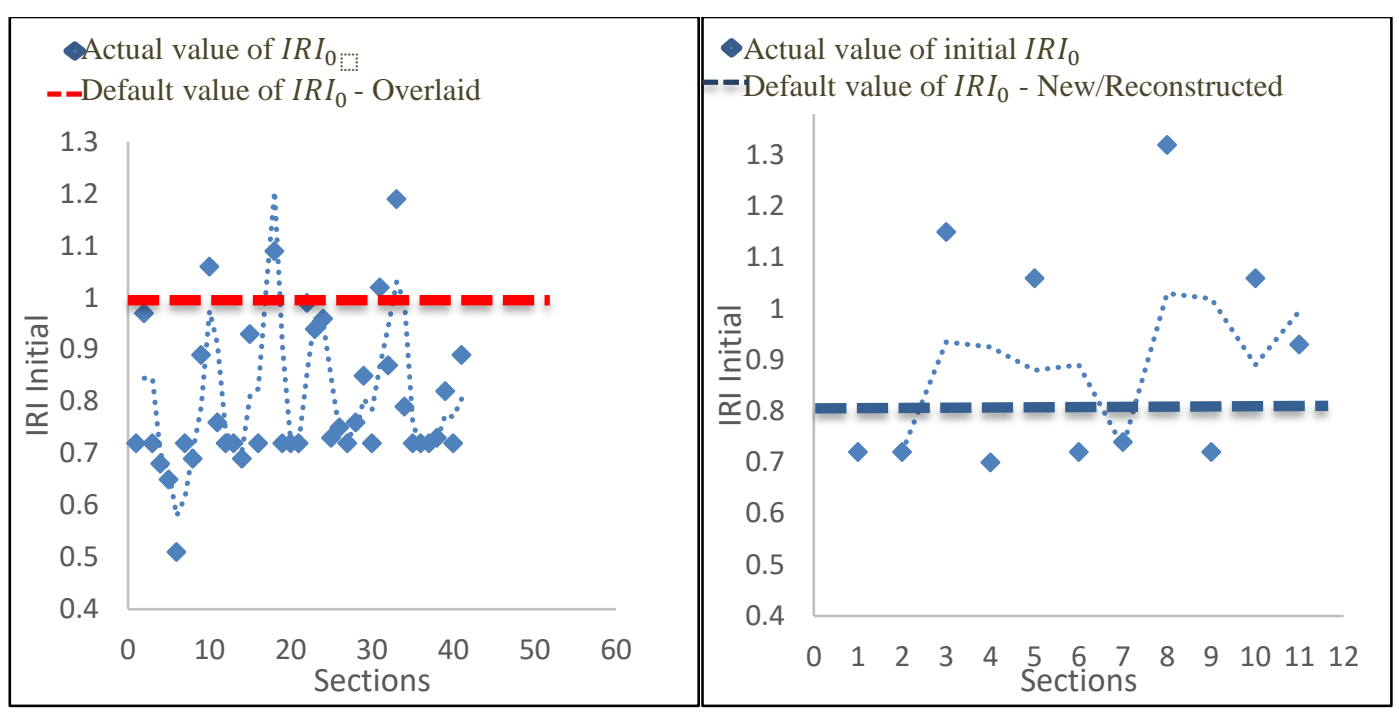

Figure 9. $\mathrm{IRI}_{0}$ fluctuation - actual vs. default values

Table 9. Comparing $\mathrm{S}_{\mathrm{e}}$ values for different $\mathrm{IRI}_{0}$ using global coefficients

\begin{tabular}{|c|c|c|c|}
\hline Method & Number of sections & IRI $_{\mathbf{0}}$ & $\mathbf{S}_{\mathbf{e}}$ \\
\hline 1 & 52 & $0.8(\mathrm{New})-1(\mathrm{Old})$ & 0.42 \\
\hline 2 & 52 & 0.65 & 0.31 \\
\hline 3 & 52 & From PMS database & 0.27 \\
\hline
\end{tabular}

Based on the results derived from figure 9 and table 9, it can be concluded that:

- The standard error of residual of calculated IRI (using default model) ranges from 0.27 to 0.42 .

- $I R I_{0}$ dominated the variation in the total IRI that is predicted.

Considering the governing effect of $\mathrm{IRI}_{0}$ on the predicted IRI values, it was decided to explore the best calibration method based on different initial IRI values to be used in the calibration. It is important to understand that the actual $\mathrm{IRI}_{0}$ value in future design is a policy requirement of the MTO. Each set of coefficient values $\left(C_{1}, C_{2}, C_{3}, C_{4}\right)$ needed to be re-evaluated by using them within a simulated procedure of actual design considering using default parameters for $\mathrm{IRI}_{0}$ values.

\subsubsection{Method 1: Using Actual $\mathrm{IRI}_{0}$}

For the first method, to produce prediction of IRI values, for each section their actual $\mathrm{IRI}_{0}$ values were used. Actual $\mathrm{IRI}_{0}$ refers to IRI values from the PMS database in the year of reconstruction, major rehabilitation or construction for the respective section.

Evaluating IRI measured database, for some sections, extensive fluctuation was observed in the trend of their IRI values. That could be a result of either a minor rehabilitation or a non- 
accurate measurement. For some sections, even small rehabilitation affected the IRI values to the extent of, their value of IRI in 2015 was smaller compared to the ones in their construction year. To minimize mentioned errors, those sections were eliminated from the final database. In addition, the lack of available information of $\mathrm{IRI}_{0}$ values for most of SMA sections resulted into their exclusion from the final database of this method.

Split sample method was used to perform a local calibration of the IRI model, with 27 sections (70\% of database) used for calibration. For calibration purposes, software calculation of IRI was simulated within an Excel file. Therefore, for each section, MEPDG software was executed at 50 percent reliability to predict the area of fatigue cracking, average rut and length of transverse cracking within their lifetime considering the latest major rehabilitation up to 2015 .

Following information was used to simulate the prediction of IRI values within an Excel file:

For each section, actual $\mathrm{IRI}_{0}$ value was found from available PMS file. For all sections, using this study rutting model local calibration coefficients, MEPDG software was executed at 50 percent reliability to predict the amount of rutting. For cracking models, their global calibration coefficient values were used.

For each section, from the output of the software, following information was obtained: For rutting, the amount of rut depth within each layer was obtained. For area of fatigue cracking $\left(F C_{\text {Total }}\right)$, using the output of the software, the amount of AC top-down fatigue cracking $(\mathrm{m} / \mathrm{km})$

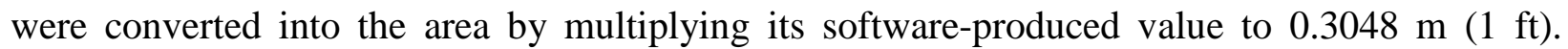
Subsequently for each section, the percentage of its crack within the total lane area was calculated. Finally, for each section, obtained results were added to the values of AC total bottom-up fatigue and thermal reflective cracking (\% lane area).

For each section, the amount of mean annual precipitation, mean annual freezing index and clay size particles in subgrade were exported from the output of the software to simulate site factor calculation within the Excel file.

Using above information, the ultimate predicted IRI values were calculated using an Excel simulation model. Subsequently optimization analysis was performed based on calculated predicted IRI and their correspondent observed values. Using Microsoft Excel Solver, new optimized coefficient values were obtained considering the least residual sum of square and zero bias. To validate new obtained coefficients, using local IRI model software was executed on the 
remaining sections. F-test (model preciseness) and t-test (bias) was performed on the validation set.

\subsubsection{Method 2: Calculating $\mathrm{IRI}_{0}$ from linear regression}

Another method proposed by this study was to determine the best-fit $\mathrm{IRI}_{0}$ by including it as part of the local calibration coefficients. Determination of $\mathrm{IRI}_{0}$ should be performed for new/reconstructed and overlaid pavements separately. Considering the limited number of available sections, for this part of the study analysis has been performed only on overlaid sections.

MEPDG software was run for the 41 Superpave sections, using global coefficient values for distress models except for rutting. Using the same method as described before, software procedure in calculating IRI was simulated.

As mentioned previously, a local IRI model needs to be developed considering the least residual sum of square and zero bias. For that, five variables were introduced and solved for $C_{1}, C_{2}, C_{3}, C_{4}, I R I_{0}$. Finally, to validate the result, the newly obtained model software was executed on the remaining 12 sections. F-test (model preciseness) and t-test (bias) was performed on the validation set.

\subsubsection{Method 3: Using Default IRI ${ }_{0}$}

The final method presented by this research is based on using Ontario's default values for initial IRI. IRI model was calibrated based on the rate of IRI deterioration caused by distress factors included cracking and rutting.

For this analysis, MEPDG software was executed on total of 52 Ontario Superpave pavement sections considering their default $\mathrm{IRI}_{0}$ value. From the output of the software, an Excel sheet was created to simulate the calculation of predicted $\Delta$ IRI (rate of deterioration). Observed $\Delta$ IRI values were calculated based on the PMS 2015 database considering the following equation:

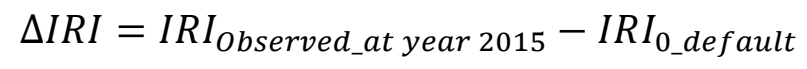

The first step was to find the best local calibration coefficients, considering the least residual sum of square and zero bias. To compare and evaluate the final results, a similar procedure to method 1 was performed. 


\subsection{Results and Discussions}

\subsubsection{Bias and Error of Global Calibration}

To validate the IRI Global model capability in predicting IRI values for Ontario's Superpave pavements, preliminary evaluation was performed on 52 selected pavement sections. For each section, MEPDG software was executed at 50\% reliability to predict IRI values for each section service time considering their latest major rehabilitation year up to 2015 . Subsequently statistical analysis was performed based on MEPDG results and their respective observed values by using the following null hypothesis tests:

- Null hypothesis 1: To determine if predicted and observed dataset are from the same population, a t-test was performed on IRI experimental database. As a result, p-value founds to be less than 0.05 which indicates that predicted and observed IRI are not from the same population.

- Null hypothesis 2: In addition to bias, global model was studied for its preciseness by performing F-test. As a result, p-value founds to be less than 0.05 which indicates poor preciseness. Based on the results derived from table 10 and figure 10, it was concluded that using global model for prediction of IRI values for Ontario's conditions would be resulted into bias prediction with average bias value of $0.21 \mathrm{~m} / \mathrm{km}$. Hence it was decided to perform a local calibration on MEPDG IRI model to reduce bias and to define it with Ontario's conditions.

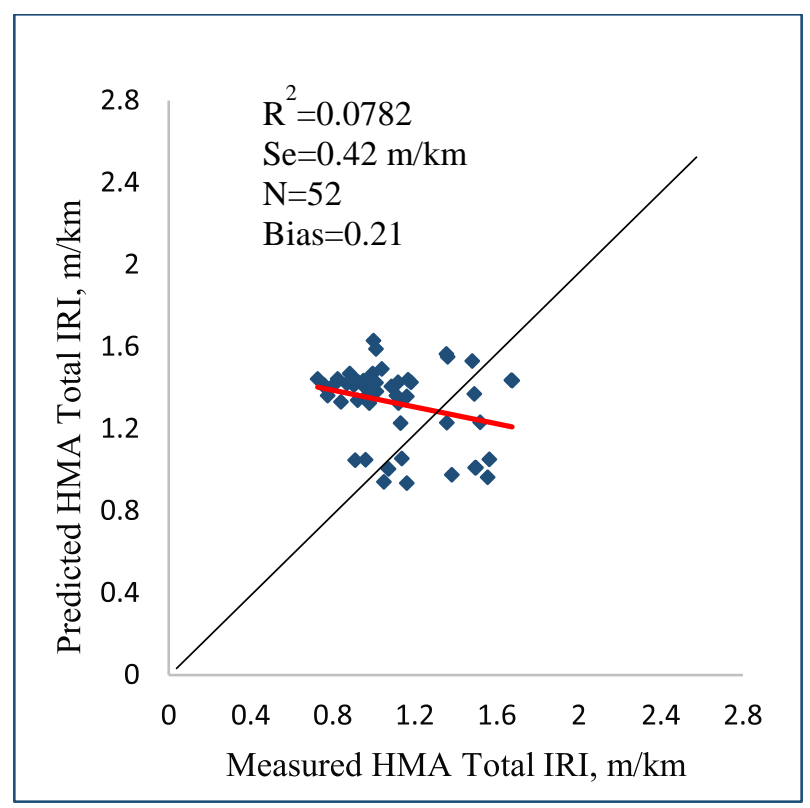


Figure 10. Performance of the default IRI model applied in Ontario's Superpave roads Table 10. Hypothesis tests of the default model

\begin{tabular}{|c|c|c|c|c|c|c|}
\hline $\begin{array}{c}\text { Null hypothesis } \\
\text { Testing }\end{array}$ & DF & Parameter & $\begin{array}{c}\text { Test } \\
\text { Statistic }\end{array}$ & $\begin{array}{c}\text { Critical value } \\
\text { of the test } \\
\text { statistics }\end{array}$ & p-value & Result \\
\hline F-test & 51 & - & 1.87 & 1.59 & 0.013 & Rejected \\
\hline t-test & 51 & - & -4.44 & 2.007 & $<0.0001$ & Rejected \\
\hline
\end{tabular}

\subsubsection{Calibration Results}

After verifying the existence of bias, observed and predicted values (obtained from the software) were used to determine the most precise calibration coefficients for IRI model considering Ontario's conditions.

\subsubsection{Method 1 - Using Actual $\mathbf{I R I}_{\mathbf{0}}$}

For method 1, 27 sections (70\% of database) were chosen randomly from the total of 41 Superpave sections. Calibration analysis was performed considering actual values of $\mathrm{IRI}_{0}$. This analysis resulted in the following calibration parameters with standard error of $0.13 \mathrm{~m} / \mathrm{km}$ and average bias equal to 0 (see figure 11).

- $\mathrm{C}_{1}, \mathrm{C}_{2}, \mathrm{C}_{3}, \mathrm{C}_{4}=$ Local calibration factor for rut depth, fatigue cracking, transverse cracking and site factor found to be equal to 85.83, 0.00013, $0.00026,0.00193$ respectively.

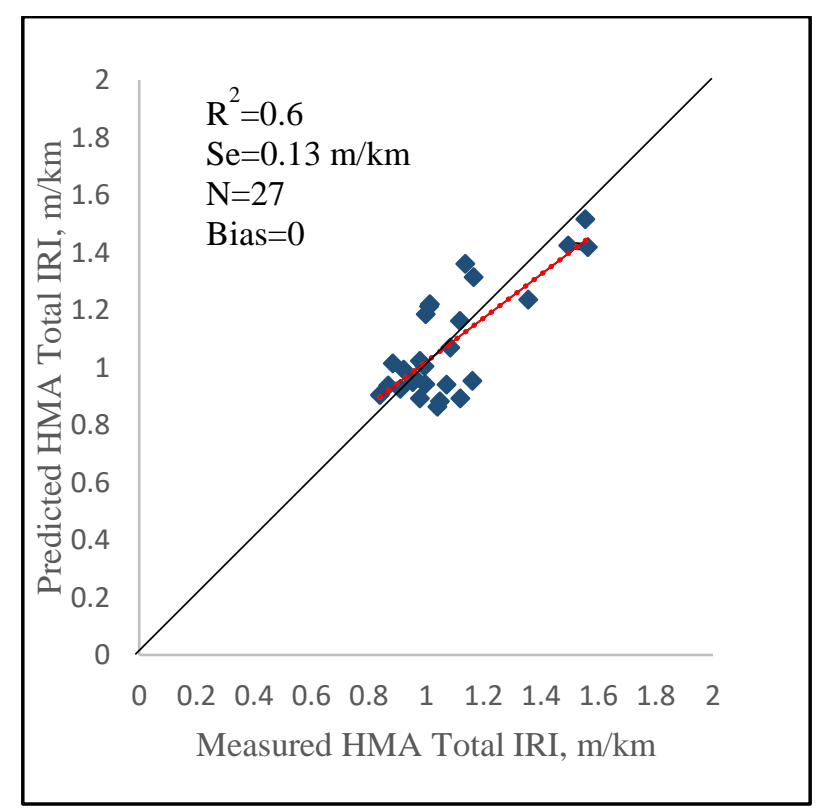

Figure 11. Measured vs. MEPDG-predicted IRI - calibration method 1 
The previously calibrated model needs to be validated by executing the new model on the remaining $30 \%$ of the research database, therefore the newly obtained calibration factors have been substituted in the MEPDG software to be executed on the remaining 14 sections. Validation analysis resulted into standard error of $0.2 \mathrm{~m} / \mathrm{km}$ and average bias equal to $0.1 \mathrm{~m} / \mathrm{km}$ (see figure 12).

Statistical analysis has been performed to assess the accuracy and to determine bias for validation results. Based on information provided in table 11, standard error of the estimated and bias were found to be reasonable. Final results can be found in tables 12 and 13.

Table 11. Hypothesis tests - validation method 1

\begin{tabular}{|l|l|l|l|l|l|l|}
\hline $\begin{array}{c}\text { Null hypothesis } \\
\text { testing }\end{array}$ & DF & Parameter & $\begin{array}{c}\text { Test } \\
\text { Statistic }\end{array}$ & $\begin{array}{c}\text { Critical value } \\
\text { of the test } \\
\text { statistics }\end{array}$ & p-value & Result \\
\hline t-test & 13 & - & 1.7 & 2.16 & 0.06 & Accepted \\
\hline F-test & 13 & - & 1.94 & 2.57 & 0.1 & Accepted \\
\hline
\end{tabular}

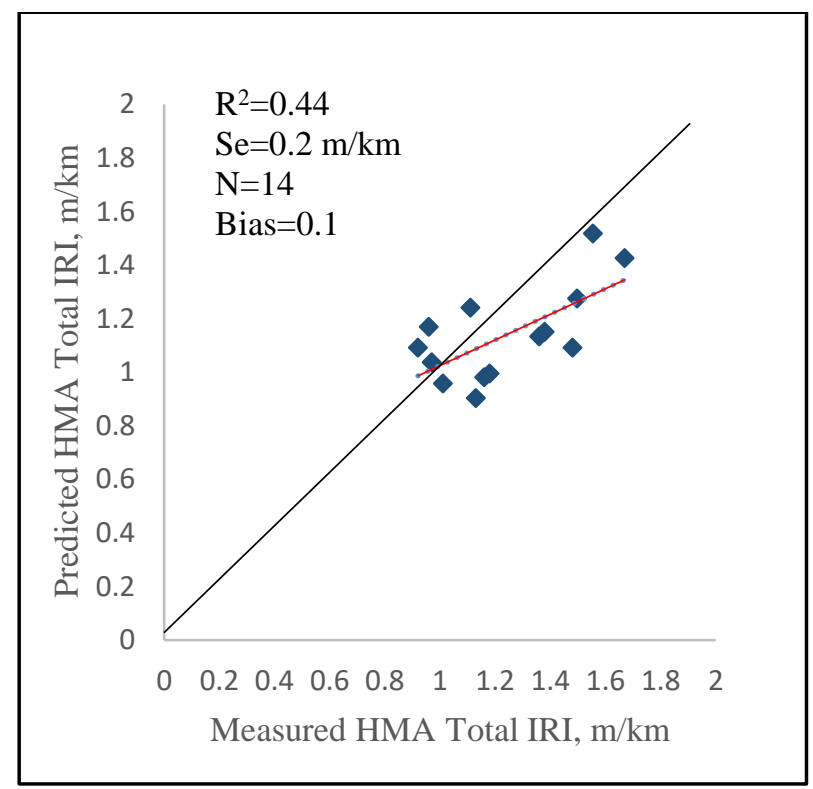

Figure 12. Measured vs. MEPDG-predicted IRI - validation method 1

Table 12.Summary of local calibration effort for Ontario's Superpave pavement IRI model method 1

\begin{tabular}{|c|c|c|}
\hline Calibration Coefficient & Global Model & Local Calibration -Ontario \\
\hline $\mathrm{C}_{1}$ & 40 & 85.83 \\
\hline $\mathrm{C}_{2}$ & 0.4 & 0.00013 \\
\hline $\mathrm{C}_{3}$ & 0.008 & 0.00026 \\
\hline $\mathrm{C}_{4}$ & 0.015 & 0.00193 \\
\hline
\end{tabular}


Table 13. Summary of statistical parameters: local calibration efforts for Ontario's Superpave pavement IRI model - method 1

\begin{tabular}{|c|c|c|c|}
\hline Statistical Parameters & Global model & $\begin{array}{c}\text { Local calibration } \\
\text { Performed on 70\% of selected } \\
\text { Ontario's Superpave pavement } \\
\text { sections }\end{array}$ & Validation \\
\hline $\mathrm{R}^{2}$ & 0.56 & 0.6 & 0.44 \\
\hline $\begin{array}{c}\text { Standard Error of the } \\
\text { Estimate, } \mathrm{S}_{\mathrm{e}}\end{array}$ & $0.14(\mathrm{~m} / \mathrm{km})$ & $0.13(\mathrm{~m} / \mathrm{km})$ & $0.2(\mathrm{~m} / \mathrm{km})$ \\
\hline Number of sections & 1926 & 27 & 14 \\
\hline
\end{tabular}

Figure 13 represents an arbitrary distribution of residual errors around zero line, from vertical distribution of the scatter, it can be concluded that predicted IRI mostly falls within two standard error of the estimate, which indicates an acceptable bias.

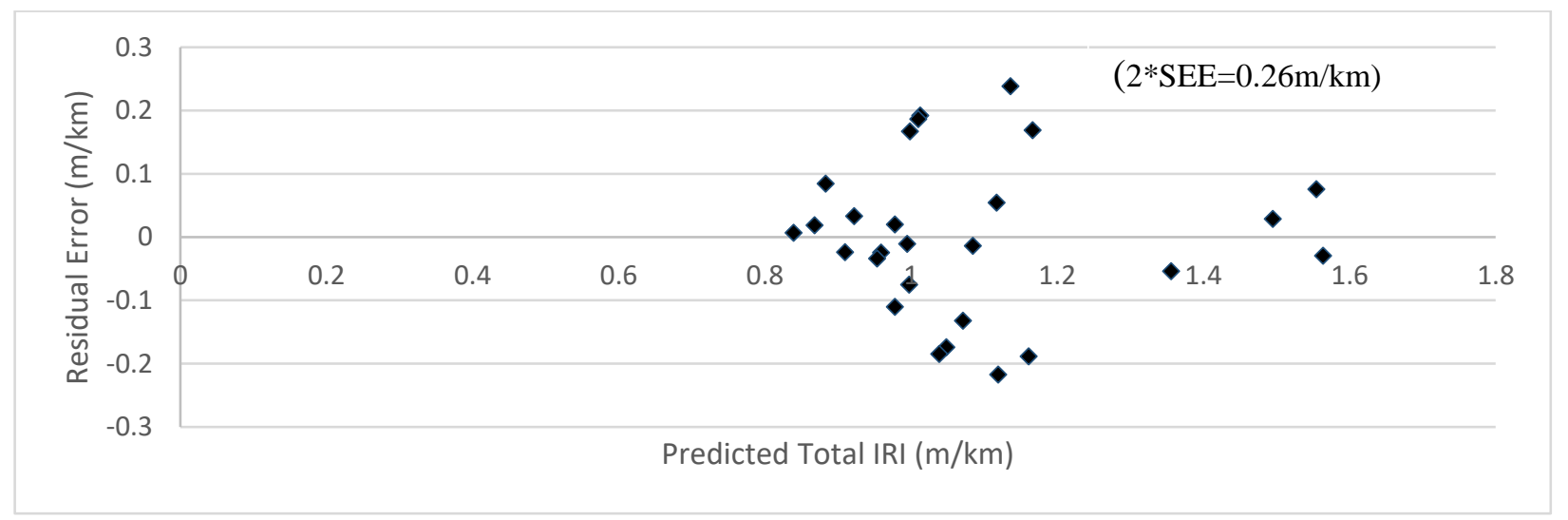

Figure 13. Residual vs. predicted IRI - method 1

\subsubsection{Method 2 - Calculating $\mathbf{I R I}_{\mathbf{0}}$ from linear regression}

For the calibration part, 29 sections were chosen randomly from overall 41 of Superpave sections. Calibration analysis was performed considering $\mathrm{IRI}_{0}$ as one of the local calibration coefficients. Based on information provided in figure 14 this analysis resulted into zero bias and standard error of residual equal to $0.26 \mathrm{~m} / \mathrm{km}$ with following calibration coefficients:

- $\mathrm{C}_{1}, \mathrm{C}_{2}, \mathrm{C}_{3}, \mathrm{C}_{4}, \mathrm{IRI}_{0}=$ Calibration factor for rut depth, fatigue cracking, transverse cracking, site factor and $\mathrm{IRI}_{0}$, values are equal to $33.87,0.39,0.0026,0.02,0.65$ respectively. 


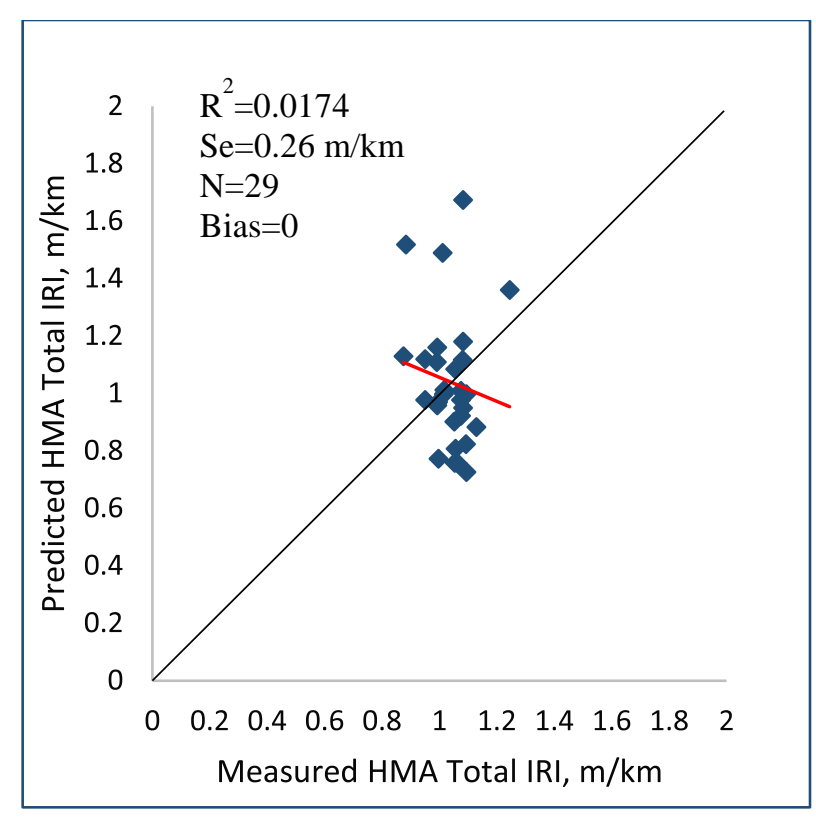

Figure 14. Measured vs. MEPDG-predicted IRI - calibration method 2

To verify the result, MEPDG software was executed on the remaining 12 sections using the newly obtained coefficient values. As shown in table 14 and figure 15, using new calibration coefficients and $\mathrm{IRI}_{0}$ values, will be resulted into precise model with negligible average bias equal to $0.06 \mathrm{~m} / \mathrm{km}$. Final detailed results can be found in table 15 and 16 and figure 14 .

Figure 16 shows arbitrary distribution of residual errors around zero line, vertical distribution of the scatter shows the predicted IRI values are mostly falls within two standard error of the estimate, which indicates an acceptable bias.

Table 14. Hypothesis tests - validation method 2

\begin{tabular}{|c|c|c|c|c|c|c|}
\hline $\begin{array}{c}\text { Null hypothesis } \\
\text { Testing }\end{array}$ & DF & Parameter & $\begin{array}{c}\text { Test } \\
\text { Statistic }\end{array}$ & $\begin{array}{c}\text { Critical value of } \\
\text { the test statistics }\end{array}$ & p-value & Result \\
\hline F-test & 11 & - & 1.39 & 2.8 & 0.3 & Accepted \\
\hline t-test & 11 & - & 0.64 & 2.2 & 0.53 & Accepted \\
\hline
\end{tabular}




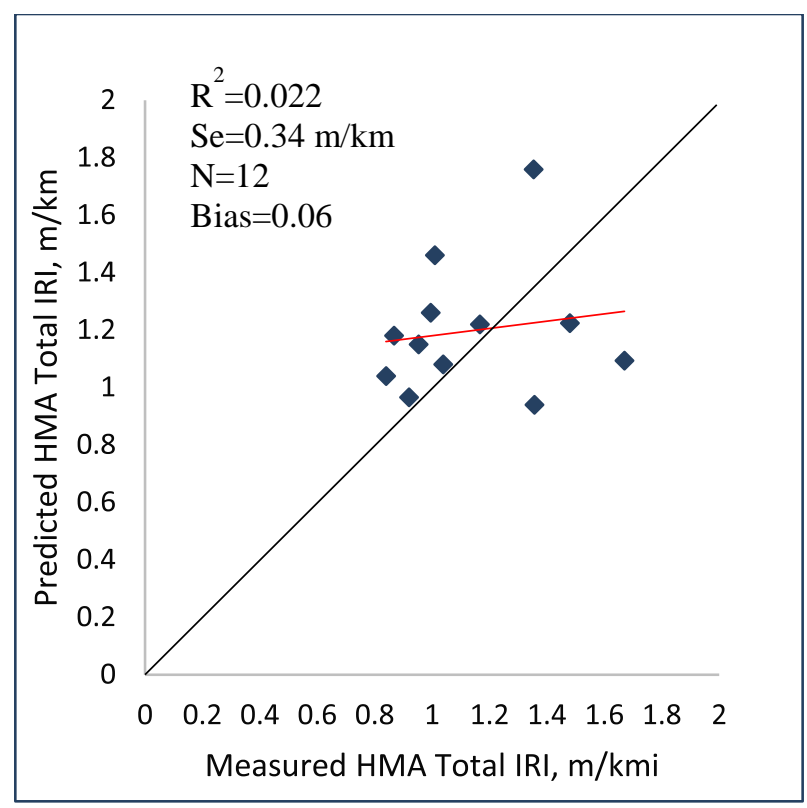

Figure 15. Measured vs. MEPDG-predicted IRI - validation method 2

Table 15. Summary of local calibration efforts for Ontario's Superpave pavement IRI model

\begin{tabular}{|c|c|c|}
\hline Calibration Coefficient & Global Model & Local Calibration -Ontario \\
\hline $\mathrm{C}_{1}$ & 40 & 33.87 \\
\hline $\mathrm{C}_{2}$ & 0.4 & 0.39 \\
\hline $\mathrm{C}_{3}$ & 0.008 & 0.0026 \\
\hline $\mathrm{C}_{4}$ & 0.015 & 0.02 \\
\hline $\mathrm{IRI}_{0}$ & 1 & 0.65 \\
\hline
\end{tabular}

Table 16. Summary of statistical parameters- local calibration efforts for Ontario's Superpave pavement IRI model - method 2

\begin{tabular}{|c|c|c|c|}
\hline Statistical Parameters & Global model & $\begin{array}{c}\text { Local calibration } \\
\text { Performed on 70\% of selected } \\
\text { Ontario's Superpave pavement } \\
\text { sections }\end{array}$ & Validation \\
\hline $\mathrm{R}^{2}$ & 0.56 & 0.0174 & 0.022 \\
\hline $\begin{array}{c}\text { Standard Error of the } \\
\text { Estimate, } \mathrm{S}_{\mathrm{e}}\end{array}$ & $0.14(\mathrm{~m} / \mathrm{km})$ & $0.26(\mathrm{~m} / \mathrm{km})$ & $0.34(\mathrm{~m} / \mathrm{km})$ \\
\hline Number of sections, & 1926 & 29 & 12 \\
\hline
\end{tabular}




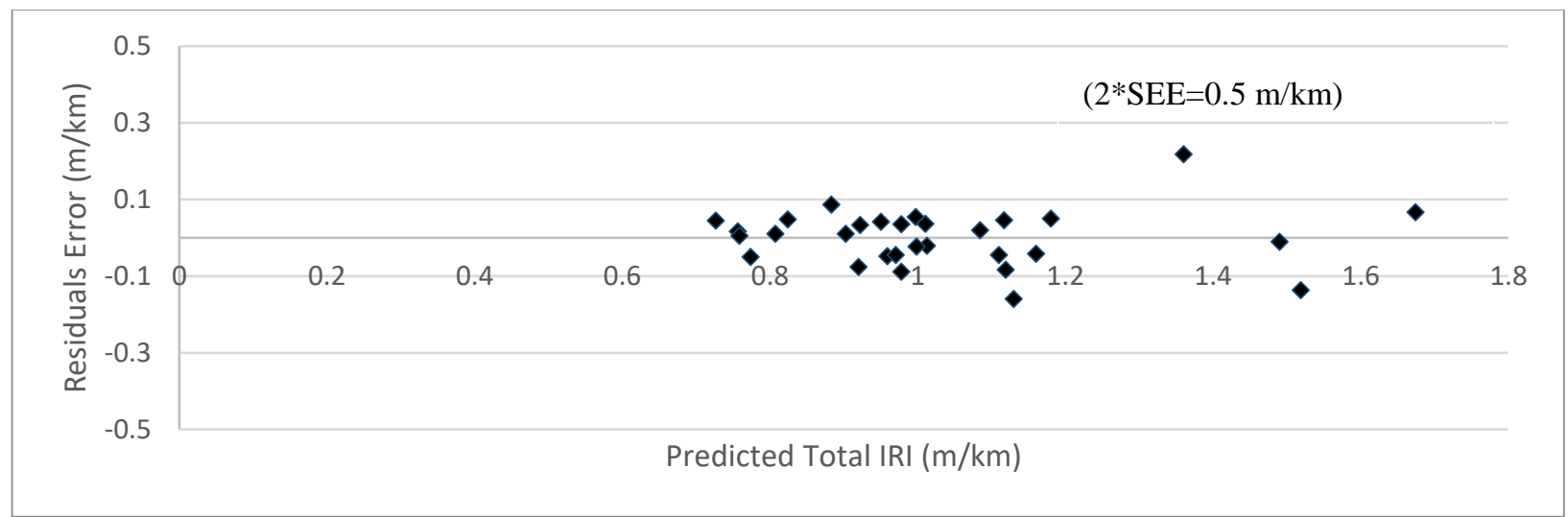

Figure 16. Residual vs. predicted IRI - method 2

\subsubsection{Method 3 - Using Default IRI}

Optimization analysis was performed using calculated predicted $\Delta$ IRI results and their respective observed values.

Using Excel Solver, new optimized coefficient parameters was obtained by generating least residual sum of square value and setting constraint of bias to be equal to zero. Based on table 17 and figure 17, optimization process led to reduced standard error equal to $0.27 \mathrm{~mm}$. Unfortunately, zero values for $\mathrm{C}_{1}, \mathrm{C}_{2}, \mathrm{C}_{3}$ coefficients were obtained, which could not be considered as an acceptable result. Hence, subsequent steps were not followed for this method. Table 18 summarized the results of all three methods used within this section.

Table 17. Summary of local calibration efforts for Ontario's Superpave pavement IRI model method 3

\begin{tabular}{|c|c|c|}
\hline Calibration Coefficient & Global Model & Local Calibration -Ontario \\
\hline $\mathrm{C}_{1}$ & 40 & 0 \\
\hline $\mathrm{C}_{2}$ & 0.4 & 0 \\
\hline $\mathrm{C}_{3}$ & 0.008 & 0 \\
\hline $\mathrm{C}_{4}$ & 0.015 & 0.025 \\
\hline
\end{tabular}




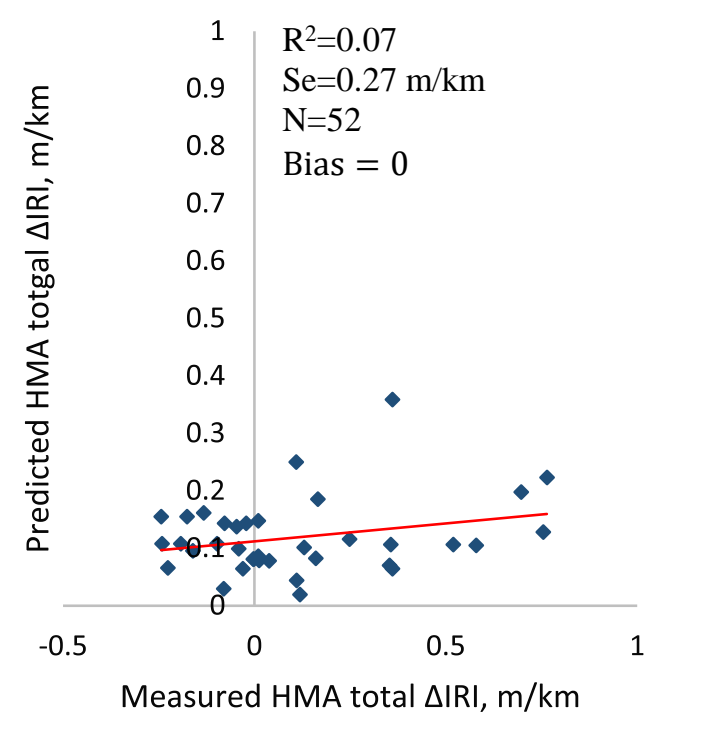

Figure 17. Measured versus MEPDG predicted $\triangle I R I$ - calibration method 3

Table 18. Summary of local calibration efforts for Ontario's Superpave pavement IRI model

\begin{tabular}{|c|c|c|c|}
\hline \multirow{2}{*}{ Parameter } & \multicolumn{3}{|c|}{ Method } \\
\cline { 2 - 4 } & $\mathbf{1}$ & $\mathbf{2}$ & $\mathbf{3}$ \\
\hline $\mathrm{C}_{1}$ & 85.83 & 33.87 & 0 \\
\hline $\mathrm{C}_{2}$ & 0.00013 & 0.39 & 0 \\
\hline $\mathrm{C}_{3}$ & 0.00026 & 0.0026 & 0.025 \\
\hline $\mathrm{C}_{4}$ & 0.00193 & 0.02 & 0.07 \\
\hline $\mathrm{R}^{2}$ & 0.6 & 0.0174 & $0.27 \mathrm{~m} / \mathrm{km}$ \\
\hline $\mathrm{S}_{\mathrm{e}}$ & $0.13 \mathrm{~m} / \mathrm{km}$ & $0.26 \mathrm{~m} / \mathrm{km}$ & \\
\hline
\end{tabular}

To present the best calibration method it is important to understand that for future design the value of $\mathrm{IRI}_{0}$ should be based on the latest MTO default parameters. Therefore, coefficients obtained from each method need to be re-evaluated by simulating the actual design procedure when using $\mathrm{IRI}_{0}$ default parameters.

In order to simulate future design conditions, software was executed in two separate rounds on the total of 52 sections. The first round used method 1 coefficient values and second round used method 2 coefficient values. It is important to understand that for both rounds, input values for $\mathrm{IRI}_{0}$ were based on the current MTO default parameters. For each simulated design 
method, based on their predicted IRI results and respective observed ones, standard deviations of residual were calculated. Based on the results shown in table 19, method 1 would be recommended as the best calibration method by this study.

Table 19. Simulated future design conditions - value of $\mathrm{S}_{\mathrm{e}}$

\begin{tabular}{|c|c|c|}
\hline \multirow{2}{*}{ Calibration Coefficient } & \multicolumn{2}{|c|}{} \\
\cline { 2 - 3 } & Method 1 & Method 2 \\
\hline $\mathrm{S}_{\mathrm{e}}$ & $0.30 \mathrm{~m} / \mathrm{km}$ & $0.40 \mathrm{~m} / \mathrm{km}$ \\
\hline
\end{tabular}




\section{CHAPTER 5 SUMMARY, CONCLUSIONS AND RECOMMENDATIONS}

This chapter summarizes and derives conclusions from works performed by this study on the local calibration of the IRI and rutting models. Finally, based on conclusions in this chapter, recommendations for the enhancement of this study for future research will be presented.

\subsection{Summary}

The focus of the current study was to perform a local calibration of rutting and IRI models, two distress models of the MEPDG, for Ontario's Superpave sections.

The literature review on rutting models illustrated the need to further enhance the result of local calibration for rutting models. In addition, as a result of the ongoing use of SMA materials within the new design, an expanded database was built that included new SMA sections. A cross-sectional calibration was performed based by the least squares method, which resulted in a more precise and reasonable result compared to global and current locally calibrated models.

For the IRI model, due to the absence of local coefficient values for cracking models, the main focus was to introduce the best method of achieving local coefficient values.

\subsection{Conclusions}

The conclusions drawn from this study are as follows:

Using global models for both rutting and IRI results in imprecise and mostly overestimated prediction results. Performing a cross-sectional local calibration on the rutting model resulted in the following calibration parameters: $\beta_{\mathrm{AC}}=1.7692, \beta_{\mathrm{GB}}=0.0968, \beta_{\mathrm{SG}}=$ 0.2787 with layer contributions of $19 \%, 9 \%$ and $72 \%$, respectively. This resulted in a reduced residual standard deviation equal to $1 \mathrm{~mm}$, a significant improvement compared to previous studies. Therefore, the calibration parameters obtained for rutting models can be used as level three rutting model calibration parameters for both new and rehabilitated Superpave pavements within Ontario's conditions.

To perform a local calibration for the IRI model, the following methods are proposed by this study: 
- Method 1 - Using actual observed $\mathrm{IRI}_{0}$ values

- Method 2 - Including IRI $_{0}$ as one of the coefficient parameters and solving for it

- Method 3 - Using Ontario's default parameter for IRI $_{0}$ values

Based on the results of this study, it was concluded that using method 1 coefficient values would lead to a more precise prediction of IRI in future designs and hence was found to be the best approach to be used for future calibrations.

\subsection{Recommendations}

More studies need to be conducted to finalize the local calibration of the MEPDG distress and performance models. Below are the major recommendations for future studies.

- The observed rut depth and IRI values available for this study did not reach the MTO thresholds. To enhance local calibration studies, it is recommended that the updating of local calibration of the rutting model be continued as new rutting observation data that reaches or exceeds the design thresholds are made available.

- The calibrated rutting models in this study have resulted in a contribution to rutting by various pavement layers similar to that in the global calibration, which can be further traced back to the AASHO test results of the 1960s. Trench investigation is recommended for a final validation of the global and local calibration results.

- The $\mathrm{IRI}_{0}$ value is an important design policy parameter to be determined by the MTO. Further analysis using existing initial IRI data in PMS and local calibration is recommended to determine the optimal $\mathrm{IRI}_{0}$ value for future design. The optimal $\mathrm{IRI}_{0}$ value is not necessarily the mean value of the $\mathrm{IRI}_{0}$ database; rather, sensitivity analyses need to be conducted to confirm the impact on initial capital and construction administration costs.

- After a successful calibration of the cracking models, a full-course local calibration of the IRI model following the methods proposed in this study is recommended. 


\section{APPENDIX A: PAVEMENT SECTIONS, STRUCTURES, AND MATERIALS}

Table A-1 Selected Superpave sections used in the study

\begin{tabular}{|c|c|c|c|c|}
\hline Section Number & ID & From_LHRS & To-LHRS & Region \\
\hline 1 & 77 & $12020+1.3$ & $12036+0.0$ & Western \\
\hline 2 & 78 & $12036+0.0$ & $12038+0.0$ & Western \\
\hline 3 & 105 & $13465+0.0$ & $13515+0.0$ & Central \\
\hline 4 & 114 & $13640+2.1$ & $13650+2.46$ & Western \\
\hline 5 & 197 & $14612+0.88$ & $14620+6.0$ & Western \\
\hline 6 & 206 & $14612+0.88$ & $14620+6.0$ & Western \\
\hline 7 & 253 & $16590+0.00$ & $16600+0.00$ & Western \\
\hline 8 & 437 & $20020+3.820$ & $20035+0.800$ & Eastern \\
\hline 9 & 587 & $24030+0.000$ & $24030+12.970$ & Western \\
\hline 10 & 589 & $24050+5.2$ & $24060+0.10$ & Western \\
\hline 11 & 600 & $24142+0.1$ & $24142+13.0$ & Western \\
\hline 12 & 670 & $27816+0.0$ & $27822+0.0$ & Central \\
\hline 13 & 673 & $27816+0.0$ & $27822+0.0$ & Central \\
\hline 14 & 697 & $29580+2.800$ & $29590+3.900$ & Central \\
\hline 15 & 698 & $29590+3.900$ & $29590+11.300$ & Eastern \\
\hline 16 & 727 & $33240+0.000$ & $33240+7.850$ & Eastern \\
\hline 17 & 728 & $33240+7.850$ & $33250+1.600$ & Eastern \\
\hline 18 & 826 & $38630+0.24$ & $38635+0.0$ & Central \\
\hline 19 & 976 & $46969+0.000$ & $46972+0.000$ & Northeastern \\
\hline 20 & 977 & $46972+0.000$ & $46977+6.200$ & Northeastern \\
\hline 21 & 1001 & $46969+0.000$ & $46972+0.000$ & Northeastern \\
\hline 22 & 1052 & $47603+0.0$ & $47607+0.0$ & Central \\
\hline 23 & 1240 & $48335+0.0$ & $48342+1.0$ & Western \\
\hline 24 & 1246 & $48255+1.65$ & $48270+1.0$ & Central \\
\hline 25 & 1247 & $48250+1.65$ & $48255+1.65$ & Central \\
\hline 26 & 1248 & $48255+1.65$ & $48270+1.0$ & Central \\
\hline 27 & 1255 & $48335+0.0$ & $48342+1.0$ & Western \\
\hline 28 & 1260 & $48250+1.65$ & $48255+1.65$ & Central \\
\hline 29 & 1261 & $48255+1.65$ & $48255+1.65$ & Central \\
\hline 30 & 1287 & $48652+1.326$ & $48660+2.465$ & Central \\
\hline 31 & 764 & $34320+0.000$ & $34330+0.800$ & Northeastern \\
\hline
\end{tabular}




\begin{tabular}{|c|c|c|c|c|}
\hline 32 & 952 & $46130+9.900$ & $46140+0.000$ & Northeastern \\
\hline 33 & 107 & $13570+5.90$ & $13580+1.00$ & Central \\
\hline 34 & 109 & $13585+0.300$ & $13585+3.244$ & Central \\
\hline 35 & 115 & $13650+2.46$ & $13650+11.44$ & Western \\
\hline 36 & 144 & $14024+0.000$ & $14040+0.000$ & Eastern \\
\hline 37 & 159 & $14200+8.000$ & $14210+0.800$ & Eastern \\
\hline 38 & 166 & $14270+0.000$ & $14270+8.700$ & Eastern \\
\hline 39 & 240 & $16460+0.000$ & $16460+8.270$ & Central \\
\hline 40 & 271 & $17360+3.900$ & $17380+0.000$ & Northeastern \\
\hline 41 & 760 & $34120+0.000$ & $34133+4.771$ & Northeastern \\
\hline 42 & 791 & $35550+14.300$ & $35560+1.100$ & Northeastern \\
\hline 43 & 1139 & $47603+0.0$ & $47607+0.0$ & Northeastern \\
\hline 44 & 1331 & $49500+0.000$ & $49540+0.000$ & Eastern \\
\hline 45 & 1332 & $49540+0.000$ & $49550+0.000$ & Eastern \\
\hline 46 & 1-SMA & $13605+0.1$ & $13605+1.2$ & Western \\
\hline 47 & 2-SMA & $13605+1.2$ & $13605+1.9$ & Western \\
\hline 48 & 3-SMA & $13605+1.9$ & $13605+2.8$ & Western \\
\hline 49 & 4-SMA & $13605+2.8$ & $13607+0.1$ & Western \\
\hline 50 & 5-SMA & $10131+0.000$ & $10135+0.800$ & Central \\
\hline 51 & 6-SMA & $10100+0.000$ & $10105+1.603$ & Central \\
\hline 52 & 7-SMA & $46820+0.5$ & $46823+0.5$ & Central \\
\hline 53 & 8-SMA & $47820+1$ & $47823+0.9$ & Western \\
\hline 54 & 9-SMA & $47805+0.9$ & $47815+3$ & Western \\
\hline 55 & 10-SMA & $47760+1$ & $47760+12.2$ & Western \\
\hline 56 & 11-SMA & $47760+12.2$ & $47784+1$ & Western \\
\hline 57 & 12-SMA & $47784+1$ & $47786+1$ & Central \\
\hline 58 & 13-SMA & $48315+0.2$ & $48315+3.3$ & Central \\
\hline 59 & 14-SMA & $48315+0.2$ & $48315+3.3$ & Central \\
\hline 60 & 15-SMA & $47810+0.9$ & $47815+1$ & Western \\
\hline 61 & 16-SMA & $13600+0.1$ & $13600+3.2$ & Western \\
\hline 62 & 17-SMA & $13600+5.2$ & $13605+0.1$ & Western \\
\hline 63 & 18-SMA & $13600+3.3$ & $13600+4.3$ & Western \\
\hline 64 & 19-SMA & $10128+0.000$ & $10131+0.000$ & Central \\
\hline
\end{tabular}


Table A-2- Material and structural information for the selected Superpave sections

\begin{tabular}{|c|c|c|c|c|c|c|c|c|c|c|c|c|c|c|}
\hline \multirow{2}{*}{$\begin{array}{l}\text { Section } \\
\text { Number }\end{array}$} & \multirow[b]{2}{*}{ ID } & \multirow{2}{*}{$\begin{array}{l}\text { Service } \\
\text { Age } \\
\text { (years) }\end{array}$} & \multicolumn{2}{|l|}{ First Layer } & \multicolumn{2}{|l|}{ Second layer } & \multicolumn{2}{|l|}{ Third Layer } & \multicolumn{2}{|l|}{ Forth Layer } & \multicolumn{2}{|l|}{ Fifth Layer } & \multirow[b]{2}{*}{ Subgrade Soil } & \multirow{2}{*}{\begin{tabular}{|l} 
Resilience \\
Modulus, \\
Mr (MPa) \\
\end{tabular}} \\
\hline & & & Material & $\begin{array}{l}\text { Thickness } \\
(\mathbf{m m})\end{array}$ & Material & $\begin{array}{l}\text { Thickness } \\
(\mathbf{m m})\end{array}$ & Material & $\begin{array}{l}\begin{array}{l}\text { Thickness } \\
(\mathbf{m m})\end{array} \\
\end{array}$ & Material & \begin{tabular}{|l|} 
Thickness \\
$(\mathrm{mm})$
\end{tabular} & Material & $\begin{array}{l}\text { Thickness } \\
\text { (mm) }\end{array}$ & & \\
\hline 1 & 77 & 10 & SP $12.5 \mathrm{FC} 2$ & 40 & SP 19 & 60 & SP 19 & 70 & Old Granular Base & 200 & Old Granular Subbase & 150 & $\mathrm{CL}$ & 36 \\
\hline 2 & 78 & 10 & SP $12.5 \mathrm{FC} 2$ & 40 & SP 19 & 60 & SP 19 & 70 & Old Granular Base & 200 & Old Granular Subbase & 150 & $\mathrm{CL}$ & 36 \\
\hline 3 & 105 & 12 & SP $12.5 \mathrm{FC} 2$ & 40 & SP 19 & 50 & SP 19 & 110 & Old Granular Base & 150 & Old Granular Subbase & 550 & CL-ML & 30 \\
\hline 4 & 114 & 7 & SP $12.5 \mathrm{FC} 1$ & 40 & SP 19 & 50 & SP 19 & 50 & Granular A & 225 & & & SM & 35 \\
\hline 5 & 197 & 9 & SP 12.5 FC2 & 40 & SP 19 & 60 & SP 19 & 60 & Pulverized Layer & 300 & Old Granular BIII & 300 & SM-SC & 30 \\
\hline 6 & 206 & 9 & SP 12.5 FC2 & 40 & SP 19 & 60 & SP 19 & 60 & Pulverized Layer & 300 & Old Granular BIII & 300 & SM-SC & 30 \\
\hline 7 & 253 & 10 & SP $12.5 \mathrm{FC} 1$ & 50 & SP 19 & 100 & Pulverized Layer & 200 & Old Granular Subbase & 300 & & & SM & 35 \\
\hline 8 & 437 & 12 & SP $12.5 \mathrm{FC} 1$ & 40 & SP 19 & 60 & SP 19 & 60 & Granular A & 150 & Granular B1 & 450 & $\mathrm{CH}$ & 20 \\
\hline 9 & 587 & 6 & SP 12.5 & 50 & CIR & 110 & Old Granular Base & 180 & Old Granular Subbase & 800 & & & SM & 40 \\
\hline 10 & 589 & 11 & SP 12.5 & 60 & SP 19 & 75 & Pulverized Layer & 320 & Old Granular Subbase & & & & CL-ML & 30 \\
\hline 11 & 600 & 5 & SP 12.5 & 40 & SP 19 & 110 & Pulverized Layer & 100 & Old Granular Base & 200 & Old Granular Subbase & 560 & CI-CL & 35 \\
\hline 12 & 670 & 11 & SP 12.5 FC2 & 40 & SP 19 & 50 & HL-8 & 130 & Old Granular Base & 550 & & & SM & 35 \\
\hline 13 & 673 & 10 & SP 12.5 FC2 & 40 & SP 19 & 50 & HL-8 & 130 & Old Granular Base & 550 & & & SM & 35 \\
\hline 14 & 697 & 7 & SP 12.5 & 40 & SP 19 & 50 & Granular A & 200 & & & & & SM & 80 \\
\hline 15 & 698 & 8 & SP 12.5 & 40 & SP 19 & 50 & Pulverized Layer & 200 & Granular A & 190 & Old Granular Subbase & 150 & SM & 80 \\
\hline 16 & 727 & 6 & SP 12.5 & 50 & HL-8 & 150 & Old Granular Base & 145 & Pulverized Layer & 150 & & & SM & 80 \\
\hline 17 & 728 & 6 & SP 12.5 & 50 & HL-8 & 150 & Old Granular Base & 145 & Pulverized Layer & 150 & & & SM & 80 \\
\hline 18 & 826 & 5 & SP 12.5 FC2 & 40 & SP 19 & 110 & EAS & 130 & Old Granular Base & 290 & Old Granular Subbase & 240 & CL-ML & 25 \\
\hline 19 & 976 & 7 & SP $12.5 \mathrm{FC} 2$ & 40 & SP 19 & 50 & CIR & 100 & HL-4 & 40 & Granular A & 420 & CL-ML & 35 \\
\hline 20 & 977 & 9 & SP $12.5 \mathrm{FC} 2$ & 40 & SP 19 & 50 & CIR & 100 & HL-4 & 40 & Granular A & 420 & CL-ML & 35 \\
\hline 21 & 1001 & 15 & SP 12.5 FC2 & 40 & SP 19 & 50 & CIR & 100 & HL-4 & 170 & Granular A & 540 & CL-ML & 70 \\
\hline 22 & 1052 & 6 & SP $12.5 \mathrm{FC} 2$ & 40 & SP 19 & 50 & HL-3 & 160 & Old Granular Base & 320 & Old Granular Subbase & 550 & CL-ML & 30 \\
\hline 23 & 1240 & 9 & SP $12.5 \mathrm{FC} 2$ & 40 & SP 19 & 100 & $\mathrm{HL}-4$ & 120 & Granular A & 225 & Granular B1 & 375 & SM & 40 \\
\hline 24 & 1246 & 11 & SP $12.5 \mathrm{FC} 2$ & 40 & SP 19 & 40 & HDB & 200 & Old Granular Base & 300 & Old Granular Subbase & 300 & $\mathrm{CI}$ & 35 \\
\hline 25 & 1247 & 2 & SP 12.5 FC2 & 40 & SP 19 & 40 & HDB & 200 & Old Granular Base & 300 & Old Granular Subbase & 300 & $\mathrm{CL}$ & 35 \\
\hline 26 & 1248 & 11 & SP $12.5 \mathrm{FC} 2$ & 40 & SP 19 & 40 & HDB & 200 & Old Granular Base & 300 & Old Granular Subbase & 300 & $\mathrm{CI}$ & 35 \\
\hline 27 & 1255 & 9 & SP $12.5 \mathrm{FC} 2$ & 40 & SP 19 & 100 & HL-4 & 120 & Granular A & 225 & Granular B1 & 375 & SM & 40 \\
\hline 28 & 1260 & 2 & SP 12.5 FC2 & 40 & SP 19 & 40 & HDB & 200 & Old Granular Base & 300 & Old Granular Subbase & 300 & CL & 35 \\
\hline 29 & 1261 & 2 & SP 12.5 FC2 & 40 & SP 19 & 40 & HDB & 200 & Old Granular Base & 300 & Old Granular Subbase & 300 & $\mathrm{CI}$ & 35 \\
\hline 30 & 1287 & 8 & SP 12.5 FC2 & 40 & SP 19 & 60 & SP 25 & 100 & Granular A & 450 & & & $\mathrm{CL}$ & 35 \\
\hline 31 & 764 & 7 & SP 12.5 & 50 & Pulverized Layer & 200 & Old Granular Base & 120 & Old Granular Subbase & 600 & & & CL-ML & 35 \\
\hline 32 & 952 & 11 & SP 12.5 & 50 & EAS & 150 & Old Granular Base & 50 & Old Granular Base & 115 & Old Granular Subbase & 612 & SM & 42 \\
\hline 33 & 107 & 16 & SP $12.5 \mathrm{FC} 2$ & 40 & SP 19 & 50 & HL3 & 110 & Old Granular Base(BI) & 700 & & & CI-CL & 30 \\
\hline 34 & 109 & 10 & SP $12.5 \mathrm{FC} 2$ & 40 & SP 19 & 50 & HL3 & 110 & Old Granular Base & 700 & & & CI-CL & 30 \\
\hline 35 & 115 & 17 & SP $12.5 \mathrm{FC} 1$ & 40 & SP 19 & 50 & SP 19 & 50 & Granular A & 225 & & & SM & 35 \\
\hline 36 & 144 & 11 & SP $12.5 \mathrm{FC} 2$ & 40 & SP 19 & 60 & SP 19 & 70 & Granular O & 150 & Granular B2 & 450 & CI-CL & 30 \\
\hline 37 & 159 & 7 & SP $12.5 \mathrm{FC} 1$ & 60 & CIR & 70 & HL-4 & 90 & Old Granular Base & 315 & Old Granular Subbase & 300 & SM & 50 \\
\hline 38 & 166 & 11 & SP $12.5 \mathrm{FC} 1$ & 40 & SP 19 & 50 & SP 19 & 50 & Pulverized Layer & 200 & Old Granular Subbase & 400 & SM & 30 \\
\hline 39 & 240 & 6 & SP $12.5 \mathrm{FC} 2$ & 40 & SP 19 & 50 & SP 19 & 50 & Old Granular Base & 500 & & & CL-ML & 30 \\
\hline 40 & 271 & 7 & SP 12.5 & 40.0 & SP 19 & 50 & CIR & 110 & HL-4 & 140 & Granular A/Granular B1 & $200 / 700$ & CL-ML & 40 \\
\hline 41 & 760 & 7 & SP 12.5 & 40 & SP 19 & 50 & EAS & 175 & Granular A & 100 & Old Granular Subbase & 625 & CL-ML & 45 \\
\hline 42 & 791 & 9 & SP $12.5 \mathrm{FCl}$ & 100 & SP 25 & 200 & Granular & 150 & Granular B & 150 & & & CL-ML & 90 \\
\hline 43 & 1139 & 17 & SP 12.5 & 40 & SP19 & 50 & HL3 & 160 & Old Granular Base & 320 & Old Granular Subbase & 550 & CL-ML & 30 \\
\hline
\end{tabular}




\begin{tabular}{|c|c|c|c|c|c|c|c|c|c|c|c|c|c|c|}
\hline \multirow{2}{*}{$\begin{array}{l}\text { Section } \\
\text { Number }\end{array}$} & \multirow[b]{2}{*}{ ID } & \multirow{2}{*}{$\begin{array}{l}\text { Service } \\
\text { Age } \\
\text { (years) }\end{array}$} & \multicolumn{2}{|l|}{ First Layer } & \multicolumn{2}{|l|}{ Second layer } & \multicolumn{2}{|l|}{ Third Layer } & \multicolumn{2}{|l|}{ Forth Layer } & \multicolumn{2}{|l|}{ Fifth Layer } & \multirow[b]{2}{*}{ Subgrade Soil } & \multirow{2}{*}{$\begin{array}{l}\text { Resilience } \\
\text { Modulus, } \\
\text { Mr (MPa) }\end{array}$} \\
\hline & & & Material & $\begin{array}{l}\text { Thickness } \\
\text { (mm) }\end{array}$ & Material & $\begin{array}{l}\text { Thickness } \\
\text { (mm) }\end{array}$ & Material & $\begin{array}{l}\text { Thickness } \\
\text { (mm) }\end{array}$ & Material & $\begin{array}{l}\text { Thickness } \\
\text { (mm) }\end{array}$ & Material & $\begin{array}{l}\text { Thickness } \\
\text { (mm) }\end{array}$ & & \\
\hline 44 & 1331 & 5 & SP $12.5 \mathrm{FC} 2$ & 40 & SP 19 & 100 & HDB & 40 & HL-4 & 185 & Old Granular Base & 225 & CL-ML & 31 \\
\hline 45 & 1332 & 9 & SP $12.5 \mathrm{FC} 2$ & 40 & SP 19 & 100 & HDB & 40 & HL-4 & 185 & Old Granular Base & 225 & CL-ML & 31 \\
\hline 46 & 1-SMA & 3 & SMA (70-28) & 50 & SP 19 & 60 & SP 19 & 50 & Old Granular Base & 260 & Old Granular Subbase & 500 & $\mathrm{SC}$ & 33 \\
\hline 47 & 2-SMA & 3 & SMA (70-28) & 50 & SP 19 & 50 & SP 19 & 60 & Old Granular Base & 260 & Old Granular Subbase & 450 & $\mathrm{SC}$ & 33 \\
\hline 48 & 3-SMA & 3 & SMA (70-28) & 50 & SP 19 & 50 & SP 19 & 110 & Old Granular Base & 260 & Old Granular Subbase & 450 & $\mathrm{SC}$ & 33 \\
\hline 49 & 4-SMA & 3 & SMA (70-28) & 50 & SP 19 & 50 & SP 19 & 110 & Old Granular Base & 260 & Old Granular Subbase & 450 & SC & 33 \\
\hline 50 & 5-SMA & 6 & SMA (70-28) & 40 & SP 19 & 160 & SP 25 & 100 & Granular A & 150 & Granular B1 & 600 & CL-ML & 30 \\
\hline 51 & 6-SMA & 6 & SMA (70-28) & 40 & SP19 & 180 & Granular A & 150 & Granular B1 & 600 & & & CL-ML & 30 \\
\hline 52 & 7-SMA & 5 & SMA (70-28) & 40 & $\begin{array}{l}\text { SP19 } \\
\end{array}$ & 50 & HL-3 & 200 & Granular A & 150 & Old Granular Subbase & 450 & CI-CL & 30 \\
\hline 53 & 8-SMA & 9 & SMA (64-28) & 40 & SP19 & 100 & SP 25 & 200 & Old Granular Base & 150 & Old Granular Subbase & 550 & $\mathrm{CL}$ & 30 \\
\hline 54 & 9-SMA & 9 & SMA (64-28) & 50 & Existing HDBC & 70 & HL-4 & 140 & Old Granular Base & 260 & Old Granular Subbase & 550 & $\mathrm{CL}$ & 30 \\
\hline 55 & 10-SMA & 7 & SMA (70-28) & 40 & SP19 & 70 & SP 25 & 160 & Granular A & 150 & Granular B1 & 750 & $\mathrm{CL}$ & 25 \\
\hline 56 & 11-SMA & 7 & SMA (70-28) & 40 & SP19 & 70 & SP 25 & 160 & Granular A & 150 & Granular B1 & 750 & $\mathrm{CL}$ & 25 \\
\hline 57 & 12-SMA & 7 & SMA (70-28) & 40 & SP19 & 70 & SP 25 & 160 & Granular A & 150 & Granular B1 & 750 & $\mathrm{CL}$ & 25 \\
\hline 58 & 13-SMA & 9 & SMA (70-28) & 40 & SP19 & 70 & HL-3 & 120 & Old Granular Base & 150 & Old Granular Subbase & 720 & CL-ML & 30 \\
\hline 59 & 14-SMA & 9 & SMA (70-28) & 40 & SP19 & 70 & HL-3 & 120 & Old Granular Base & 150 & Old Granular Subbase & 720 & CL-ML & 30 \\
\hline 60 & 15-SMA & 9 & SMA (64-28) & 50 & Existing HDBC & 70 & HL-4 & 140 & Old Granular Base & 260 & Old Granular Subbase & 550 & $\mathrm{CL}$ & 30 \\
\hline 61 & 16-SMA & 3 & SMA (70-28) & 50 & SP19 & 50 & SP19 & 110 & Old Granular Base & 150 & Old Granular Subbase & 415 & SC & 33 \\
\hline 62 & 17-SMA & 3 & SMA (70-28) & 50 & SP19 & 50 & SP19 & 110 & Old Granular Base & 260 & Old Granular Subbase & 450 & $\mathrm{SC}$ & 33 \\
\hline 63 & 18-SMA & 3 & SMA (70-28) & 50 & SP19 & 50 & SP19 & 110 & Old Granular Base & 260 & Old Granular Subbase & 450 & $\mathrm{SC}$ & 33 \\
\hline 64 & 19-SMA & 4 & SMA (70-28) & 40 & SP19 & 100 & SP 25 & 140 & Granular A & 150 & Granular B1 & 450 & CL-ML & 30 \\
\hline
\end{tabular}


APPENDIX B: CLIMATE, TRAFFIC AND OTHER INPUTS USED IN AASHTOWARE PAVEMENT ME DESIGN

Table B-1 Climate input information used for this study

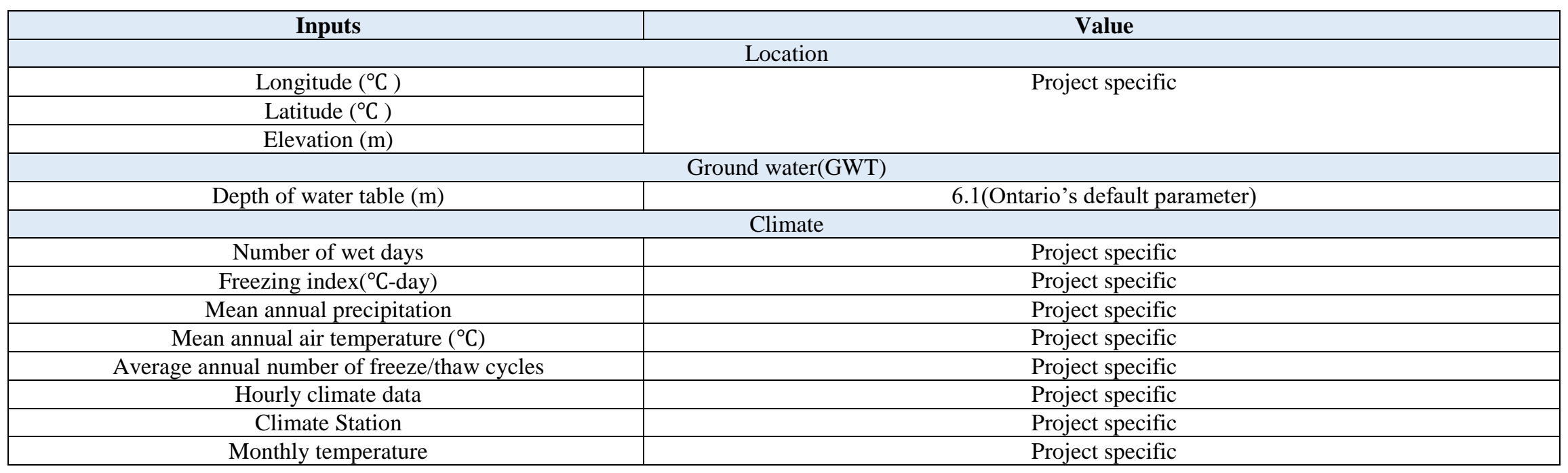


Table B-2 Traffic input values used for this study

\begin{tabular}{|c|c|}
\hline Inputs & Value \\
\hline Two-way AADTT & Project detail \\
\hline Number of Lanes & Project detail \\
\hline Percent of Truck in design direction & $50 \%$ \\
\hline Percent of Truck in design lane & Table 5-MTO default parameters for AASHTOWare ME design-2016 \\
\hline Operational Speed & Project detail \\
\hline Vehicle class distribution & Project detail \\
\hline Growth rate & Project detail \\
\hline Monthly adjustment & 1 \\
\hline Axle per truck & Project detail \\
\hline Average axle width & $2.6(\mathrm{~m})$ \\
\hline Dual tire spacing & $305(\mathrm{~mm})$ \\
\hline Tire pressure & $827.4(\mathrm{kPa})$ \\
\hline Tandem Axle Spacing & $1.5(\mathrm{~m})$ \\
\hline Tridem Axle Spacing & $1.7(\mathrm{~m})$ \\
\hline Quad Axle Spacing & $1.3(\mathrm{~m})$ \\
\hline Average Spacing for short axles & $3.658(\mathrm{~m})$ \\
\hline Average Spacing for medium axles & $4.572(\mathrm{~m})$ \\
\hline Average Spacing for long axles & $5.486(\mathrm{~m})$ \\
\hline Percent Truck with short/medium/long axles & $33 / 33 / 34$ \\
\hline Mean Wheel Location & $460(\mathrm{~mm})$ \\
\hline Traffic Wander Standard Deviation & $254(\mathrm{~mm})$ \\
\hline Design Lane Width & Project detail \\
\hline
\end{tabular}


Table B-3 Material input values for ac and unbound materials

\begin{tabular}{|c|c|c|c|}
\hline Input Group & & & Value \\
\hline \multirow[t]{14}{*}{ Asphalt layers } & \multicolumn{2}{|c|}{ Material type and thickness } & Project specific \\
\hline & \multirow[t]{4}{*}{ Mixture volumetric } & Air void (\%) & \multirow[t]{3}{*}{ Refer to table $\mathrm{C}-1$} \\
\hline & & Effective binder content (\%) & \\
\hline & & Unit weight $(\mathrm{Kg} / \mathrm{m} 3)$ & \\
\hline & & Poisson ratio & 0.35 (OGDL, 0.4) \\
\hline & \multirow[t]{6}{*}{ Mechanical properties } & Asphalt binder & Table B-1 \\
\hline & & Creep compliance $(1 / \mathrm{GPa})$ & \multirow[t]{3}{*}{ Level-3 software default values } \\
\hline & & Dynamic modulus & \\
\hline & & $\mathrm{G}^{*}$ predictive model & \\
\hline & & Reference temperature $\left({ }^{\circ} \mathrm{C}\right)$ & $21.1^{\circ} \mathrm{C}$ \\
\hline & & Indirect tensile strength at $-10^{\circ} \mathrm{C}(\mathrm{MPa})$ & Model calculated values \\
\hline & \multirow[t]{3}{*}{ Thermal properties } & Heat capacity $\left(\mathrm{J} /\left(\mathrm{Kg} \cdot{ }^{\circ} \mathrm{K}\right)\right)$ & 963 \\
\hline & & Thermal conductivity $\left(\mathrm{W} / \mathrm{m} \cdot{ }^{\circ} \mathrm{K}\right)$ & 1.16 \\
\hline & & Thermal contraction & Model calculated values \\
\hline \multirow[t]{5}{*}{ Unbound layers } & \multicolumn{2}{|c|}{ Material type and thickness } & Project specific \\
\hline & \multicolumn{2}{|c|}{ Coefficient of lateral earth pressure } & 0.5 \\
\hline & \multicolumn{2}{|c|}{ Poisson ratio } & 0.35 \\
\hline & \multirow{2}{*}{\multicolumn{2}{|c|}{ Resilient modulus (MPa) }} & Table C-2 \\
\hline & & & Table C-2 \\
\hline
\end{tabular}




\section{APPENDIX C: MTO DEFAULT PARAMETERS FOR AASHTOWARE PAVEMENT ME DESIGN}

This section will provide information on the latest updated default parameter introduced by MTO in 2016 to be used as default parameter for input level 3 in MEPDG software.

Table C-1 Typical Superpave and SMA materials and their properties (MTO 2016)

\begin{tabular}{|c|c|c|c|c|c|}
\hline \multicolumn{2}{|r|}{ Asphalt Layers } & SP 12.5 & SP 19.0 & SP 25.0 & SMA 12.5 \\
\hline \multicolumn{2}{|c|}{ Thickness (mm) } & \multicolumn{4}{|c|}{ Project specific } \\
\hline \multicolumn{2}{|c|}{ Mixture Volumetric } & & & & \\
\hline \multicolumn{2}{|c|}{ Unit Weight $\left(\mathrm{kg} / \mathrm{m}^{3}\right)$} & See Note 1 & 2460 & 2469 & See Note 1 \\
\hline \multicolumn{2}{|c|}{ Effective Binder Content - by Volume (\%) } & 11.8 & 11.2 & 10.4 & 14.6 \\
\hline \multicolumn{2}{|c|}{ Air Voids $(\%)^{\text {Note } 2}$} & \multicolumn{4}{|c|}{7.0} \\
\hline \multicolumn{2}{|c|}{ Poisson's Ratio Note 3} & \multicolumn{4}{|c|}{0.35 for existing HMA (select calculated for new HMA) } \\
\hline \multicolumn{2}{|c|}{ Mechanical Properties } & & & & \\
\hline \multicolumn{2}{|c|}{ Dynamic Modulus } & \multicolumn{4}{|c|}{ "Input level: 3" selected } \\
\hline \multirow{4}{*}{$\begin{array}{l}\text { Aggregate } \\
\text { Gradation }\end{array}$} & $\%$ Passing the $19 \mathrm{~mm}$ Sieve & $100 \%$ & $96.9 \%$ & $89.1 \%$ & $100.0 \%$ \\
\hline & $\%$ Passing the $9.5 \mathrm{~mm}$ Sieve & $83.2 \%$ & $72.5 \%$ & $63.3 \%$ & $73.1 \%$ \\
\hline & $\%$ Passing the $4.75 \mathrm{~mm}$ Sieve & $54 \%$ & $52.8 \%$ & $49.3 \%$ & $29.7 \%$ \\
\hline & $\%$ Passing the $75 \square \mathrm{m}$ Sieve & $4 \%$ & $3.9 \%$ & $3.8 \%$ & $9.3 \%$ \\
\hline \multicolumn{2}{|c|}{ G Star Predictive Model } & \multicolumn{4}{|c|}{ "Use viscosity based model (nationally calibrated)" selected } \\
\hline \multicolumn{2}{|c|}{ Reference Temperature } & \multicolumn{4}{|c|}{$21.1^{0} \mathrm{C}$} \\
\hline \multicolumn{2}{|c|}{ Asphalt Binder Note 4} & PG 64-28 & PG 58-28 & PG 58-28 & PG 70-28 \\
\hline \multicolumn{2}{|c|}{ Indirect Tensile Strength - 10 deg.C (MPa) } & \multicolumn{4}{|c|}{ Calculated } \\
\hline \multicolumn{2}{|c|}{ Creep Compliance $(1 / \mathrm{GPa})$} & \multicolumn{4}{|c|}{ "Input level: 3" selected } \\
\hline \multirow{2}{*}{\multicolumn{2}{|c|}{$\begin{array}{c}\text { Thermal } \\
\text { Thermal Conductivity (Watt/Meter-Kelvin) }\end{array}$}} & \\
\hline & & \multicolumn{4}{|c|}{1.16} \\
\hline \multicolumn{2}{|c|}{ Heat Capacity (joule/Kg-Kelvin) } & \multicolumn{4}{|c|}{963} \\
\hline \multicolumn{2}{|c|}{ Thermal Contraction } & \multicolumn{4}{|c|}{ Calculated } \\
\hline
\end{tabular}

Note 1: For SP 12.5, the unit weight is $2,460 \mathrm{~kg} / \mathrm{m}^{3}$. For SP 12.5FC1, FC2 and SMA 12.5, unit weight varies from different regions: Central and North regions $-2,520 \mathrm{~kg} / \mathrm{m}^{3}$; East region $-2,390 \mathrm{~kg} / \mathrm{m}^{3} ;$ West region $-2,530 \mathrm{~kg} / \mathrm{m}^{3}$

Note 2: For existing HMA layers, should use measured in-situ air voids.

Note 3: For new HMA mixtures, use calculated Poisson's ratio by expanding the row on 'Poisson's ratio' and set to 'true'. For the row on 'Is Poisson's Ratio calculated?' Refer to Mechanistic-Empirical Pavement Design Guide table 11-3 for other reference temperatures and open-graded HMA Poisson ratios.

Note 4: Typical PG shown only; PGAC varies based on locations and traffic loading conditions. Refer to MTO Superpave Guide to select the proper PGAC grade. 
Table C-2 Ontario typical granular material properties (MTO 2016)

\begin{tabular}{|c|c|c|c|c|c|c|}
\hline \multicolumn{2}{|c|}{ Unbound } & Granular A & $\begin{array}{c}\text { Granular B- } \\
\text { I }\end{array}$ & $\begin{array}{c}\text { Granular B- } \\
\text { II }\end{array}$ & $\begin{array}{c}\text { Granular B- } \\
\text { III }\end{array}$ & Granular O \\
\hline \multicolumn{2}{|l|}{ Layer Thickness (mm) } & \multicolumn{5}{|c|}{ Project specific } \\
\hline \multicolumn{2}{|l|}{ Poisson's Ratio } & \multicolumn{5}{|c|}{0.35} \\
\hline \multicolumn{2}{|l|}{ Coefficient of Lateral Pressure } & \multicolumn{5}{|c|}{0.5} \\
\hline \multicolumn{7}{|l|}{$\begin{array}{l}\text { Modulus } \\
\end{array}$} \\
\hline Resilient Modulus & & 250 & 150 & 200 & 150 & 200 \\
\hline \multicolumn{7}{|c|}{$\begin{array}{l}\text { Sieve } \\
\end{array}$} \\
\hline \multicolumn{7}{|c|}{ Gradation and other engineering properties } \\
\hline \multirow{8}{*}{$\begin{array}{l}\text { Aggregate Gradation (percent } \\
\text { passing) }\end{array}$} & $75 \mu \mathrm{m}$ & 5 & 4 & 5 & 4 & 2.5 \\
\hline & $300 \mathrm{~mm}$ & 13.5 & 33.5 & 13.5 & 18.5 & - \\
\hline & $1.18 \mathrm{~mm}$ & 27.5 & 55 & 25 & 35 & 7.5 \\
\hline & $4.75 \mathrm{~mm}$ & 45 & 60 & 37.5 & 55 & 32.5 \\
\hline & $9.5 \mathrm{~mm}$ & 61.5 & - & - & 66 & 60 \\
\hline & $13.2 \mathrm{~mm}$ & 77.5 & - & - & - & 70 \\
\hline & $19.0 \mathrm{~mm}$ & 92.5 & - & - & - & 87.5 \\
\hline & $25 \mathrm{~mm}$ & 100 & 75 & 75 & 75 & 97.5 \\
\hline \multicolumn{2}{|l|}{ Liquid Limit } & 6 & 11 & 11 & 11 & 6 \\
\hline \multicolumn{2}{|l|}{ Plasticity Index } & \multicolumn{5}{|c|}{0} \\
\hline \multicolumn{2}{|l|}{ Is layer compacted } & \multicolumn{5}{|c|}{ Yes } \\
\hline \multicolumn{2}{|l|}{ Maximum dry unit weight } & \multicolumn{5}{|c|}{ Calculated } \\
\hline \multicolumn{2}{|l|}{ Saturated hydraulic conductivity } & \multicolumn{5}{|c|}{ Calculated } \\
\hline \multicolumn{2}{|c|}{ Specific gravity of solids } & \multicolumn{5}{|c|}{ Calculated } \\
\hline \multicolumn{2}{|c|}{ Optimum gravimetric water content $(\mathrm{T})$} & \multicolumn{5}{|c|}{ Calculated } \\
\hline
\end{tabular}


Table C-3 Ontario typical subgrade properties (MTO 2016)

\begin{tabular}{|c|c|c|c|c|c|c|c|c|c|c|}
\hline & & \multicolumn{9}{|c|}{ Subgrade Type } \\
\hline & & $\mathbf{C L}$ & $\mathbf{C I}$ & $\mathbf{C H}$ & CL-ML & ML & MI & MH & $\mathbf{S M}$ & SC \\
\hline \multicolumn{11}{|c|}{ Unbound } \\
\hline \multicolumn{2}{|c|}{ Layer Thickness (mm) } & \multicolumn{9}{|c|}{ Semi-infinite } \\
\hline \multicolumn{2}{|c|}{ Poisson's Ratio } & \multicolumn{3}{|c|}{$\begin{array}{c}0.45 \text { (saturated) } \\
0.2 \text { (unsaturated) }\end{array}$} & \multicolumn{4}{|c|}{0.325} & \multicolumn{2}{|c|}{$\begin{array}{c}0.3 \text { (dense) } \\
0.15 \text { (coarse-grained } \\
0.25 \text { (fine-grained) }\end{array}$} \\
\hline \multicolumn{2}{|c|}{ Coefficient of Lateral Pressure $\left(\mathrm{k}_{0}\right)$} & \multicolumn{3}{|c|}{$\begin{array}{c}0.65 \text { (very stiff and hard } \\
\text { residual) } \\
0.72 \text { (medium stiff) }\end{array}$} & \multicolumn{4}{|c|}{0.73} & \multicolumn{2}{|c|}{0.68} \\
\hline \multicolumn{11}{|c|}{ Modulus } \\
\hline \multicolumn{2}{|c|}{ Resilient Modulus (MPa) } & \multicolumn{9}{|c|}{ Within current study based on project specific } \\
\hline \multicolumn{11}{|c|}{ Gradation and other engineering properties } \\
\hline \multirow{10}{*}{$\begin{array}{l}\text { Aggregate Gradation (percent } \\
\text { passing) }\end{array}$} & $0.002 \mathrm{~mm}$ & 30 & 37 & 60 & 16 & 11 & 25 & 40 & 8 & 13 \\
\hline & $0.075 \mathrm{~mm}$ & 80 & 88 & 92 & 84 & 74 & 82 & 84 & 29 & 32 \\
\hline & $0.180 \mathrm{~mm}$ & 84 & 92 & 94 & 89 & 86 & 91 & 91 & 58 & 48 \\
\hline & $0.425 \mathrm{~mm}$ & 91 & 95 & 96 & 92 & 91 & 95 & 96 & 72 & 56 \\
\hline & $2.00 \mathrm{~mm}$ & 95 & 98 & 98 & 96 & 95 & 98 & 99 & 84 & 86 \\
\hline & $4.75 \mathrm{~mm}$ & 97 & 99 & 99 & 98 & 96 & 100 & 100 & 90 & 93 \\
\hline & $9.5 \mathrm{~mm}$ & 99 & 100 & 100 & 99 & 100 & 100 & 100 & 94 & 100 \\
\hline & $12.5 \mathrm{~mm}$ & 100 & 100 & 100 & 100 & 100 & 100 & 100 & 97 & 100 \\
\hline & $19.0 \mathrm{~mm}$ & 100 & 100 & 100 & 100 & 100 & 100 & 100 & 98 & 100 \\
\hline & $25.0 \mathrm{~mm}$ & 100 & 100 & 100 & 100 & 100 & 100 & 100 & 100 & 100 \\
\hline \multicolumn{2}{|c|}{ Liquid Limit } & 26 & 41 & 67 & 22 & 26 & 42 & 53 & 18 & 22 \\
\hline \multicolumn{2}{|c|}{ Plasticity Index } & 12 & 21 & 43 & 6 & 3 & 15 & 21 & 4 & 10 \\
\hline \multicolumn{2}{|c|}{ Is layer compacted } & \multicolumn{9}{|c|}{ Yes } \\
\hline \multicolumn{2}{|c|}{ Maximum dry unit weight $\left(\mathrm{kg} / \mathrm{m}^{3}\right)$} & \multicolumn{9}{|c|}{ Calculated } \\
\hline \multicolumn{2}{|c|}{ Saturated hydraulic conductivity $(\mathrm{m} / \mathrm{hr})$} & \multicolumn{9}{|c|}{ Calculated } \\
\hline \multicolumn{2}{|c|}{ Specific gravity of solids } & \multicolumn{9}{|c|}{ Calculated } \\
\hline \multicolumn{2}{|c|}{ Optimum gravimetric water content $(\mathrm{T})$} & \multicolumn{9}{|c|}{ Calculated } \\
\hline
\end{tabular}


Table C-4 Ontario typical Marshal Mix properties (MTO 2016)

\begin{tabular}{|c|c|c|c|c|c|c|c|c|c|c|}
\hline \multicolumn{2}{|c|}{ Asphalt Layers } & DFC & HDBC & MDBC & HL-1 & HL-2 & HL-3 & HL-4 & HL-6 & HL-8 \\
\hline \multicolumn{2}{|c|}{ Thickness (mm) } & \multicolumn{9}{|c|}{ Project specific } \\
\hline \multicolumn{11}{|c|}{ Mixture Volumetric } \\
\hline \multicolumn{2}{|c|}{ Unit Weight $(\mathrm{kg} / \mathrm{m} 3)$} & 2520 & 2460 & 2500 & 2520 & 2410 & 2520 & 2480 & 2460 & 2460 \\
\hline \multicolumn{2}{|c|}{ Effective Binder Content - by Volume (\%) } & 12.4 & 10.9 & 12.3 & 12.4 & 14.2 & 12.4 & 12.2 & 10.9 & 10.9 \\
\hline \multicolumn{2}{|c|}{ Air Voids (\%) Note 1} & 3.5 & 4 & 4 & 4 & 5 & 4 & 4 & 4 & 4 \\
\hline \multicolumn{2}{|c|}{ Poisson's Ratio } & \multicolumn{9}{|c|}{0.35} \\
\hline \multicolumn{11}{|c|}{ Mechanical Properties } \\
\hline \multicolumn{2}{|c|}{ Dynamic Modulus } & \multicolumn{9}{|c|}{ Calculated } \\
\hline \multirow[t]{4}{*}{ Aggregate Gradation } & $\%$ Passing the $19 \mathrm{~mm}$ Sieve & 100 & 97 & 97 & 100 & 100 & 100 & 100 & 97 & 97 \\
\hline & $\%$ Passing the $9.5 \mathrm{~mm}$ Sieve & 82.5 & 63 & 63 & 82.5 & 100 & 82.5 & 72 & 72 & 63 \\
\hline & $\%$ Passing the $4.75 \mathrm{~mm}$ Sieve & 52.5 & 43.5 & 40 & 55 & 92.5 & 55 & 53.5 & 53.5 & 42.5 \\
\hline & $\%$ Passing the $75 \square \mathrm{m}$ Sieve & 2.5 & 3 & 3 & 2.5 & 5.5 & 2.5 & 3 & 3 & 3 \\
\hline \multicolumn{2}{|c|}{ G Star Predictive Model } & \multicolumn{9}{|c|}{ "Use viscosity based model (nationally calibrated)" selected } \\
\hline \multicolumn{2}{|c|}{ Reference Temperature } & \multicolumn{9}{|c|}{$21.1^{\circ} \mathrm{C}$} \\
\hline \multicolumn{2}{|c|}{ Asphalt Binder } & \multicolumn{9}{|c|}{ Penetration Grade Note 2} \\
\hline \multicolumn{2}{|c|}{ Indirect Tensile Strength -10 deg.C $(\mathrm{MPa})$} & \multicolumn{9}{|c|}{ Calculated } \\
\hline \multicolumn{2}{|c|}{ Creep Compliance (1/GPa) } & \multicolumn{9}{|c|}{ "Input level: 3" selected } \\
\hline \multicolumn{11}{|c|}{ Thermal } \\
\hline \multicolumn{2}{|c|}{ Thermal Conductivity (watt/meter-Kelvin) } & \multicolumn{9}{|c|}{1.16} \\
\hline \multicolumn{2}{|c|}{ Heat Capacity (joule/kg-Kelvin) } & \multicolumn{9}{|c|}{963} \\
\hline \multicolumn{2}{|c|}{ Thermal Contraction } & \multicolumn{9}{|c|}{ Calculated } \\
\hline
\end{tabular}


Table C-5 Ontario climate stations detailed information (MTO 2016)

\begin{tabular}{|c|c|c|c|c|c|c|c|}
\hline \multirow[b]{2}{*}{ Station } & \multirow[b]{2}{*}{ Station Name } & \multirow[b]{2}{*}{ Location } & \multirow[b]{2}{*}{ Latitude } & \multirow[b]{2}{*}{ Longitude } & \multirow{2}{*}{$\begin{array}{l}\text { Elevation } \\
\quad(\mathbf{m})\end{array}$} & \multicolumn{2}{|c|}{ Period (yyyymmdd) } \\
\hline & & & & & & From & To \\
\hline 15801 & ARMSTRONG| ON & ARMSTRONG AIRPORT & 50.294 & -88.905 & 322 & 19530101 & 19680630 \\
\hline 94932 & ATIKOKAN|ON & ATIKOKAN & 48.750 & -91.617 & 395 & 19661001 & 19860930 \\
\hline 15806 & BIG TROUT LAKE| ON & BIG TROUT LAKE & 53.833 & -89.867 & 224 & 19700101 & 19891231 \\
\hline 94862 & CHAPLEAU| ON & CHAPLEAU & 47.833 & -83.433 & 428 & 19651101 & 19760331 \\
\hline 94797 & EARLTON|ON & EARLTON AIRPORT & 47.700 & -79.850 & 243 & 19591001 & 19790930 \\
\hline 94864 & GERALDTON|ON & GERALDTON & 49.700 & -86.950 & 331 & 19671101 & 19770331 \\
\hline 94888 & GERALDTON| ON & GERALDTON AIRPORT & 49.783 & -86.931 & 349 & 20000101 & 20070630 \\
\hline 94803 & GORE BAY|ON & GORE BAY AIRPORT & 45.883 & -82.567 & 194 & 19711001 & 19910930 \\
\hline 14998 & GRAHAM| ON & GRAHAM AIRPORT & 49.267 & -90.583 & 503 & 19530101 & 19661231 \\
\hline 04797 & HAMILTON| ON & HAMILTON AIRPORT & 43.172 & -79.934 & 238 & 20070101 & 20111231 \\
\hline 14899 & KAPUSKASING| ON & KAPUSKASING AIRPORT & 49.414 & -82.468 & 226 & 19870701 & 20121231 \\
\hline 14999 & KENORA| ON & KENORA AIRPORT & 49.790 & -94.365 & 410 & 19870701 & 20121231 \\
\hline 94799 & KILLALOE| ON & KILLALOE & 45.567 & -77.417 & 174 & 19530101 & 19720731 \\
\hline 94805 & LONDON|ON & LONDON AIRPORT & 43.033 & -81.151 & 278 & 19740201 & 19940131 \\
\hline 94857 & MOUNT FOREST| ON & MOUNT FOREST & 43.983 & -80.750 & 415 & 19620101 & 19760731 \\
\hline 15804 & NAKINA| ON & NAKINA AIRPORT & 50.183 & -86.700 & 325 & 19530101 & 19671031 \\
\hline 04705 & NORTH BAY $\mid$ ON & NORTH BAY AIRPORT & 46.364 & -79.423 & 370 & 19740201 & 19940131 \\
\hline 04772 & OTTAWA| ON & $\begin{array}{c}\text { MACDONALD-CARTIER } \\
\text { INTERNATIONAL AIRPORT }\end{array}$ & 45.323 & -75.669 & 114 & 19870701 & 20111231 \\
\hline 04706 & OTTAWA|ON & OTTAWA ROCKCLIFFE AIRPORT & 45.450 & -75.633 & 54 & 19530101 & 19640331 \\
\hline 54706 & PETAWAWA| ON & PETAWAWA AIRPORT & 45.950 & -77.317 & 130 & 19730701 & 19930630 \\
\hline 94842 & SAULT STE MARIE| ON & SAULT STE MARIE AIRPORT & 46.483 & -84.509 & 192 & 19870701 & 20070630 \\
\hline 94858 & SIMCOE $\mid \mathrm{ON}$ & SIMCOE & 42.850 & -80.267 & 240 & 19620101 & 19770731 \\
\hline 15909 & SIOUX LOOKOUT|ON & SIOUX LOOKOUT AIRPORT & 50.117 & -91.900 & 383 & 19870701 & 20121231 \\
\hline 04713 & STIRLING|ON & STIRLING & 44.317 & -77.633 & 139 & 19530101 & 19681130 \\
\hline 94828 & SUDBURY|ON & SUDBURY AIRPORT & 46.625 & -80.799 & 347 & 19870701 & 20070630 \\
\hline 94804 & THUNDER BAY|ON & THUNDER BAY AIRPORT & 48.369 & -89.327 & 199 & 19740101 & 19931231 \\
\hline 94831 & TIMMINS|ON & VICTOR POWER AIRPORT & 48.570 & -81.377 & 295 & 19740701 & 19940630 \\
\hline 54753 & TORONTO|ON & BUTTONVILLE AIRPORT & 43.862 & -79.370 & 198 & 19870701 & 20121231 \\
\hline 94791 & TORONTO|ON & $\begin{array}{c}\text { LESTER B. PEARSON } \\
\text { INTERNATIONAL AIRPORT }\end{array}$ & 43.677 & -79.631 & 173 & 19870701 & 20070630 \\
\hline 04715 & TRENTON| ON & TRENTON AIRPORT & 44.117 & -77.533 & 86 & 19740601 & 19940531 \\
\hline
\end{tabular}




\begin{tabular}{|c|c|c|c|c|c|c|c|}
\hline \multirow[b]{2}{*}{ Station } & \multirow[b]{2}{*}{ Station Name } & \multirow[b]{2}{*}{ Location } & \multirow[b]{2}{*}{ Latitude } & \multirow[b]{2}{*}{ Longitude } & \multirow{2}{*}{$\begin{array}{c}\text { Elevation } \\
\text { (m) }\end{array}$} & \multicolumn{2}{|c|}{ Period (yyyymmdd) } \\
\hline & & & & & & From & To \\
\hline 94808 & WHITE RIVER/ ON & WHITE RIVER & 48.600 & -85.283 & 379 & 19560101 & 19751231 \\
\hline 94809 & WIARTON|ON & WIARTON AIRPORT & 44.746 & -81.107 & 222 & 19750701 & 19950630 \\
\hline 94810 & WINDSOR $\mid$ ON & WINDSOR AIRPORT & 42.276 & -82.956 & 190 & 19750701 & 19950630 \\
\hline 15807 & WINISK| ON & WINISK AIRPORT & 55.233 & -85.117 & 13 & 19590201 & 19650630 \\
\hline
\end{tabular}


Table C-6. Percentage of trucks within design lane - recommended values for Ontario (MTO 2016)

\begin{tabular}{|c|c|c|}
\hline Number of Lanes in One Direction & AADT (both directions) & Percentage of Trucks in Design Lane (\%) \\
\hline 1 & All & 900 \\
\hline 2 & $<15,000$ & 80 \\
\hline 3 & $>15,000$ & 80 \\
& $<25,000$ & 70 \\
\hline 4 & $>45,000$ to 40,000 & 70 \\
\hline 5 & $<40,000$ & 60 \\
\hline
\end{tabular}


Table C-7. Southern Ontario - typical axle per truck values (MTO 2016)

\begin{tabular}{|c|c|c|c|c|}
\hline FHWA Class & Singles & Tandems & Tridems & Quads \\
\hline 4 & 1.620 & 0.390 & 0.000 & 0.000 \\
\hline 5 & 2.000 & 0.000 & 0.000 & 0.000 \\
\hline 6 & 1.010 & 0.993 & 0.000 & 0.000 \\
\hline 7 & 1.314 & 0.989 & 0.030 & 0.000 \\
\hline 8 & 2.163 & 0.845 & 0.003 & 0.000 \\
\hline 9 & 1.055 & 1.968 & 0.700 & 0.000 \\
\hline 10 & 1.446 & 1.234 & 0.000 & 0.088 \\
\hline 11 & 4.546 & 0.168 & 0.000 & 0.000 \\
\hline 13 & 2.857 & 1.526 & 0.848 & \\
\hline
\end{tabular}


Table C-8 Northern Ontario - typical axle-per-truck values (MTO 2016)

\begin{tabular}{|c|c|c|c|c|c|}
\hline FHWA Class & Singles & Tandems & Tridems & Quads & Total \\
\hline 4 & 1.620 & 0.390 & 0.000 & 0.000 & 2.400 \\
\hline 5 & 2.000 & 0.000 & 0.000 & 0.000 & 2.000 \\
\hline 6 & 1.014 & 0.993 & 0.000 & 0.000 & 3.000 \\
\hline 7 & 1.244 & 0.962 & 0.043 & 0.000 & 3.297 \\
\hline 8 & 2.414 & 0.674 & 0.000 & 0.000 & 3.762 \\
\hline 9 & 1.048 & 1.955 & 0.014 & 0.000 & 5.000 \\
\hline 10 & 1.358 & 1.165 & 0.840 & 0.044 & 6.384 \\
\hline 11 & 3.849 & 0.538 & 0.000 & 0.000 & 4.925 \\
\hline 12 & 2.910 & 1.514 & 0.021 & 0.000 & 6.001 \\
\hline 13 & 1.100 & 2.012 & 0.945 & 0.011 & 8.003 \\
\hline
\end{tabular}


Table C-9 Southern Ontario - single-axle load distribution (MTO 2016)

\begin{tabular}{|c|c|c|c|c|c|c|c|c|c|c|}
\hline \multirow{2}{*}{ Axle Weight Range, kg } & \multicolumn{10}{|c|}{ Frequency of a given axle weight range as a percentage } \\
\hline & 4 & 5 & 6 & 7 & 8 & 9 & 10 & 11 & 12 & 13 \\
\hline 0 to 1249 & 1.80 & 0.07 & 0.19 & 0.28 & 0.42 & 0.04 & 0.39 & 0.10 & 0.02 & 0.44 \\
\hline 1250 to 1749 & 0.96 & 0.33 & 0.14 & 0.08 & 0.42 & 0.10 & 0.17 & 0.09 & 1.10 & 0.63 \\
\hline 1750 to 2249 & 2.91 & 5.40 & 0.89 & 0.45 & 2.13 & 0.62 & 0.44 & 0.57 & 0.02 & 0.85 \\
\hline 2250 to 2749 & 3.99 & 7.52 & 0.73 & 0.70 & 2.43 & 0.43 & 0.89 & 1.69 & 3.22 & 1.21 \\
\hline 2750 to 3249 & 6.80 & 6.65 & 0.95 & 0.87 & 3.55 & 0.44 & 0.93 & 6.75 & 8.16 & 1.14 \\
\hline 3250 to 3749 & 12.00 & 11.32 & 2.12 & 0.96 & 7.82 & 0.62 & 1.44 & 5.58 & 8.73 & 1.02 \\
\hline 3750 to 4249 & 11.70 & 13.98 & 4.73 & 1.51 & 7.20 & 1.22 & 1.48 & 4.29 & 8.70 & 0.99 \\
\hline 4250 to 4749 & 11.40 & 13.94 & 13.96 & 3.14 & 19.16 & 10.40 & 4.39 & 11.03 & 14.49 & 4.93 \\
\hline 4750 to 5249 & 10.30 & 10.71 & 18.40 & 5.10 & 13.03 & 22.56 & 12.86 & 14.92 & 15.75 & 12.59 \\
\hline 5250 to 5749 & 9.00 & 10.46 & 24.84 & 8.07 & 11.20 & 40.89 & 28.90 & 11.09 & 15.01 & 33.61 \\
\hline 5750 to 6249 & 7.40 & 5.04 & 10.66 & 3.70 & 3.96 & 14.54 & 15.17 & 7.09 & 6.42 & 17.86 \\
\hline 6250 to 6749 & 5.70 & 4.36 & 8.60 & 9.64 & 6.09 & 3.05 & 6.91 & 10.44 & 5.54 & 8.99 \\
\hline 6750 to 7249 & 4.30 & 2.28 & 4.54 & 11.08 & 5.70 & 1.04 & 3.37 & 7.90 & 4.18 & 3.33 \\
\hline 7250 to 7749 & 3.20 & 1.95 & 3.67 & 13.64 & 3.76 & 0.92 & 3.46 & 6.14 & 2.13 & 2.35 \\
\hline 7750 to 8249 & 2.58 & 1.65 & 1.45 & 11.34 & 2.12 & 0.90 & 3.14 & 3.66 & 1.42 & 1.29 \\
\hline 8250 to 8749 & 1.80 & 1.25 & 1.54 & 6.99 & 3.03 & 0.83 & 3.46 & 2.95 & 1.03 & 1.58 \\
\hline 8750 to 9249 & 1.40 & 0.80 & 1.37 & 5.97 & 1.45 & 0.49 & 2.87 & 1.75 & 0.32 & 1.08 \\
\hline 9250 to 9749 & 1.00 & 0.73 & 0.42 & 3.87 & 1.57 & 0.28 & 3.12 & 0.87 & 0.83 & 2.32 \\
\hline 9750 to 10249 & 0.75 & 0.50 & 0.36 & 5.90 & 1.41 & 0.16 & 1.96 & 0.66 & 0.00 & 0.72 \\
\hline 10250 to 10749 & 0.50 & 0.51 & 0.23 & 2.27 & 0.95 & 0.13 & 1.55 & 0.38 & 0.10 & 0.98 \\
\hline 10750 to 11249 & 0.25 & 0.27 & 0.04 & 1.73 & 0.59 & 0.11 & 1.15 & 0.14 & 0.08 & 0.49 \\
\hline 11250 to 11749 & 0.15 & 0.08 & 0.04 & 0.23 & 0.26 & 0.06 & 0.38 & 0.43 & 0.11 & 0.21 \\
\hline 11750 to 12249 & 0.10 & 0.06 & 0.02 & 0.25 & 0.18 & 0.03 & 0.35 & 0.19 & 0.19 & 0.18 \\
\hline 12250 to 12749 & 0.00 & 0.07 & 0.04 & 0.47 & 0.31 & 0.03 & 0.23 & 0.00 & 0.71 & 0.08 \\
\hline 12750 to 13249 & 0.00 & 0.02 & 0.00 & 0.04 & 0.12 & 0.01 & 0.11 & 0.75 & 1.27 & 0.17 \\
\hline 13250 to 13749 & 0.00 & 0.01 & 0.00 & 0.18 & 0.11 & 0.01 & 0.10 & 0.00 & 0.00 & 0.06 \\
\hline 13750 to 14249 & 0.00 & 0.01 & 0.00 & 0.11 & 0.06 & 0.01 & 0.13 & 0.18 & 0.24 & 0.18 \\
\hline 14250 to 14749 & 0.00 & 0.01 & 0.00 & 0.00 & 0.32 & 0.00 & 0.10 & 0.07 & 0.00 & 0.00 \\
\hline 14750 to 15249 & 0.00 & 0.01 & 0.05 & 0.06 & 0.11 & 0.01 & 0.05 & 0.18 & 0.00 & 0.09 \\
\hline 15250 to 15749 & 0.00 & 0.01 & 0.00 & 0.22 & 0.12 & 0.01 & 0.13 & 0.00 & 0.00 & 0.24 \\
\hline 15750 to 16249 & 0.00 & 0.00 & 0.00 & 0.13 & 0.05 & 0.01 & 0.10 & 0.04 & 0.00 & 0.10 \\
\hline 16250 to 16749 & 0.00 & 0.00 & 0.00 & 0.02 & 0.14 & 0.01 & 0.04 & 0.03 & 0.00 & 0.00 \\
\hline 16750 to 17249 & 0.00 & 0.00 & 0.00 & 0.23 & 0.13 & 0.01 & 0.07 & 0.00 & 0.00 & 0.10 \\
\hline
\end{tabular}




\begin{tabular}{|c|r|r|r|r|r|r|r|r|r|r|}
\hline 17250 to 17749 & 0.00 & 0.00 & 0.00 & 0.09 & 0.08 & 0.02 & 0.04 & 0.04 & 0.00 & 0.00 \\
\hline 17750 to 18249 & 0.00 & 0.00 & 0.00 & 0.00 & 0.00 & 0.00 & 0.01 & 0.00 & 0.00 & 0.12 \\
\hline 18250 to 18749 & 0.00 & 0.00 & 0.00 & 0.37 & 0.02 & 0.00 & 0.03 & 0.00 & 0.00 & 0.01 \\
\hline 18750 to 19249 & 0.00 & 0.00 & 0.02 & 0.06 & 0.00 & 0.00 & 0.01 & 0.00 & 0.00 & 0.04 \\
\hline 19250 to 19749 & 0.01 & 0.00 & 0.00 & 0.16 & 0.00 & 0.01 & 0.04 & 0.00 & 0.23 & 0.00 \\
\hline 19750 to 22749 & 0.00 & 0.00 & 0.00 & 0.09 & 0.00 & 0.00 & 0.03 & 0.00 & 0.00 & 0.02 \\
\hline Total & 100 & 100 & 100 & 100 & 100 & 100 & 100 & 100 & 100 & 100 \\
\hline
\end{tabular}


Table C-10 Southern Ontario - tandem-axle load distribution (MTO 2016)

\begin{tabular}{|c|c|c|c|c|c|c|c|c|c|c|}
\hline \multirow[t]{2}{*}{ Axle Weight Range, kg } & \multicolumn{10}{|c|}{ Frequency of a given axle weight range as a percentage } \\
\hline & 4 & 5 & 6 & 7 & 8 & 9 & 10 & 11 & 12 & 13 \\
\hline 0 to 2449 & 5.28 & 0.00 & 1.47 & 0.73 & 4.02 & 0.24 & 0.35 & 0.00 & 0.24 & 0.54 \\
\hline 2500 to 3449 & 10.00 & 0.00 & 4.13 & 0.75 & 3.89 & 0.52 & 0.87 & 7.65 & 1.17 & 3.19 \\
\hline 3500 to 4449 & 11.90 & 0.00 & 23.50 & 1.24 & 3.99 & 2.43 & 1.46 & 10.35 & 2.59 & 6.79 \\
\hline 4500 to 5449 & 9.63 & 0.00 & 5.98 & 2.44 & 16.68 & 7.60 & 2.61 & 11.54 & 9.53 & 5.34 \\
\hline 5500 to 6449 & 8.00 & 0.00 & 7.90 & 4.83 & 16.58 & 8.85 & 6.73 & 6.55 & 10.47 & 7.17 \\
\hline 6500 to 7449 & 7.80 & 0.00 & 8.95 & 13.24 & 16.90 & 7.84 & 9.25 & 5.05 & 9.39 & 4.82 \\
\hline 7500 to 8449 & 6.80 & 0.00 & 8.92 & 12.21 & 10.77 & 7.95 & 7.71 & 9.90 & 13.51 & 3.36 \\
\hline 8500 to 9449 & 6.15 & 0.00 & 8.53 & 9.02 & 10.58 & 8.24 & 5.65 & 9.52 & 11.91 & 2.92 \\
\hline 9500 to 10449 & 5.80 & 0.00 & 5.77 & 4.01 & 6.35 & 7.45 & 4.62 & 13.19 & 13.83 & 2.51 \\
\hline 10500 to 11449 & 5.30 & 0.00 & 5.74 & 7.10 & 3.29 & 6.63 & 3.67 & 8.52 & 6.91 & 2.11 \\
\hline 11500 to 12449 & 4.70 & 0.00 & 4.03 & 6.90 & 1.63 & 5.87 & 3.41 & 0.00 & 4.29 & 2.30 \\
\hline 12500 to 13449 & 4.10 & 0.00 & 2.99 & 3.49 & 1.48 & 5.60 & 3.99 & 4.20 & 6.09 & 3.06 \\
\hline 13500 to 14449 & 3.33 & 0.00 & 2.95 & 2.48 & 1.17 & 5.79 & 5.04 & 4.57 & 2.19 & 2.97 \\
\hline 14500 to 15449 & 3.91 & 0.00 & 1.76 & 2.11 & 0.60 & 7.31 & 5.70 & 1.76 & 1.72 & 4.46 \\
\hline 15500 to 16449 & 2.22 & 0.00 & 1.65 & 3.53 & 0.66 & 8.91 & 7.03 & 1.58 & 1.33 & 6.63 \\
\hline 16500 to 17449 & 1.84 & 0.00 & 1.98 & 1.82 & 0.89 & 5.61 & 8.50 & 3.49 & 1.02 & 10.12 \\
\hline 17500 to 18449 & 1.44 & 0.00 & 0.54 & 2.12 & 0.35 & 1.71 & 7.60 & 0.00 & 0.38 & 10.96 \\
\hline 18500 to 19449 & 0.90 & 0.00 & 0.77 & 5.29 & 0.10 & 0.77 & 6.04 & 0.00 & 1.33 & 9.82 \\
\hline 19500 to 20449 & 0.50 & 0.00 & 0.51 & 4.89 & 0.00 & 0.31 & 4.56 & 1.44 & 1.63 & 5.24 \\
\hline 20500 to 21449 & 0.30 & 0.00 & 0.52 & 3.64 & 0.07 & 0.15 & 2.11 & 0.00 & 0.43 & 1.87 \\
\hline 21500 to 22449 & 0.10 & 0.00 & 0.52 & 3.53 & 0.00 & 0.09 & 1.12 & 0.69 & 0.00 & 1.35 \\
\hline 22500 to 23449 & 0.00 & 0.00 & 0.42 & 1.47 & 0.00 & 0.05 & 0.73 & 0.00 & 0.00 & 0.61 \\
\hline 23500 to 24449 & 0.00 & 0.00 & 0.27 & 1.44 & 0.00 & 0.04 & 0.30 & 0.00 & 0.00 & 0.43 \\
\hline 24500 to 25449 & 0.00 & 0.00 & 0.09 & 0.34 & 0.00 & 0.01 & 0.21 & 0.00 & 0.00 & 0.41 \\
\hline 25500 to 26449 & 0.00 & 0.00 & 0.01 & 0.12 & 0.00 & 0.01 & 0.11 & 0.00 & 0.00 & 0.43 \\
\hline 26500 to 27449 & 0.00 & 0.00 & 0.00 & 0.37 & 0.00 & 0.01 & 0.20 & 0.00 & 0.00 & 0.29 \\
\hline 27500 to 28449 & 0.00 & 0.00 & 0.03 & 0.27 & 0.00 & 0.01 & 0.14 & 0.00 & 0.00 & 0.04 \\
\hline 28500 to 29449 & 0.00 & 0.00 & 0.00 & 0.08 & 0.00 & 0.00 & 0.09 & 0.00 & 0.04 & 0.02 \\
\hline 29500 to 30449 & 0.00 & 0.00 & 0.00 & 0.31 & 0.00 & 0.00 & 0.03 & 0.00 & 0.00 & 0.05 \\
\hline 30500 to 31449 & 0.00 & 0.00 & 0.03 & 0.00 & 0.00 & 0.00 & 0.09 & 0.00 & 0.00 & 0.00 \\
\hline 31500 to 32449 & 0.00 & 0.00 & 0.00 & 0.16 & 0.00 & 0.00 & 0.01 & 0.00 & 0.00 & 0.00 \\
\hline 32500 to 33449 & 0.00 & 0.00 & 0.04 & 0.00 & 0.00 & 0.00 & 0.01 & 0.00 & 0.00 & 0.01 \\
\hline 33500 to 34449 & 0.00 & 0.00 & 0.00 & 0.00 & 0.00 & 0.00 & 0.02 & 0.00 & 0.00 & 0.01 \\
\hline
\end{tabular}




\begin{tabular}{|c|c|c|c|c|c|c|c|c|c|c|}
\hline 34500 to 35449 & 0.00 & 0.00 & 0.00 & 0.00 & 0.00 & 0.00 & 0.02 & 0.00 & 0.00 & 0.00 \\
\hline 35500 to 36449 & 0.00 & 0.00 & 0.00 & 0.00 & 0.00 & 0.00 & 0.01 & 0.00 & 0.00 & 0.03 \\
\hline 36500 to 37449 & 0.00 & 0.00 & 0.00 & 0.00 & 0.00 & 0.00 & 0.00 & 0.00 & 0.00 & 0.00 \\
\hline 37500 to 38449 & 0.00 & 0.00 & 0.00 & 0.03 & 0.00 & 0.00 & 0.00 & 0.00 & 0.00 & 0.01 \\
\hline 38500 to 39449 & 0.00 & 0.00 & 0.00 & 0.00 & 0.00 & 0.00 & 0.00 & 0.00 & 0.00 & 0.03 \\
\hline 39500 to 40449 & 0.00 & 0.00 & 0.00 & 0.04 & 0.00 & 0.00 & 0.01 & 0.00 & 0.00 & 0.10 \\
\hline Total & 100 & 100 & 100 & 100 & 100 & 100 & 100 & 100 & 100 & 100 \\
\hline
\end{tabular}


Table C-11 Southern Ontario - tridem-axle load distribution (MTO 2016)

\begin{tabular}{|c|c|c|c|c|c|c|c|c|c|c|}
\hline \multirow[b]{2}{*}{ Axle Weight Range, kg } & \multicolumn{10}{|c|}{ Frequency of a given axle weight range as a percentage } \\
\hline & 4 & 5 & 6 & 7 & 8 & 9 & 10 & 11 & 12 & 13 \\
\hline 0 to 5249 & 0.00 & 0.00 & 0.00 & 4.26 & 0.00 & 39.94 & 4.98 & 0.00 & 0.00 & 6.50 \\
\hline 5250 to 6749 & 0.00 & 0.00 & 0.00 & 9.29 & 0.00 & 7.55 & 9.65 & 0.00 & 0.00 & 11.02 \\
\hline 6750 to 8249 & 0.00 & 0.00 & 0.00 & 10.96 & 0.00 & 19.96 & 9.53 & 0.00 & 0.00 & 6.55 \\
\hline 8250 to 9749 & 0.00 & 0.00 & 0.00 & 0.30 & 0.00 & 5.90 & 7.21 & 0.00 & 0.00 & 3.69 \\
\hline 9750 to 11249 & 0.00 & 0.00 & 0.00 & 14.23 & 0.00 & 0.67 & 5.21 & 0.00 & 0.00 & 2.44 \\
\hline 11250 to 12749 & 0.00 & 0.00 & 0.00 & 1.97 & 0.00 & 5.34 & 5.07 & 0.00 & 0.00 & 2.29 \\
\hline 12750 to 14249 & 0.00 & 0.00 & 0.00 & 4.54 & 0.00 & 2.18 & 4.39 & 0.00 & 0.00 & 2.18 \\
\hline 14250 to 15749 & 0.00 & 0.00 & 0.00 & 2.12 & 0.00 & 8.20 & 4.32 & 0.00 & 0.00 & 4.16 \\
\hline 15750 to 17249 & 0.00 & 0.00 & 0.00 & 12.24 & 0.00 & 3.58 & 4.56 & 0.00 & 0.00 & 4.46 \\
\hline 17250 to 18749 & 0.00 & 0.00 & 0.00 & 0.64 & 0.00 & 1.74 & 4.82 & 0.00 & 0.00 & 4.54 \\
\hline 18750 to 20249 & 0.00 & 0.00 & 0.00 & 0.00 & 0.00 & 3.42 & 5.87 & 0.00 & 0.00 & 3.90 \\
\hline 20250 to 21749 & 0.00 & 0.00 & 0.00 & 0.50 & 0.00 & 1.23 & 5.44 & 0.00 & 0.00 & 7.33 \\
\hline 21750 to 23249 & 0.00 & 0.00 & 0.00 & 0.00 & 0.00 & 0.00 & 6.96 & 0.00 & 0.00 & 11.94 \\
\hline 23250 to 24749 & 0.00 & 0.00 & 0.00 & 9.88 & 0.00 & 0.00 & 6.31 & 0.00 & 0.00 & 14.87 \\
\hline 24750 to 26249 & 0.00 & 0.00 & 0.00 & 3.00 & 0.00 & 0.29 & 5.68 & 0.00 & 0.00 & 8.24 \\
\hline 26250 to 27749 & 0.00 & 0.00 & 0.00 & 6.69 & 0.00 & 0.00 & 4.50 & 0.00 & 0.00 & 3.49 \\
\hline 27750 to 29249 & 0.00 & 0.00 & 0.00 & 9.24 & 0.00 & 0.00 & 2.20 & 0.00 & 0.00 & 1.43 \\
\hline 29250 to 30749 & 0.00 & 0.00 & 0.00 & 4.56 & 0.00 & 0.00 & 1.25 & 0.00 & 0.00 & 0.34 \\
\hline 30750 to 32249 & 0.00 & 0.00 & 0.00 & 5.58 & 0.00 & 0.00 & 0.60 & 0.00 & 0.00 & 0.35 \\
\hline 32250 to 33749 & 0.00 & 0.00 & 0.00 & 0.00 & 0.00 & 0.00 & 0.32 & 0.00 & 0.00 & 0.16 \\
\hline 33750 to 35249 & 0.00 & 0.00 & 0.00 & 0.00 & 0.00 & 0.00 & 0.31 & 0.00 & 0.00 & 0.04 \\
\hline 35250 to 36749 & 0.00 & 0.00 & 0.00 & 0.00 & 0.00 & 0.00 & 0.25 & 0.00 & 0.00 & 0.01 \\
\hline 36750 to 38249 & 0.00 & 0.00 & 0.00 & 0.00 & 0.00 & 0.00 & 0.28 & 0.00 & 0.00 & 0.06 \\
\hline 38250 to 39749 & 0.00 & 0.00 & 0.00 & 0.00 & 0.00 & 0.00 & 0.11 & 0.00 & 0.00 & 0.00 \\
\hline 39750 to 41249 & 0.00 & 0.00 & 0.00 & 0.00 & 0.00 & 0.00 & 0.04 & 0.00 & 0.00 & 0.00 \\
\hline 41250 to 42749 & 0.00 & 0.00 & 0.00 & 0.00 & 0.00 & 0.00 & 0.05 & 0.00 & 0.00 & 0.00 \\
\hline 42750 to 44249 & 0.00 & 0.00 & 0.00 & 0.00 & 0.00 & 0.00 & 0.09 & 0.00 & 0.00 & 0.01 \\
\hline 44250 to 45749 & 0.00 & 0.00 & 0.00 & 0.00 & 0.00 & 0.00 & 0.00 & 0.00 & 0.00 & 0.00 \\
\hline 45750 to 47249 & 0.00 & 0.00 & 0.00 & 0.00 & 0.00 & 0.00 & 0.00 & 0.00 & 0.00 & 0.00 \\
\hline 47250 to 48749 & 0.00 & 0.00 & 0.00 & 0.00 & 0.00 & 0.00 & 0.00 & 0.00 & 0.00 & 0.00 \\
\hline 48750 to 52749 & 0.00 & 0.00 & 0.00 & 0.00 & 0.00 & 0.00 & 0.00 & 0.00 & 0.00 & 0.00 \\
\hline 100 & 100 & 100 & 100 & 100 & 100 & 100 & 100 & 100 & 100 & 100 \\
\hline
\end{tabular}


Table C-12 Southern Ontario - quad-axle load distribution (MTO 2016)

\begin{tabular}{|c|c|c|c|c|c|c|c|c|c|c|}
\hline \multirow[t]{2}{*}{ Axle Weight Range, kg } & \multicolumn{10}{|c|}{ Frequency of a given axle weight range as a percentage } \\
\hline & 4 & 5 & 6 & 7 & 8 & 9 & 10 & 11 & 12 & 13 \\
\hline 0 to 5249 & 0.00 & 0.00 & 0.00 & 0.00 & 0.00 & 0.00 & 1.25 & 0.00 & 0.00 & 4.32 \\
\hline 5250 to 6749 & 0.00 & 0.00 & 0.00 & 0.00 & 0.00 & 0.00 & 4.16 & 0.00 & 0.00 & 8.96 \\
\hline 6750 to 8249 & 0.00 & 0.00 & 0.00 & 0.00 & 0.00 & 0.00 & 6.17 & 0.00 & 0.00 & 13.83 \\
\hline 8250 to 9749 & 0.00 & 0.00 & 0.00 & 0.00 & 0.00 & 0.00 & 6.06 & 0.00 & 0.00 & 5.35 \\
\hline 9750 to 11249 & 0.00 & 0.00 & 0.00 & 0.00 & 0.00 & 0.00 & 4.70 & 0.00 & 0.00 & 0.75 \\
\hline 11250 to 12749 & 0.00 & 0.00 & 0.00 & 0.00 & 0.00 & 0.00 & 5.89 & 0.00 & 0.00 & 0.00 \\
\hline 12750 to 14249 & 0.00 & 0.00 & 0.00 & 0.00 & 0.00 & 0.00 & 3.56 & 0.00 & 0.00 & 2.19 \\
\hline 14250 to 15749 & 0.00 & 0.00 & 0.00 & 0.00 & 0.00 & 0.00 & 2.04 & 0.00 & 0.00 & 2.96 \\
\hline 15750 to 17249 & 0.00 & 0.00 & 0.00 & 0.00 & 0.00 & 0.00 & 2.87 & 0.00 & 0.00 & 13.84 \\
\hline 17250 to 18749 & 0.00 & 0.00 & 0.00 & 0.00 & 0.00 & 0.00 & 2.37 & 0.00 & 0.00 & 0.82 \\
\hline 18750 to 20249 & 0.00 & 0.00 & 0.00 & 0.00 & 0.00 & 0.00 & 3.58 & 0.00 & 0.00 & 3.16 \\
\hline 20250 to 21749 & 0.00 & 0.00 & 0.00 & 0.00 & 0.00 & 0.00 & 3.03 & 0.00 & 0.00 & 8.64 \\
\hline 21750 to 23249 & 0.00 & 0.00 & 0.00 & 0.00 & 0.00 & 0.00 & 5.41 & 0.00 & 0.00 & 2.03 \\
\hline 23250 to 24749 & 0.00 & 0.00 & 0.00 & 0.00 & 0.00 & 0.00 & 6.94 & 0.00 & 0.00 & 5.77 \\
\hline 24750 to 26249 & 0.00 & 0.00 & 0.00 & 0.00 & 0.00 & 0.00 & 8.55 & 0.00 & 0.00 & 11.63 \\
\hline 26250 to 27749 & 0.00 & 0.00 & 0.00 & 0.00 & 0.00 & 0.00 & 6.94 & 0.00 & 0.00 & 7.89 \\
\hline 27750 to 29249 & 0.00 & 0.00 & 0.00 & 0.00 & 0.00 & 0.00 & 4.36 & 0.00 & 0.00 & 0.24 \\
\hline 29250 to 30749 & 0.00 & 0.00 & 0.00 & 0.00 & 0.00 & 0.00 & 3.84 & 0.00 & 0.00 & 0.38 \\
\hline 30750 to 32249 & 0.00 & 0.00 & 0.00 & 0.00 & 0.00 & 0.00 & 3.72 & 0.00 & 0.00 & 0.00 \\
\hline 32250 to 33749 & 0.00 & 0.00 & 0.00 & 0.00 & 0.00 & 0.00 & 3.79 & 0.00 & 0.00 & 0.00 \\
\hline 33750 to 35249 & 0.00 & 0.00 & 0.00 & 0.00 & 0.00 & 0.00 & 3.12 & 0.00 & 0.00 & 3.09 \\
\hline 35250 to 36749 & 0.00 & 0.00 & 0.00 & 0.00 & 0.00 & 0.00 & 3.61 & 0.00 & 0.00 & 4.15 \\
\hline 36750 to 38249 & 0.00 & 0.00 & 0.00 & 0.00 & 0.00 & 0.00 & 1.50 & 0.00 & 0.00 & 0.00 \\
\hline 38250 to 39749 & 0.00 & 0.00 & 0.00 & 0.00 & 0.00 & 0.00 & 0.79 & 0.00 & 0.00 & 0.00 \\
\hline 39750 to 41249 & 0.00 & 0.00 & 0.00 & 0.00 & 0.00 & 0.00 & 0.35 & 0.00 & 0.00 & 0.00 \\
\hline 41250 to 42749 & 0.00 & 0.00 & 0.00 & 0.00 & 0.00 & 0.00 & 1.02 & 0.00 & 0.00 & 0.00 \\
\hline 42750 to 44249 & 0.00 & 0.00 & 0.00 & 0.00 & 0.00 & 0.00 & 0.16 & 0.00 & 0.00 & 0.00 \\
\hline 44250 to 45749 & 0.00 & 0.00 & 0.00 & 0.00 & 0.00 & 0.00 & 0.06 & 0.00 & 0.00 & 0.00 \\
\hline 45750 to 47249 & 0.00 & 0.00 & 0.00 & 0.00 & 0.00 & 0.00 & 0.16 & 0.00 & 0.00 & 0.00 \\
\hline 47250 to 48749 & 0.00 & 0.00 & 0.00 & 0.00 & 0.00 & 0.00 & 0.00 & 0.00 & 0.00 & 0.00 \\
\hline 48750 to 52749 & 0.00 & 0.00 & 0.00 & 0.00 & 0.00 & 0.00 & 0.00 & 0.00 & 0.00 & 0.00 \\
\hline Total & 100 & 100 & 100 & 100 & 100 & 100 & 100 & 100 & 100 & 100 \\
\hline
\end{tabular}


Table C-13 Northern Ontario - single-axle load distribution (MTO 2016)

\begin{tabular}{|c|c|c|c|c|c|c|c|c|c|c|}
\hline \multirow[t]{2}{*}{ Axle Weight Range, kg } & \multicolumn{10}{|c|}{ Frequency of a given axle weight range as a percentage } \\
\hline & 4 & 5 & 6 & 7 & 8 & 9 & 10 & 11 & 12 & 13 \\
\hline 0 to 1249 & 1.80 & 0.20 & 0.22 & 0.00 & 2.14 & 0.06 & 0.63 & 5.59 & 0.59 & 0.15 \\
\hline 1250 to 1749 & 0.96 & 0.61 & 0.00 & 0.00 & 1.88 & 0.09 & 0.20 & 0.00 & 0.00 & 0.46 \\
\hline 1750 to 2249 & 2.91 & 11.58 & 0.47 & 0.26 & 5.38 & 0.61 & 0.66 & 0.00 & 2.59 & 0.58 \\
\hline 2250 to 2749 & 3.99 & 10.37 & 0.35 & 0.00 & 6.19 & 0.42 & 0.66 & 0.00 & 1.27 & 0.61 \\
\hline 2750 to 3249 & 6.80 & 8.26 & 0.09 & 0.03 & 7.42 & 0.22 & 1.61 & 5.59 & 2.50 & 1.04 \\
\hline 3250 to 3749 & 12.00 & 11.40 & 7.08 & 0.17 & 9.96 & 0.77 & 2.06 & 0.00 & 6.41 & 1.13 \\
\hline 3750 to 4249 & 11.70 & 11.52 & 8.11 & 0.32 & 13.50 & 1.20 & 2.21 & 1.96 & 4.29 & 1.47 \\
\hline 4250 to 4749 & 11.40 & 12.33 & 10.21 & 3.28 & 13.60 & 4.72 & 3.17 & 6.93 & 12.67 & 3.71 \\
\hline 4750 to 5249 & 10.30 & 8.79 & 14.42 & 5.52 & 7.22 & 11.71 & 9.34 & 16.96 & 5.81 & 12.37 \\
\hline 5250 to 5749 & 9.00 & 8.64 & 30.26 & 3.80 & 8.18 & 42.47 & 27.56 & 4.48 & 22.17 & 33.59 \\
\hline 5750 to 6249 & 7.40 & 3.72 & 9.15 & 9.29 & 2.61 & 23.52 & 19.40 & 10.05 & 14.30 & 25.58 \\
\hline 6250 to 6749 & 5.70 & 2.32 & 5.20 & 23.71 & 4.02 & 4.64 & 8.64 & 1.96 & 6.63 & 10.57 \\
\hline 6750 to 7249 & 4.30 & 3.04 & 4.34 & 9.42 & 3.75 & 2.47 & 3.75 & 13.96 & 8.89 & 1.60 \\
\hline 7250 to 7749 & 3.20 & 1.53 & 3.12 & 17.49 & 4.88 & 1.94 & 3.57 & 13.47 & 1.44 & 1.41 \\
\hline 7750 to 8249 & 2.58 & 0.62 & 2.29 & 4.60 & 3.01 & 1.40 & 3.00 & 0.00 & 0.00 & 0.91 \\
\hline 8250 to 8749 & 1.80 & 1.66 & 1.45 & 2.23 & 1.26 & 0.66 & 3.31 & 7.03 & 1.04 & 1.67 \\
\hline 8750 to 9249 & 1.40 & 1.14 & 1.62 & 4.85 & 0.74 & 0.69 & 3.19 & 0.00 & 3.26 & 0.84 \\
\hline 9250 to 9749 & 1.00 & 0.90 & 1.41 & 4.02 & 1.42 & 0.38 & 2.37 & 7.03 & 0.00 & 0.91 \\
\hline 9750 to 10249 & 0.75 & 0.51 & 0.00 & 6.21 & 0.17 & 0.24 & 1.10 & 3.03 & 0.00 & 0.22 \\
\hline 10250 to 10749 & 0.50 & 0.12 & 0.00 & 1.78 & 0.00 & 0.25 & 1.19 & 0.00 & 0.00 & 0.21 \\
\hline 10750 to 11249 & 0.25 & 0.05 & 0.00 & 1.16 & 0.79 & 1.20 & 0.76 & 0.00 & 3.26 & 0.00 \\
\hline 11250 to 11749 & 0.15 & 0.42 & 0.21 & 0.29 & 0.74 & 0.08 & 0.27 & 0.00 & 1.25 & 0.06 \\
\hline 11750 to 12249 & 0.10 & 0.15 & 0.00 & 0.25 & 0.00 & 0.04 & 0.10 & 1.96 & 0.59 & 0.00 \\
\hline 12250 to 12749 & 0.00 & 0.12 & 0.00 & 1.15 & 0.00 & 0.06 & 0.29 & 0.00 & 0.00 & 0.07 \\
\hline 12750 to 13249 & 0.00 & 0.00 & 0.00 & 0.00 & 0.00 & 0.00 & 0.35 & 0.00 & 1.04 & 0.00 \\
\hline 13250 to 13749 & 0.00 & 0.00 & 0.00 & 0.00 & 0.00 & 0.02 & 0.17 & 0.00 & 0.00 & 0.00 \\
\hline 13750 to 14249 & 0.00 & 0.00 & 0.00 & 0.00 & 0.00 & 0.01 & 0.07 & 0.00 & 0.00 & 0.00 \\
\hline 14250 to 14749 & 0.00 & 0.00 & 0.00 & 0.00 & 0.82 & 0.02 & 0.04 & 0.00 & 0.00 & 0.28 \\
\hline 14750 to 15249 & 0.00 & 0.00 & 0.00 & 0.00 & 0.00 & 0.03 & 0.08 & 0.00 & 0.00 & 0.00 \\
\hline 15250 to 15749 & 0.00 & 0.00 & 0.00 & 0.00 & 0.32 & 0.01 & 0.09 & 0.00 & 0.00 & 0.00 \\
\hline 15750 to 16249 & 0.00 & 0.00 & 0.00 & 0.02 & 0.00 & 0.00 & 0.05 & 0.00 & 0.00 & 0.11 \\
\hline 16250 to 16749 & 0.00 & 0.00 & 0.00 & 0.00 & 0.00 & 0.02 & 0.01 & 0.00 & 0.00 & 0.00 \\
\hline 16750 to 17249 & 0.00 & 0.00 & 0.00 & 0.14 & 0.00 & 0.02 & 0.05 & 0.00 & 0.00 & 0.12 \\
\hline
\end{tabular}




\begin{tabular}{|c|r|r|r|r|r|r|r|r|r|r|}
\hline 17250 to 17749 & 0.00 & 0.00 & 0.00 & 0.00 & 0.00 & 0.02 & 0.01 & 0.00 & 0.00 & 0.23 \\
\hline 17750 to 18249 & 0.00 & 0.00 & 0.00 & 0.00 & 0.00 & 0.01 & 0.00 & 0.00 & 0.00 & 0.03 \\
\hline 18250 to 18749 & 0.00 & 0.00 & 0.00 & 0.00 & 0.00 & 0.00 & 0.00 & 0.00 & 0.00 & 0.07 \\
\hline 18750 to 19249 & 0.00 & 0.00 & 0.00 & 0.01 & 0.00 & 0.00 & 0.00 & 0.00 & 0.00 & 0.00 \\
\hline 19250 to 19749 & 0.01 & 0.00 & 0.00 & 0.00 & 0.00 & 0.00 & 0.03 & 0.00 & 0.00 & 0.00 \\
\hline 19750 to 22749 & 0.00 & 0.00 & 0.00 & 0.00 & 0.00 & 0.00 & 0.01 & 0.00 & 0.00 & 0.00 \\
\hline Total & 100 & 100 & 100 & 100 & 100 & 100 & 100 & 100 & 100 & 100 \\
\hline
\end{tabular}


Table C-14 Northern Ontario - tandem-axle load distribution (MTO 2016)

\begin{tabular}{|c|c|c|c|c|c|c|c|c|c|c|}
\hline \multirow[t]{2}{*}{ Axle Weight Range, kg } & \multicolumn{10}{|c|}{ Frequency of a given axle weight range as a percentage } \\
\hline & 4 & 5 & 6 & 7 & 8 & 9 & 10 & 11 & 12 & 13 \\
\hline 0 to 2449 & 5.28 & 0.00 & 0.00 & 0.08 & 5.81 & 0.10 & 0.51 & 0.00 & 0.00 & 0.92 \\
\hline 2500 to 3449 & 10.00 & 0.00 & 2.55 & 2.82 & 3.76 & 0.29 & 1.20 & 0.00 & 1.13 & 4.36 \\
\hline 3500 to 4449 & 11.90 & 0.00 & 24.63 & 0.32 & 12.00 & 1.26 & 1.78 & 0.00 & 0.00 & 6.47 \\
\hline 4500 to 5449 & 9.63 & 0.00 & 9.79 & 0.81 & 16.34 & 3.61 & 2.37 & 39.95 & 3.70 & 4.46 \\
\hline 5500 to 6449 & 8.00 & 0.00 & 3.94 & 24.47 & 27.43 & 4.77 & 3.98 & 60.05 & 6.17 & 7.05 \\
\hline 6500 to 7449 & 7.80 & 0.00 & 8.59 & 10.08 & 12.08 & 5.48 & 7.60 & 0.00 & 7.23 & 5.43 \\
\hline 7500 to 8449 & 6.80 & 0.00 & 10.85 & 6.24 & 0.81 & 4.86 & 6.11 & 0.00 & 10.13 & 1.86 \\
\hline 8500 to 9449 & 6.15 & 0.00 & 10.84 & 19.07 & 6.21 & 6.40 & 6.43 & 0.00 & 17.36 & 1.75 \\
\hline 9500 to 10449 & 5.80 & 0.00 & 3.29 & 2.01 & 4.91 & 6.58 & 3.44 & 0.00 & 19.40 & 1.45 \\
\hline 10500 to 11449 & 5.30 & 0.00 & 2.27 & 0.78 & 1.98 & 8.89 & 4.85 & 0.00 & 6.54 & 1.70 \\
\hline 11500 to 12449 & 4.70 & 0.00 & 0.67 & 1.69 & 1.98 & 8.71 & 3.85 & 0.00 & 3.84 & 1.33 \\
\hline 12500 to 13449 & 4.10 & 0.00 & 5.02 & 1.16 & 0.64 & 8.43 & 3.85 & 0.00 & 5.44 & 2.28 \\
\hline 13500 to 14449 & 3.33 & 0.00 & 2.54 & 0.84 & 0.00 & 6.32 & 5.20 & 0.00 & 5.34 & 3.17 \\
\hline 14500 to 15449 & 3.91 & 0.00 & 1.36 & 1.19 & 0.00 & 8.48 & 5.62 & 0.00 & 0.00 & 4.45 \\
\hline 15500 to 16449 & 2.22 & 0.00 & 0.83 & 0.66 & 5.54 & 10.65 & 6.54 & 0.00 & 6.26 & 10.30 \\
\hline 16500 to 17449 & 1.84 & 0.00 & 3.29 & 3.59 & 0.00 & 7.85 & 9.18 & 0.00 & 0.00 & 11.82 \\
\hline 17500 to 18449 & 1.44 & 0.00 & 2.65 & 5.49 & 0.51 & 3.73 & 7.84 & 0.00 & 6.26 & 14.14 \\
\hline 18500 to 19449 & 0.90 & 0.00 & 1.23 & 1.82 & 0.00 & 1.71 & 6.42 & 0.00 & 0.00 & 9.13 \\
\hline 19500 to 20449 & 0.50 & 0.00 & 1.65 & 3.33 & 0.00 & 0.61 & 5.47 & 0.00 & 0.00 & 3.66 \\
\hline 20500 to 21449 & 0.30 & 0.00 & 1.86 & 3.68 & 0.00 & 0.34 & 2.61 & 0.00 & 0.00 & 1.32 \\
\hline 21500 to 22449 & 0.10 & 0.00 & 0.70 & 2.58 & 0.00 & 0.23 & 1.34 & 0.00 & 0.00 & 0.67 \\
\hline 22500 to 23449 & 0.00 & 0.00 & 0.32 & 0.26 & 0.00 & 0.23 & 1.65 & 0.00 & 0.00 & 0.37 \\
\hline 23500 to 24449 & 0.00 & 0.00 & 0.77 & 2.59 & 0.00 & 0.23 & 0.37 & 0.00 & 0.00 & 0.32 \\
\hline 24500 to 25449 & 0.00 & 0.00 & 0.36 & 1.19 & 0.00 & 0.08 & 0.41 & 0.00 & 0.00 & 0.13 \\
\hline 25500 to 26449 & 0.00 & 0.00 & 0.00 & 0.05 & 0.00 & 0.11 & 0.21 & 0.00 & 0.00 & 0.33 \\
\hline 26500 to 27449 & 0.00 & 0.00 & 0.00 & 2.53 & 0.00 & 0.01 & 0.59 & 0.00 & 0.00 & 0.07 \\
\hline 27500 to 28449 & 0.00 & 0.00 & 0.00 & 0.27 & 0.00 & 0.02 & 0.33 & 0.00 & 0.00 & 0.85 \\
\hline 28500 to 29449 & 0.00 & 0.00 & 0.00 & 0.19 & 0.00 & 0.01 & 0.00 & 0.00 & 1.20 & 0.05 \\
\hline 29500 to 30449 & 0.00 & 0.00 & 0.00 & 0.00 & 0.00 & 0.01 & 0.10 & 0.00 & 0.00 & 0.09 \\
\hline 30500 to 31449 & 0.00 & 0.00 & 0.00 & 0.00 & 0.00 & 0.00 & 0.04 & 0.00 & 0.00 & 0.06 \\
\hline 31500 to 32449 & 0.00 & 0.00 & 0.00 & 0.21 & 0.00 & 0.00 & 0.06 & 0.00 & 0.00 & 0.00 \\
\hline 32500 to 33449 & 0.00 & 0.00 & 0.00 & 0.00 & 0.00 & 0.00 & 0.00 & 0.00 & 0.00 & 0.00 \\
\hline 33500 to 34449 & 0.00 & 0.00 & 0.00 & 0.00 & 0.00 & 0.00 & 0.00 & 0.00 & 0.00 & 0.01 \\
\hline
\end{tabular}




\begin{tabular}{|c|c|c|c|c|c|c|c|c|c|c|}
\hline 34500 to 35449 & 0.00 & 0.00 & 0.00 & 0.00 & 0.00 & 0.00 & 0.00 & 0.00 & 0.00 & 0.00 \\
\hline 35500 to 36449 & 0.00 & 0.00 & 0.00 & 0.00 & 0.00 & 0.00 & 0.00 & 0.00 & 0.00 & 0.00 \\
\hline 36500 to 37449 & 0.00 & 0.00 & 0.00 & 0.00 & 0.00 & 0.00 & 0.00 & 0.00 & 0.00 & 0.00 \\
\hline 37500 to 38449 & 0.00 & 0.00 & 0.00 & 0.00 & 0.00 & 0.00 & 0.00 & 0.00 & 0.00 & 0.00 \\
\hline 38500 to 39449 & 0.00 & 0.00 & 0.00 & 0.00 & 0.00 & 0.00 & 0.00 & 0.00 & 0.00 & 0.00 \\
\hline 39500 to 40449 & 0.00 & 0.00 & 0.00 & 0.00 & 0.00 & 0.00 & 0.05 & 0.00 & 0.00 & 0.00 \\
\hline Total & 100 & 100 & 100 & 100 & 100 & 100 & 100 & 100 & 100 & 100 \\
\hline
\end{tabular}


Table C-15 Northern Ontario - tridem-axle load distribution (MTO 2016)

\begin{tabular}{|c|c|c|c|c|c|c|c|c|c|c|}
\hline \multirow{2}{*}{ Axle Weight Range, kg } & \multicolumn{10}{|c|}{ Frequency of a given axle weight range as a percentage } \\
\hline & 4 & 5 & 6 & 7 & & & 9 & \begin{tabular}{l|l}
10 & 11 \\
\end{tabular} & 12 & 13 \\
\hline 0 to 5249 & 0.00 & 0.00 & 0.00 & 0.00 & 0.00 & 7.03 & 5.26 & 0.00 & 0.00 & 5.63 \\
\hline 5250 to 6749 & 0.00 & 0.00 & 0.00 & 20.16 & 0.00 & 5.16 & 7.54 & 0.00 & 100 & 13.67 \\
\hline 6750 to 8249 & 0.00 & 0.00 & 0.00 & 0.00 & 0.00 & 0.00 & 8.63 & 0.00 & 0.00 & 6.55 \\
\hline 8250 to 9749 & 0.00 & 0.00 & 0.00 & 44.60 & 0.00 & 0.19 & 6.67 & 0.00 & 0.00 & 2.23 \\
\hline 9750 to 11249 & 0.00 & 0.00 & 0.00 & 9.52 & 0.00 & 0.85 & 4.91 & 0.00 & 0.00 & 2.02 \\
\hline 11250 to 12749 & 0.00 & 0.00 & 0.00 & 0.00 & 0.00 & 5.33 & 4.48 & 0.00 & 0.00 & 1.16 \\
\hline 12750 to 14249 & 0.00 & 0.00 & 0.00 & 0.00 & 0.00 & 1.04 & 4.85 & 0.00 & 0.00 & 1.75 \\
\hline 14250 to 15749 & 0.00 & 0.00 & 0.00 & 0.00 & 0.00 & 77.00 & 5.07 & 0.00 & 0.00 & 2.42 \\
\hline 15750 to 17249 & 0.00 & 0.00 & 0.00 & 0.00 & 0.00 & 0.13 & 5.21 & 0.00 & 0.00 & 3.41 \\
\hline 17250 to 18749 & 0.00 & 0.00 & 0.00 & 0.00 & 0.00 & 0.00 & 4.96 & 0.00 & 0.00 & 4.27 \\
\hline 18750 to 20249 & 0.00 & 0.00 & 0.00 & 0.00 & 0.00 & 2.79 & 7.72 & 0.00 & 0.00 & 4.74 \\
\hline 20250 to 21749 & 0.00 & 0.00 & 0.00 & 0.00 & 0.00 & 0.00 & 6.05 & 0.00 & 0.00 & 10.07 \\
\hline 21750 to 23249 & 0.00 & 0.00 & 0.00 & 13.18 & 0.00 & 0.00 & 5.54 & 0.00 & 0.00 & 13.11 \\
\hline 23250 to 24749 & 0.00 & 0.00 & 0.00 & 12.54 & 0.00 & 0.28 & 6.90 & 0.00 & 0.00 & 17.57 \\
\hline 24750 to 26249 & 0.00 & 0.00 & 0.00 & 0.00 & 0.00 & 0.20 & 5.38 & 0.00 & 0.00 & 6.99 \\
\hline 26250 to 27749 & 0.00 & 0.00 & 0.00 & 0.00 & 0.00 & 0.00 & 4.27 & 0.00 & 0.00 & 2.47 \\
\hline 27750 to 29249 & 0.00 & 0.00 & 0.00 & 0.00 & 0.00 & 0.00 & 2.05 & 0.00 & 0.00 & 0.51 \\
\hline 29250 to 30749 & 0.00 & 0.00 & 0.00 & 0.00 & 0.00 & 0.00 & 1.57 & 0.00 & 0.00 & 0.48 \\
\hline 30750 to 32249 & 0.00 & 0.00 & 0.00 & 0.00 & 0.00 & 0.00 & 0.98 & 0.00 & 0.00 & 0.27 \\
\hline 32250 to 33749 & 0.00 & 0.00 & 0.00 & 0.00 & 0.00 & 0.00 & 0.87 & 0.00 & 0.00 & 0.07 \\
\hline 33750 to 35249 & 0.00 & 0.00 & 0.00 & 0.00 & 0.00 & 0.00 & 0.47 & 0.00 & 0.00 & 0.55 \\
\hline 35250 to 36749 & 0.00 & 0.00 & 0.00 & 0.00 & 0.00 & 0.00 & 0.29 & 0.00 & 0.00 & 0.06 \\
\hline 36750 to 38249 & 0.00 & 0.00 & 0.00 & 0.00 & 0.00 & 0.00 & 0.18 & 0.00 & 0.00 & 0.00 \\
\hline 38250 to 39749 & 0.00 & 0.00 & 0.00 & 0.00 & 0.00 & 0.00 & 0.09 & 0.00 & 0.00 & 0.00 \\
\hline 39750 to 41249 & 0.00 & 0.00 & 0.00 & 0.00 & 0.00 & 0.00 & 0.04 & 0.00 & 0.00 & 0.00 \\
\hline 41250 to 42749 & 0.00 & 0.00 & 0.00 & 0.00 & 0.00 & 0.00 & 0.00 & 0.00 & 0.00 & 0.00 \\
\hline 42750 to 44249 & 0.00 & 0.00 & 0.00 & 0.00 & 0.00 & 0.00 & 0.00 & 0.00 & 0.00 & 0.00 \\
\hline 44250 to 45749 & 0.00 & 0.00 & 0.00 & 0.00 & 0.00 & 0.00 & 0.00 & 0.00 & 0.00 & 0.00 \\
\hline 45750 to 47249 & 0.00 & 0.00 & 0.00 & 0.00 & 0.00 & 0.00 & 0.02 & 0.00 & 0.00 & 0.00 \\
\hline 47250 to 48749 & 0.00 & 0.00 & 0.00 & 0.00 & 0.00 & 0.00 & 0.00 & 0.00 & 0.00 & 0.00 \\
\hline 48750 to 52749 & 0.00 & 0.00 & 0.00 & 0.00 & 0.00 & 0.00 & 0.00 & 0.00 & 0.00 & 0.00 \\
\hline Total & 100 & 100 & 100 & 100 & 100 & 100 & 100 & 100 & 100 & 100 \\
\hline
\end{tabular}


Table C-16 Northern Ontario - quad-axle load distribution (MTO 2016)

\begin{tabular}{|c|c|c|c|c|c|c|c|c|c|c|}
\hline \multirow{3}{*}{$\begin{array}{c}\text { Axle Weight Range, kg } \\
0 \text { to } 5249 \\
\end{array}$} & \multicolumn{10}{|c|}{ Frequency of a given axle weight range as a percentage } \\
\hline & 4 & 5 & & & 7 & 89 & 10 & 11 & 12 & 13 \\
\hline & 0.00 & 0.00 & 0.00 & 0.00 & 0.00 & 0.00 & 3.18 & 0.00 & 0.00 & 5.82 \\
\hline 5250 to 6749 & 0.00 & 0.00 & 0.00 & 0.00 & 0.00 & 0.00 & 5.32 & 0.00 & 0.00 & 9.55 \\
\hline 6750 to 8249 & 0.00 & 0.00 & 0.00 & 0.00 & 0.00 & 0.00 & 10.24 & 0.00 & 0.00 & 3.11 \\
\hline 8250 to 9749 & 0.00 & 0.00 & 0.00 & 0.00 & 0.00 & 0.00 & 5.20 & 0.00 & 0.00 & 0.00 \\
\hline 9750 to 11249 & 0.00 & 0.00 & 0.00 & 0.00 & 0.00 & 0.00 & 2.00 & 0.00 & 0.00 & 0.00 \\
\hline 11250 to 12749 & 0.00 & 0.00 & 0.00 & 0.00 & 0.00 & 0.00 & 3.36 & 0.00 & 0.00 & 0.00 \\
\hline 12750 to 14249 & 0.00 & 0.00 & 0.00 & 0.00 & 0.00 & 0.00 & 2.61 & 0.00 & 0.00 & 3.12 \\
\hline 14250 to 15749 & 0.00 & 0.00 & 0.00 & 0.00 & 0.00 & 0.00 & 2.12 & 0.00 & 0.00 & 6.44 \\
\hline 15750 to 17249 & 0.00 & 0.00 & 0.00 & 0.00 & 0.00 & 0.00 & 4.23 & 0.00 & 0.00 & 3.85 \\
\hline 17250 to 18749 & 0.00 & 0.00 & 0.00 & 0.00 & 0.00 & 0.00 & 2.47 & 0.00 & 0.00 & 9.36 \\
\hline 18750 to 20249 & 0.00 & 0.00 & 0.00 & 0.00 & 0.00 & 0.00 & 1.01 & 0.00 & 0.00 & 0.00 \\
\hline 20250 to 21749 & 0.00 & 0.00 & 0.00 & 0.00 & 0.00 & 0.00 & 0.23 & 0.00 & 0.00 & 0.00 \\
\hline 21750 to 23249 & 0.00 & 0.00 & 0.00 & 0.00 & 0.00 & 0.00 & 7.58 & 0.00 & 0.00 & 3.41 \\
\hline 23250 to 24749 & 0.00 & 0.00 & 0.00 & 0.00 & 0.00 & 0.00 & 3.05 & 0.00 & 0.00 & 2.40 \\
\hline 24750 to 26249 & 0.00 & 0.00 & 0.00 & 0.00 & 0.00 & 0.00 & 4.19 & 0.00 & 0.00 & 45.88 \\
\hline 26250 to 27749 & 0.00 & 0.00 & 0.00 & 0.00 & 0.00 & 0.00 & 7.42 & 0.00 & 0.00 & 0.09 \\
\hline 27750 to 29249 & 0.00 & 0.00 & 0.00 & 0.00 & 0.00 & 0.00 & 3.19 & 0.00 & 0.00 & 6.97 \\
\hline 29250 to 30749 & 0.00 & 0.00 & 0.00 & 0.00 & 0.00 & 0.00 & 5.90 & 0.00 & 0.00 & 0.00 \\
\hline 30750 to 32249 & 0.00 & 0.00 & 0.00 & 0.00 & 0.00 & 0.00 & 6.43 & 0.00 & 0.00 & 0.00 \\
\hline 32250 to 33749 & 0.00 & 0.00 & 0.00 & 0.00 & 0.00 & 0.00 & 5.29 & 0.00 & 0.00 & 0.00 \\
\hline 33750 to 35249 & 0.00 & 0.00 & 0.00 & 0.00 & 0.00 & 0.00 & 4.38 & 0.00 & 0.00 & 0.00 \\
\hline 35250 to 36749 & 0.00 & 0.00 & 0.00 & 0.00 & 0.00 & 0.00 & 8.46 & 0.00 & 0.00 & 0.00 \\
\hline 36750 to 38249 & 0.00 & 0.00 & 0.00 & 0.00 & 0.00 & 0.00 & 1.64 & 0.00 & 0.00 & 0.00 \\
\hline 38250 to 39749 & 0.00 & 0.00 & 0.00 & 0.00 & 0.00 & 0.00 & 0.00 & 0.00 & 0.00 & 0.00 \\
\hline 39750 to 41249 & 0.00 & 0.00 & 0.00 & 0.00 & 0.00 & 0.00 & 0.00 & 0.00 & 0.00 & 0.00 \\
\hline 41250 to 42749 & 0.00 & 0.00 & 0.00 & 0.00 & 0.00 & 0.00 & 0.00 & 0.00 & 0.00 & 0.00 \\
\hline 42750 to 44249 & 0.00 & 0.00 & 0.00 & 0.00 & 0.00 & 0.00 & 0.50 & 0.00 & 0.00 & 0.00 \\
\hline 44250 to 45749 & 0.00 & 0.00 & 0.00 & 0.00 & 0.00 & 0.00 & 0.00 & 0.00 & 0.00 & 0.00 \\
\hline 45750 to 47249 & 0.00 & 0.00 & 0.00 & 0.00 & 0.00 & 0.00 & 0.00 & 0.00 & 0.00 & 0.00 \\
\hline 47250 to 48749 & 0.00 & 0.00 & 0.00 & 0.00 & 0.00 & 0.00 & 0.00 & 0.00 & 0.00 & 0.00 \\
\hline 48750 to 52749 & 0.00 & 0.00 & 0.00 & 0.00 & 0.00 & 0.00 & 0.00 & 0.00 & 0.00 & 0.00 \\
\hline Total & 100 & 100 & 100 & 100 & 100 & 100 & 100 & 100 & 100 & 100 \\
\hline
\end{tabular}




\section{REFERENCES}

AASHTO (2016). Mechanistic-Empirical Pavement Design Guide: A Manual of Practice. First Official Edition. American Association of State Highway and Transportation Officials, Washington DC.

AASHTO (2010). Guide for the Local Calibration of the Mechanical-Empirical Pavement Design Guide, American Association of State Highway and Transportation Officials, Washington DC.

AASHTO (2016). AASHTOWare Pavement ME Design Released Notes, http://medesign.com/MEDesign/Documents.html

Agardh, S. (2005). "Rut Depth Prediction on Flexible Pavement- Calibration and Validation of Incremental Recursive Model.” Doctoral Thesis, Lund Institute of Technology, Sweden.

Ahmed, S (2017). "Local calibration of cracking models of MEPDG for Ontario's flexible pavement." Master Thesis, Ryerson University, Canada.

Al-Omari, B. and M.I. Darter (1992). Relationships Between IRI and PSR. Report Number UILU-ENG-92-2013. Springfield, IL: Illinois Department of Transportation.

Anderson, D. I., and D. E. Peterson (1979). Pavement Rehabilitation Design Strategies. FHWA UT-79/6. Salt Lake City: Utah Department of Transportation, 1979.

Arizona Department of Transportation Research Center (2014) "Calibration and Implementation of the AASHTO Mechanistic-Empirical Pavement Design Guide in Arizona”. USA.

Bayomy, F., EI-Badawy, S., and Awed, A., (2012). "Implementation of the MEPDG for Flexible Pavements in Idaho." Idaho Transportation Department Research Program, FHWA-ID-12193.

Caliendo, C. (2012). "Local calibration and implementation of the mechanistic-empirical pavement design guide for flexible pavement design." Journal of Transportation Engineering, 138(3), 348-360.

Crawford, G. (2009). "National Trends in Pavement Design." Southeastern States Pavement Management Association, Pavement Management and Design, New Orleans, Louisiana.

Crovetti, J. A., and Hall, K. T. (2012). "Local Calibration of the Mechanistic Empirical Pavement Design Software for Wisconsin.” SPR \#0092-09-30, SPR \# 0092-09-31 
Wisconsin Department of Transportation Research \& Library Unit, 4802 Sheboygan Ave. Madison, WI 53707.

Darter, M. I., Titus-Glover, L., and VonQuintus, H. L. (2009). "Implementation of the Mechanistic-Empirical Pavement Design Guide in Utah: Validation, Calibration, and Development of the UDOT MEPDG User's Guide.", Utah Department of Transportation, Report No. UT--09.11.

Donahue, J. (2008). "Local calibration of the MEPDG for HMA pavements in Missouri." Journal of the Association of Asphalt Paving Technologists, Volume: 77, Asphalt Paving Technology 2008, 975-984.

Dzotepe, G. A., and Ksaibati, K. (2011). "The Effects of Environmental Factors on the Implementation of the Mechanistic-Empirical Pavement Design Guide (MEPDG)." Department of Transportation, University Transportation Center Program, University of Wyoming.

Glover, L. T. and Mallela, J. (2009). Guidelines for Implementing NCHRP 1-37A M-E Design Procedures in Ohio: Volume 4 - MEPDG Models Validation \& Recalibration.

Gautam, G. P. (2015). “Local Calibration of MEPDG Rutting Model for Ontario's Superpave Pavements" Master Thesis, Ryerson University, Canada.

Haas, R. and Tighe, S. (2007). "Mechanistic-Empirical Pavement Design: Evolution and Future Challenges" Annual Conference Transportation Association of Canada.

Gramling, W. L., Hunt, J. E., and Suzuki, G. S. (1991). "Rational Approach to Cross-Profile and Rut Depth Analysis.” Transportation Research Record, (1311), 173-179.

Hoegh, K., Khazanovich, L., and Jensen, M. (2010). "Local Calibration of MechanisticEmpirical Pavement Design Guide Rutting Model for Minnesota Road Research Project Test Sections.” Transportation Research Record, (2180), pp. 130-141.

Jadoun, F. M. (2011). "Calibration of the Flexible Pavement Distress Prediction Models in the Mechanistic-Empirical Pavement Design Guide (MEPDG) for North Carolina.” Doctor of Philosophy, North Carolina State University, North Carolina.

Jannat, G. E. (2014) "Development of regression equations for local calibration of rutting and IRI as predicted by the MEPDG models for flexible pavements using Ontario's long-term PMS data” International Journal of Pavement Engineering, Vol. 17, No. 2, 166-175 
Jannat, G. E. (2012). "Database Development for Ontario's Local Calibration of MechanisticEmpirical Pavement Design Guide (MEPDG) Distress Models" Master Thesis, Ryerson University, Canada.

Kim, S., Ceylan, H., Ma, D., and Gopalakrishnan, K. (2014). "Calibration of Pavement ME Design and Mechanistic-Empirical Pavement Design Guide Performance Prediction Models for Iowa Pavement Systems," ASCE Journal of Transportation Engineering, Vol. 21, Issue 10.

Kim, Y. R., Jadoun, F. M., Hou, T., and Muthadi, N. (2001). " Local Calibration of the MEPDG for Flexible Pavement Design." Final Report submitted to the North Carolina Department of Transportation, Research Project No. HWY-2007-07

Mallela, J., Glover, L. T., Sadasivam, S., Bhattacharya, B., Darter, M. I., and VonQuintus (2013). "Implementation of the AASHTO Mechanistic-Empirical Pavement Design Guide for Cororado." Colorado Department of Transportation, Applied Research Associates, Inc., Report No. CDOT-2013-4.

Missouri Department of Transportation (2009) Implementing The AASHTO Mechanistic Empirical Pavement Design Guide in Missouri, Volume II: MEPDG Model Validation and Calibration.

NCHRP (2001). Guide for Mechanistic-Empirical Design of New and Rehabilitated Pavement Structures. APPENDIX OO, http://onlinepubs.trb.org/onlinepubs/archive/mepdg/guide.htm

NCHRP (2004). Guide for Mechanistic-Empirical design of new and rehabilitated pavement structures. Appendix GG-1: Calibration of Permanent Deformation Models for Flexible Pavements., http://onlinepubs.trb.org/onlinepubs/archive/mepdg/guide.htm

NCHRP (2004). Guide for Mechanistic-Empirical design of new and rehabilitated pavement structures. Appendix GG-1: Calibration of Permanent Deformation Models for Flexible Pavements., http://onlinepubs.trb.org/onlinepubs/archive/mepdg/guide.htm

Paterson, W. D. O. (1989). "A Transferable Causal Model for Predicting Roughness Progression in Flexible Pavements." Transportation Research Record 1215. Washington, DC: Transportation Research Board.

Thyagarajan, S. T. (2009). "Improvements to Strain Computation and Reliability Analysis of Flexible Pavements In The Mechanistic-Empirical Pavement Design Guide" Doctoral Thesis, Washington state University,USA. 
Transportation Research Board, American Association of State Highway and Transportation, National Research Council, Washington, D.C.

VonQuintus, H. L., Mallela, J., Bonaquist, R., Schwartz, C. W., and Carvalho, R. L. (2012). “aNCHRP REPORT 719 Calibration of Rutting Models for Structural and Mix Design."

VonQuintus, H. L., and Moulthrop, J. S. (2007). "Mechanistic-Empirical Pavement Design Guide Flexible Pavement Performance Prediction Models for Montana.”, Montana Department of Transportation, Helena, Montana.

Williams, D. R. C., and Shaidur, R. (2013). "Mechanistic-Empirical Pavement Design Guide Calibration for Pavement Rehabilitation." SPR 718 Institute for Transportation Iowa State University, 2711 South Loop Drive, Suite 4700 Ames, IA 50010-8664.

Waseem, A. (2013). "Methodology Development and Local Calibration of MEPDG Permanent Deformation Models for Ontario's Flexible Pavements" Master Thesis, Ryerson University, Canada.

"Weather stations for MEPDG in Ontario", accessed January 16, 2017, https://www.google.com/maps/d/viewer?msa=0\&mid=13iBJ4hBSeGc_gTw_KJsEtwHXPXk. 